Do automated digital health behaviour change interventions have a positive effect on self-efficacy? A systematic review and meta-analysis

\author{
Katie Newby \\ Coventry University ${ }^{1}$, ORCID ID 0000-0002-9348-0116, @NewbyKatie \\ Grace Teah \\ Coventry University ${ }^{1}, 0000-0001-5820-1233$ \\ Richard Cooke \\ University of Liverpool, 0000-0003-0476-6284 \\ Xinru Li \\ Leiden University, 0000-0001-6859-2311 \\ Katherine Brown \\ Coventry University ${ }^{1}, 0000-0003-2472-5754$ \\ Bradley Salisbury-Finch \\ Coventry University, 0000-0002-6129-9654 \\ Kayleigh Kwah \\ Coventry University, 0000-0003-2307-1285 \\ Naomi Bartle \\ Coventry University, 0000-0002-8399-0390 \\ Kristina Curtis \\ Coventry University, 0000-0001-6845-1236
}

\footnotetext{
${ }^{1}$ Affiliation changes: Katie Newby and Katherine Brown have moved to the University of Hertfordshire, UK. Grace Teah has moved to the University of Otago, New Zealand. Joanne Parsons has moved to the University of Warwick, UK.
} 


\title{
Emmie Fulton
}

Coventry University, 0000-0002-5979-3207

\author{
Joanne Parsons \\ Coventry University ${ }^{1}, 0000-0002-6542-8492$ \\ Elise Dusseldorp \\ Leiden University, 0000-0002-6305-4060 \\ Stefanie L Williams \\ Coventry University, 0000-0001-9473-6446
}

\begin{abstract}
Author note
This work was supported by a Coventry University Early Career Researcher Pump Priming Award.

Correspondence concerning this article should be addressed to Katie Newby, Department of Psychology and Sports Science, Snow Building, Life and Medical Sciences, College Lane Campus, University of Hertfordshire, Hatfield AL10 9AB; Email: k.newby@herts.ac.uk. Telephone: +44 (0)1707 284615.
\end{abstract}

Disclosure statement: No potential conflict of interest was reported by the authors Data availability statement: The data that support the findings of this study are openly available in OSF at https://osf.io/vf52h [DOI 10.17605/OSF.IO/VF52H]. 


\begin{abstract}
Self-efficacy is an important determinant of health behaviour. Digital interventions are a potentially acceptable and cost-effective way of delivering programmes of health behaviour change at scale. Whether behaviour change interventions work to increase self-efficacy in this context is unknown. This systematic review and meta-analysis sought to identify whether automated digital interventions are associated with positive changes in self-efficacy amongst non-clinical populations for five major health behaviours, and which BCTs are associated with that change. A systematic literature search identified 20 studies $(n=5624)$ that assessed changes in self-efficacy and were included in a random effects meta-analysis. Interventions targeted: healthy eating $(\mathrm{k}=4)$, physical activity $(\mathrm{k}=9)$, sexual behaviour $(\mathrm{k}=3)$, and smoking $(\mathrm{k}=4)$. No interventions targeting alcohol use were identified. Overall, interventions had a small, positive effect on self-efficacy $(\bar{g}=0.190$, CI $[0.078 ; 0.303])$. The effect of interventions on self-efficacy did not differ as a function of health behaviour type (Qbetween $=7.3704 \mathrm{p}=0.061, \mathrm{df}=3$ ). Inclusion of the BCT 'information about social and environmental consequences' had a small, negative effect on self-efficacy $(\Delta \bar{g}=$ 0.297, $\mathrm{Q}=7.072, \mathrm{p}=0.008$ ). Whilst this review indicates that digital interventions can be used to change self-efficacy, which techniques work best in this context is not clear.
\end{abstract}

Keywords: Self-efficacy, digital, health behaviour, behaviour change techniques 
Do automated digital health behaviour change interventions have a positive effect on self-efficacy? A systematic review and meta-analysis

Self-efficacy is defined as 'people's judgments of their capabilities to organize and execute courses of action required to attain designated types of performances' (Bandura, 1986). It is a key construct within several dominant theories within health psychology including social cognitive theory (Bandura, 1997), protection motivation theory (Rogers \& Prentice-Dunn, 1997), the transtheoretical model (Prochaska \& DiClemente, 1982), and the health action process approach (Schwarzer, 1992). Selfefficacy is conceptualised as being necessary to both motivate and sustain behaviour. The magnitude and strength of self-efficacy are expected to predict whether an individual will both attempt a new behaviour and how long they will persist with that behaviour in the face of obstacles and aversive experiences (Bandura, 1997).

Self-efficacy has been consistently shown to predict the adoption and maintenance of a number of health behaviours including alcohol use (Cooke, Dahdah, Norman, \& French, 2016), condom use (Sheeran \& Taylor, 1999), healthy eating (e.g. (Burke, Beilin, Cutt, Mansour, \& Mori, 2008; Fuemmeler et al., 2006; Langenberg et al., 2000; Luszczynska, Tryburcy, \& Schwarzer, 2007), physical activity (e.g. (Bauman et al., 2012; Cortis et al., 2017), and smoking (Gwaltney, Metrik, Kahler, \& Shiffman, 2009). Moreover, changing self-efficacy has been shown to lead to medium-sized changes in behaviour if successfully manipulated (Sheeran et al., 2016). Given the significance of self-efficacy to the adoption and maintenance of health behaviours, understanding how best to change it is an important goal of behavioural science as this knowledge enhances our ability to develop effective health behaviour change interventions that in turn can reduce the burden of preventable disease. 
Meta-analysis is one method available to researchers aiming to identify what works to bring about desired behavioural change (Michie, West, Sheals, \& Godinho, 2018). This approach involves identifying behaviour change interventions of interest, extracting their effect size and coding their behaviour change methods using a standardised coding frame, and then using meta-regression or moderation analysis to examine differences in effect size as a function of whether or not they contain a given behaviour change method. When embarking on this type of work, researchers must first decide how to code the different behaviour change methods. In the case of selfefficacy, one option is to code methods based on the four sources of self-efficacy as outlined in Badura's Social Cognitive Theory (1977). These four sources include enactive mastery experience, vicarious experience, verbal persuasion, and physiological or affective states. Enactive mastery experience is expected to enhance individuals' perceptions of self-efficacy through successful performance of the target behaviour. Vicarious experience is provided when one sees a 'similar other' successfully perform the behaviour and appraises their own performance against that. Verbal persuasion occurs when others express faith in the individual's capabilities. Finally, the fourth source of self-efficacy is thought to occur when negative emotional states are reduced and misinterpretations of bodily states corrected. Whilst coding interventions according to these four sources is an option, existing intervention coding frameworks based on Social Cognitive Theory (e.g. Ashford, Edmunds, \& French, 2010) are neither widely used nor recognised. Furthermore, as outlined above, selfefficacy is a key concept within several theories of health behaviour. Using a coding frame based on a single theory therefore risks reducing the potential application and value of this work. 
An alternative coding framework is Michie and colleagues 93-item taxonomy of Behaviour Change Techniques (BCTs; Michie et al., 2013). This is a formal and standardized classification system of labels and definitions for 'observable, replicable, and irreducible components of an intervention designed to alter or redirect causal processes that regulate behaviour' (Michie et al., 2013). The taxonomy is widely recognised within the behavioural science community and has been used across a broad range of behavioural domains to specify intervention content, support development, and synthesise information across intervention evaluations (see http://www.bct-taxonomy.com/interventions; last accessed on October 22, 2019 for a searchable database of over 400 articles reporting interventions coded by BCTs). Whilst the BCT taxonomy was initially conceived as a tool to enable the content of behaviour change interventions to be coded (Michie et al., 2013), recent developments have moved this work forward. Specifically, an expert consensus exercise has been used to elicit agreement about the processes of behaviour change (termed 'mechanisms of action' or MoAs) through which BCTs operate (Connell et al., 2018). The closest of these MoAs to self-efficacy is 'beliefs about capabilities' defined as 'beliefs about one's own ability to successfully carry out a behaviour' (Connell et al., 2018). BCTs identified as 'definitely' having a link with this MoA are 'graded tasks' (defined as, 'set easy-to-perform tasks, making them increasingly difficult, but achievable, until behaviour is performed'), 'behavioural practice/rehearsal' (defined as, 'prompt practice or rehearsal of the performance of the behaviour one or more times in a context or at a time when the performance may not be necessary, in order to increase habit and skill'), 'verbal persuasion about capability' (defined as, 'tell the person that they can successfully perform the wanted behaviour, arguing against self-doubts and asserting that they can and will succeed'), 
and 'problem solving' (defined as, 'analyse, or prompt the person to analyse, factors influencing the behaviour and generate or select strategies that include overcoming barriers and/or increasing facilitators'). Whilst these BCTs are akin to Bandura's four sources of self-efficacy, with 'behavioural practice/rehearsal', 'graded tasks' and 'problem solving' being most closely aligned to the source 'mastery experiences', and 'verbal persuasion about capability' being most closely aligned to the source 'verbal persuasion', there are BCTs missing from this group which are also analogous. These include for example, 'instruction on how to perform behaviour' (defined as, 'advise or agree on how to perform the behaviour'), which might be expected to contribute to 'mastery experience'; 'vicarious consequences' (defined as, 'prompt observation of the consequences for others when they perform the behaviour'), which might be expected to contribute to 'vicarious experience'; and 'reduce negative emotions' (defined as, 'advise on ways of reducing negative emotions to facilitate performance of the behaviour') which might be expected to contribute to 'physiological or affective states'. As such, the work of Connell and colleagues (2018) should not be taken as definitive evidence of which BCTs are linked to which self-efficacy; additional BCTs not identified by the expert consensus may also be relevant. Thus whilst the BCT taxonomy provides an established tool with which to reliably code intervention content, work to isolate which BCTs work best to change self-efficacy should not begin with a restricted pool based on this consensus work. To do so risks prematurely discarding $\mathrm{BCT}$ s that could make an important contribution to changing this key determinant of behaviour.

To date, two meta-analyses have sought to identify BCTs associated with changes in self-efficacy for healthy adult populations: Prestwich and colleagues 
(2014) and Williams and French $(2011)^{2}$. These reviews focused on self-efficacy for dietary behaviour and physical activity respectively. In line with the above rationale, neither review restricted the initial pool of BCTs; the presence of all BCTs listed in the taxonomy were coded and examined. Prestwich and colleagues (2014) found increases in dietary self-efficacy to be associated with the inclusion of 'stress management', 'prompt self-monitoring of behaviour', 'provide feedback on performance', 'prompt review of behavioural goals', 'provide contingent rewards', and 'plan social support/social change'. 'Stress management' (most closely aligned to 'reduce negative emotions' in the 93-item taxonomy), as argued by the authors, most likely helps to address negative 'physiological or affective states' which can have the effect of undermining self-efficacy. 'Plan social support/social change' and 'provide contingent rewards' (most closely aligned to 'social support' (unspecified, practical or emotional) and 'social reward' respectively in the 93-item taxonomy) may facilitate access to others who help to persuade the individual that they are able to perform the behaviour. As such this BCT may contribute to the third source of self-efficacy, 'verbal persuasion'. All remaining BCTs identified by Prestwich and colleagues (2014) most likely contribute towards 'enactive mastery experience' through, directing attention to successful performance of the behaviour ('prompt selfmonitoring of behaviour' and 'prompt review of behavioural goals') and providing positive feedback ('provide feedback on performance').

Williams and French (2011) on the other hand found the BCTs 'action planning', 'provide instruction' and 'reinforcing effort or progress towards behaviour' to be associated with significantly higher levels of physical activity self-efficacy, and

\footnotetext{
2 These reviews both used predecessors of the 93-item taxonomy used in the present review. A 26-item version was used by Prestwich et al. (2014) and a 40-item version used by Williams and French (2011).
} 
'relapse prevention' and 'setting graded tasks' to be associated with significantly lower levels. All BCTs found to be associated with higher levels of self-efficacy in this review most likely contribute to the first source of self-efficacy, 'enactive mastery experience'. Williams and French (2011) suggested that 'action planning' and 'provide instruction' (most closely aligned to 'action planning' and 'instruction on how to perform the behaviour' respectively in the 93-item taxonomy) could support individuals to develop specific goals thus increasing their self-efficacy as there is less ambiguity about what they need to do. They also argued that 'reinforcing effort or progress' (aligned to a number of BCTs in the 93-item taxonomy focussed on reward, namely 'material reward (behaviour)', 'reward (outcome)', 'non-specific-reward', 'social reward' and 'self-reward') is likely to increase self-efficacy through focussing individuals on successes and progress towards performing the behaviour. Williams and French (2011) identified two BCTs which were associated with significantly lower levels of self-efficacy. They hypothesised that 'setting graded tasks' (most closely aligned to 'graded tasks' in the 93-item taxonomy) may have a negative effect on self-efficacy under circumstances where the difficulty of a task increases before the mastery at the current level has been achieved. Of note, this finding is contrary to the findings of the expert consensus study (Connell et al., 2018) where there was agreement that 'graded tasks' was 'definitely linked' to self-efficacy. Williams and French (2011) also suggested that 'relapse prevention' (most closely aligned to 'problem solving' in the 93-item taxonomy) may undermine self-efficacy by focussing the individual on potential future problems and barriers to the behaviour. Regardless of the method selected to identify which BCTs are effective in bringing about a desired change, methodological rigour is important to maximise what can be inferred from the data. Meta-analyses used for this purpose have however been 
criticised for being methodologically weak (2015). Peters, de Bruin \& Crutzen (2015) have outlined four key limitations. The first limitation concerns the failure to identify and examine the effect of BCTs that are present only within the intervention under examination and not also within the 'usual' or 'standard' care of the control group. If the same BCT is present in both conditions then the meta-analysis is not able to discern the unique effect of that BCT. The second limitation concerns the potential for interaction between BCTs. In complex behaviour change interventions, BCTs are not delivered in isolation, they are present in a package along with other BCTs. Metaanalyses however typically overlook this. One way of addressing this is to examine the potential of BCTs to have enhanced effects when present in clusters using a statistical technique called Meta-CART (Dusseldorp, van Genugten, van Buuren, Verheijden, \& van Empelen, 2014). The third limitation concerns the failure to identify whether conditions required for any given BCT to work are in place and then to model this in the analysis. Conditions (also known as 'parameters of effectiveness') for self-efficacy are clearly demarcated in the work of Bandura (1977). In order to enhance self-efficacy using 'vicarious experience' for example, it is considered important that individuals are able to identify with the model performing the behaviour, that the model is seen to 'struggle' with the behaviour (as opposed to mastering it easily), and that the model is seen to be positively reinforced for the desirable behaviour (Bandura, 1977). Whilst failure to meet criteria such as these in the implementation of a BCT can seriously undermine their effectiveness, few metaanalyses to date that have attempted to code whether parameters of effectiveness for included BCTs have been met or to account for this in the analysis. The final limitation concerns the failure to control for contextual factors such as sample characteristics (e.g. age, gender), study design (e.g. measurement instruments), and 
study quality indicators (e.g. blinding of study personnel and participants). These factors limit the confidence with which effects can be ascribed to the BCTs and should therefore be controlled for, either statistically, or by restricting studies included in the meta-analysis.

The present meta-analysis responds to the criticisms of previous meta-analyses by following the guidance provided by Peters and colleagues (2015). Furthermore, it builds upon the evidence of Prestwich and colleagues (2014) and Williams and French (2011) by addressing a further factor which has potential to confound the effect of BCTs: mode of intervention delivery. Modes of intervention delivery describe the way in which BCTs are delivered. This can be a confounding factor because BCTs and mode of delivery may interact in important ways such that a BCT is only effective (or indeed is ineffective) when delivered using a specific mode. Whilst the reviews reported by Prestwich and colleagues (2014) and Williams and French (2011) have contributed to knowledge about which BCTs work best to increase self-efficacy, it is not possible to discern the effect that mode of intervention delivery may have had on BCT effectiveness. Whilst a small number of meta-analyses have examined the effect of BCTs on health behaviour when delivered via a specific mode (van Genugten, Dusseldorp, Webb, \& van Empelen, 2016), to date none have attempted to do so for a theoretical mediator of health behaviour, including selfefficacy.

The present meta-analysis controls for the potential confounding effect of mode of intervention delivery by restricting included interventions to one type: those delivered by automated digital methods. Since the turn of the century, there has been a rapid increase in research focussed on the development and evaluation of interventions delivered via digital methods (Murray et al., 2016; Proudfoot et al., 
2011; Ritterband \& Tate, 2009). Digital interventions are attractive for several reasons. They have the potential to be cost-effective, as once established ongoing costs can be relatively low, particularly if content is fully automated. Digital interventions also allow users to access content anonymously, repeatedly, and at convenient times. Furthermore, potential reach is high. In the United Kingdom for example, $80 \%$ of those aged over 15 years report accessing the internet daily (Office for National Statistics, 2017). Given the evident growth in this field, intervention developers require at their disposal, knowledge of which BCTs work best in this context to increase important behavioural determinants.

The aim of the present meta-analysis is thus to examine the overall effect of automated digital behaviour change interventions on self-efficacy and further, to identify which BCTs are associated with that effect. In order to ensure a sufficiently large pool of available studies examining the effect of automated digital interventions, the review is not limited to a single behavioural domain. Instead studies targeting change in one of five health behaviours are included, namely, alcohol use, healthy eating, physical activity, sexual behaviour, and smoking. These behaviours have been selected as they are leading causes of morbidity and mortality. According to a review of epidemiological, clinical, and laboratory studies linking risk factors and mortality in the USA, these behaviours together are responsible for an estimated $39 \%$ of total deaths (Mokdad, Marks, Stroup, \& Gerberding, 2004). Arming intervention developers with evidence concerning how best to successfully enhance self-efficacy for these behaviours is therefore of importance as part of efforts to tackle major public health priorities. The review focuses on the adult non-clinical population so that conclusions can be made about which BCTs work best for the delivery of public health interventions aimed at the general population. This is necessary as evidence 
indicates that BCTs are not uniformly effective in increasing self-efficacy for clinical and non-clinical populations (Olander et al., 2013). Furthermore, in line with the arguments presented above, interventions are coded in line with the full 93-item BCT taxonomy, rather than a sub-set based on a priori hypotheses, to avoid missing any potentially important relationships.

\section{Research questions}

In summary, the present systematic review and meta-analysis addresses four research questions: (i) What is the overall effect of automated digital behaviour change interventions on self-efficacy? (ii) Does the overall effect of automated digital behaviour change interventions on self-efficacy vary as a function of the behaviour being addressed? (iii) Which BCTs have an effect on self-efficacy when delivered via automated digital interventions? (iv) Are there are any BCTs which in combination amplify (or attenuate) the effect on self-efficacy when delivered via automated digital interventions?

\section{Method}

This systematic review was conducted in accordance with the protocol (CRD42017055855) published on the International Prospective Register of Systematic Reviews (PROSPERO) http://www.crd.york.ac.uk/PROSPERO, and is reported in accordance with the Preferred Reporting Items for Systematic reviews and Meta-Analyses (PRISMA; Moher, Liberati, Tetzlaff, \& Altman, 2009), and the MetaAnalysis Reporting Methods (MARS; APA Publications and Communications Board Working Group on Journal Article Reporting Standards, 2008).

\section{Eligibility Criteria}

To be included in the review, studies had to fulfil the following criteria:

1. To be published in the English language 
2. To recruit a sample of adults (aged 18 years or older) from the general population (non-clinical). Studies reporting interventions aimed specifically at clinical populations, that is, those with a pre-existing medical condition (e.g. COPD, HIV, diabetes) or those identified as obese ( $\geq$ BMI 30) or alcoholic, were excluded. Studies reporting interventions targeting pregnant women or students exclusively (as defined by the authors of the individual studies) were also excluded as findings were thought to have limited generalisability beyond those specific populations

3. To provide a description of a digital intervention that attempted to have a positive impact on self-efficacy for one of the following five health behaviours: alcohol use, healthy eating, physical activity, sexual behaviour, or smoking. Interventions were considered to have attempted to have had a positive impact on self-efficacy if self-efficacy was included as an outcome variable. Digital interventions were required to be fully automated, that is involve no human contact between the deliverer and the recipient. This is because it was hypothesised that a method of delivery (e.g. Instant Message) was likely to be differentially effective according to whether it was delivered by a person (able to adapt messages according to the perceived need/understanding of the recipient) or by a computer

4. The comparator had to be no treatment or usual care

5. To report statistical information (e.g. mean, standard deviation and sample size for both control and intervention groups) required to calculate an effect size for changes in self-efficacy following the intervention, or for study authors to make this information available on request 
6. To test the intervention using either a randomised controlled trial or quasirandomised controlled trial. This criterion was included as controlled trials provide the most valid and reliable evidence concerning the effectiveness of interventions

\section{Search Strategy}

Peer-reviewed publications were searched for using the following databases:

CINAHL, Medline, PsycINFO, Scopus (including Science Direct) and Web of Science. Full search terms can be found in the online supplemental materials (see supplemental material 1). No date restrictions or limitations on country of study were set. Last searches were completed in April 2018. Reference sections of included papers were examined to identify any relevant studies that were not identified by the initial search. Forward citation searches were also conducted on included papers and additionally on existing relevant systematic reviews/meta-analyses for the same purpose. The latter were identified using the same procedure outlined above except that the study design filter was set as follows: review OR meta-analysis. Authors of the present review assessed the list of systematic reviews/meta-analyses for completeness and three additional papers were added. The final list is presented in supplemental material 2.

To identify unpublished studies, the EThOS database was used to search for relevant $\mathrm{PhD}$ theses using the search terms 'digital' and 'self-efficacy'. Furthermore, requests were distributed electronically via affiliated groups (namely the European Association of Social Psychology, European Health Psychology Society, Midlands Health Psychology Network, Social, Personality and Health Network and Society for Personality and Social Psychology) asking members if they were aware of any unpublished papers meeting the eligibility criteria. 


\section{Screening}

Titles of papers identified from database searches were initially split into eight groups and each group screened independently by one of the following authors: [initials of eight individuals blinded]. Following this initial screening, included papers were dual screened by abstract. This time papers were split into six groups and screened by either [initials of six individuals blinded]. The second screener for each group was either [initials of two individuals blinded]. A third stage of screening was undertaken using the full text of all studies that had not yet been excluded. This followed the same dual screening procedure as used for the abstract screening stage. At both the abstract and full-text screening stages, any discrepancies were resolved by discussion and a consensus reached on included studies. If a consensus was not achieved, the query was resolved by assistance from a third author. This process led to a sample of studies which met all eligibility criteria. Finally, studies that contained insufficient statistical information to enable an effect size to be calculated were identified. For these papers, attempts were made to contact authors to request data. If this was unsuccessful then the study was excluded. The screening process is described in Figure 1 below.

Figure 1 here.

\section{Extraction and Coding}

A data extraction sheet was developed, pilot tested on five randomly selected studies, and refined accordingly (see supplemental material 3 for finalised version). Data was then extracted/coded from included studies as follows.

Self-efficacy. Data to allow for the calculation of effect sizes for self-efficacy were extracted. Given that a primary focus of the analysis was on identifying the most effective techniques to promote self-efficacy, the first measure of self-efficacy taken 
following delivery of the complete intervention was used for studies with multiple follow-up measures. Where there was more than one intervention condition reported for a study, information was extracted for each to enable effect sizes to be calculated for each comparison. Where data was provided for more than one measure of selfefficacy, information was extracted for each measure to enable an average effect size to be calculated.

Study and sample characteristics. The following study characteristics were coded: health behaviour (alcohol use, healthy eating, physical activity, sexual behaviour, smoking), study design (RCT or quasi-RCT), measure of self-efficacy (single-item or composite), income level of the country in which the study was conducted (low, medium, high), and quality of intervention development (a score of one was assigned for each of the following and summed to create a maximum score of three: theory-based, developed using a systematic approach, and co-designed with the target population. Criteria and scoring methods devised by the team). For sample characteristics, the percentage of women, and the group that the mean age of participants fell into (categorised as 18-24 years, 25-34 years, 35-64 years, and 65+ years), were coded.

BCTs. Authors of all included studies were contacted and asked to provide any materials that may contain further intervention description (e.g. an intervention manual, intervention materials, ethics application). This was to enable, as far as possible, the full range of BCTs to be captured. Coding of BCTs within interventions was completed using the 93-item Behaviour Change Technique Taxonomy v1 (Michie et al., 2013). Both intervention and control group conditions were coded. In line with guidance from Peters and colleagues (2015), BCTs that were present in both conditions were removed to ensure that only unique intervention content was isolated. 
Dual coding was performed by [initials of four individuals blinded], all of whom had received formal training on BCT coding. Any disagreements were discussed, and a consensus was reached where required.

BCT parameters of effectiveness. In line with guidance by Peters and colleagues (2015), researchers planned to make an assessment of whether parameters of effectiveness had been met for all BCTs identified as having a significant effect on self-efficacy (fully met, partially met or unclear). Of BCTs identified as having a significant effect on self-efficacy, the frequency with which they were coded within interventions was too low to enable the effect of this factor to be modelled. Parameters of efficacy were therefore neither coded nor assessed within the present review.

Practical applications used to deliver BCTs. 'Practical applications' describe the ways in which theoretical methods of behaviour change such as BCTs are translated into practical intervention elements (Bartholomew, Parcel, Kok, Gottlieb, \& Fernandez, 2016). To illustrate, examples of practical strategies for the BCT 'Demonstration of the behaviour' could include a video demo of how to prepare a healthy meal or pictures providing step-by-step guidance on correct condom application. Practical applications were additionally extracted by [initials of one individual blinded] for interventions described within each included study. Agreement with these was checked by [initials of one individual blinded]. Minor changes were made following consensus discussion. Whilst the coding of practical applications was not originally specified within the review protocol (CRD42017055855), it was agreed that examples of how intervention developers had translated BCTs into digital intervention content would be of additional interest and value. 
BCT dose. It was not possible to conduct the per protocol (CRD42017055855) coding of BCT dose. The team planned to assess dose by counting the number of times each unique BCT was delivered by an intervention. However, due to limited intervention descriptions provided within the papers of included studies it was not possible to reliably assess this.

\section{Assessment of Bias}

The Cochrane Risk of Bias Tool was used to assess the 'risk that studies will overestimate or underestimate the true intervention effect in their results' (Higgins \& Green, 2011). Two researchers ([initials blinded]) independently assessed risk of bias in each trial according to: adequacy of sequence generation, allocation concealment, blinding of participants and personnel, blinding of outcome assessment, incomplete outcome data, and selective reporting. Any disagreements in scoring were discussed until a consensus was reached. Risk of bias was classified in each study as low (all criteria graded low), moderate (one criterion graded high or two criteria graded unclear), or high (two or more criteria graded high or more than two graded unclear) (Bridle, Spanjers, Patel, Atherton, \& Lamb, 2012).

\section{Statistical Methods}

Please see https://osf.io/vf52h/ for the raw data file used in all analyses.

Comprehensive Meta-Analysis (CMA) version 3 (Biostat, version 3, 2014) was used to calculate effect sizes using means and standard deviations for the intervention and control groups at pre-test and post-test. If pre- and post-test correlations were not reported, a correlation of 0.5 was assumed between baseline and post-test (van Genugten, Dusseldorp, Massey, \& van Empelen, 2017). All effect sizes were expressed as Hedges' $\bar{g}$, an estimate of Cohen's d that corrects for the bias introduced by studies with a small sample size (van Genugten et al., 2017). As such, it can be 
interpreted using the same rule of thumb (Cohen, 1992). To estimate the pooled effect size a random effects model was used. This model was used as it allows for some variation in true effect sizes and as such takes into account possible differences between the studies, for example, in the mix of participants or in the implementation of the intervention (Borenstein, Hedges, Higgins, \& Rothstein, 2009). The amount of heterogeneity between studies was assessed using the $\mathrm{I}^{2}$ statistic. Evidence of publication bias, was assessed using Funnel Plots, the Begg's rank correlation test (Begg \& Mazumdar, 1994) and the Egger's regression test (Egger, Smith, Schneider, \& Minder, 1997).

A pooled and weighted Hedges' $\bar{g}$ for self-efficacy was first calculated for all included studies using the software. This analysis addressed the first aim of the study: to examine the overall effect of digital behaviour change interventions on selfefficacy.

\section{Moderator analyses.}

Analysis of behaviour type. To establish whether self-efficacy varied as a function of the targeted health behaviour, a moderation analysis was performed. This addressed the second aim of the review.

Analysis of BCTs. To address the third aim, moderation analysis was used to identify which BCTs had statistically significant effects on self-efficacy. BCTs included in three or more comparisons were examined. This cut-off point was selected as fewer comparisons would likely produce unreliable results. The use of three comparisons has been demonstrated as sufficient to assess heterogeneity (Borenstein et al., 2009). Subsequently, a special type of moderation analysis called Meta-CART was performed to address the fourth aim of the review: to identify whether any BCTs in combination amplified or attenuated the effect on self-efficacy. Meta-CART 
integrates classification and regression trees (Breiman, 1983) into the field of metaanalysis. It was first proposed in the re-analysis of data from Michie et al. (2009) by Dusseldorp et al. (2014) to analyse the effectiveness of combinations of BCTs. Its performance in identifying interaction effects was evaluated by Li et al. (2017). In the present study, to take residual heterogeneity unexplained by the BCTs into account, a random effects meta-CART with one-standard-error pruning rule was used (Li et al., 2017).

Gender. Meta-regression was used to test the effect of the proportion of women in the sample as a moderator of the effect size for self-efficacy. Metaregression was chosen to examine the effect of gender as in the majority of papers data was presented as the percentage of males and/or females.

Risk of bias. A sensitivity analysis was conducted, entering the risk of bias classifications, to examine whether the effect on self-efficacy was robust once studies with a high risk of bias were removed.

It was not possible to conduct the following per protocol (CRD42017055855) moderation analyses due to insufficient variability in the relevant study variables: conformity to BCT parameters of effectiveness, study design, age group of study participants, measurement of self-efficacy, income of study country, and quality of intervention development.

\section{Results}

Of 7,648 potential studies initially identified (after duplicates were removed), twenty four satisfied the eligibility criteria. Four studies were removed as they contained insufficient statistical information to enable study effect sizes to be calculated (Buller et al., 2009; Kelders, van Gemert-Pijnen, J. E. W. C, Werkman, \& Seydel, 2010; 
Swartz, Noell, Schroeder, \& Ary, 2006; Uechi \& Tan, 2015) leaving twenty studies in total $(\mathrm{n}=5624)$. The twenty included studies are listed in supplemental material 4 .

\section{Study characteristics}

Characteristics of each of the studies included in the meta-analysis can be found in the online supplemental materials (supplemental material 5). All studies were randomised controlled trials. In two of the studies (Brown, 2016; Prestwich et al., 2017), two different interventions were compared to a control. The present review therefore includes twenty studies representing twenty-two different interventions. Fourteen of the twenty studies recruited both male and female participants, five recruited a female only sample, and one recruited a male only sample. For fifteen of the studies, the mean age of participants fell into the 35-64 years age bracket. For three studies, this fell into the 25-34 years age bracket. For one study, the mean age fell into the 18-24 year old bracket. One further study (Anderson, Winett, Wojcik, Winett, \& Bowden, 2001) did not provide a mean age but reported that all participants were aged 18 years or older. Additional summary characteristics are presented in Table 1.

\section{Table 1 here}

In total, thirty nine unique BCTs were coded across the twenty-two interventions included in the meta-analysis (see supplemental material 6). The most common BCTs coded were 'goal setting (behaviour)' and 'instruction on how to perform the behaviour', both coded in eleven of the interventions. Other common BCTs included 'self-monitoring of behaviour', 'problem solving', 'action planning' and 'information about health consequences'. Two studies had no unique BCTs in the intervention condition compared to the control condition (Hageman \& Pullen, 2005; Powell et al., 2016). Supplemental material 7 presents modes of intervention delivery, BCTs and practical applications coded for each intervention included in the meta-analysis. 


\section{What is the overall effect of digital behaviour change interventions on self- efficacy?}

Overall, study interventions were successful at increasing self-efficacy, with a small, significant and positive effect size $(\bar{g}=0.190$, CI [0.078; 0.303]). Figure 2 presents the forest plot and the effect sizes and confidence intervals for each study included in the analysis. The $\mathrm{I}^{2}$ statistic was calculated to be $69.8 \%$ and the Q-test for heterogeneity was significant $(\mathrm{Q}=69.556, \mathrm{df}=21, \mathrm{p}<0.001)$ indicating substantial heterogeneity between studies in terms of their true effect on self-efficacy.

Figure 2 about here

Examination of the funnel plot for self-efficacy and Begg's test $(p=0.223)$. identified no evidence of publication bias. Publication bias was however indicated by Egger's test $(p=0.018)$.

\section{Does the overall effect size vary as a function of the behaviour being addressed?}

The effect of interventions on self-efficacy did not differ as a function of health behaviour type $(Q$-between $=7.374 \mathrm{p}=0.061, \mathrm{df}=3)$. A forest plot showing subgroup effects is presented in supplemental material 8.

\section{Which BCTs have an effect on self-efficacy?}

Of the thirty nine unique BCTs coded across studies included in the meta-analysis, seventeen were present three or more times within an intervention. The effect on selfefficacy of each of these seventeen BCTs was examined using moderator analysis. 'Information about social and environmental consequences' had a small negative effect on self-efficacy $(\Delta \bar{g}=-0.297, Q=7.072, \mathrm{p}=0.008)$. Interventions that included the BCT 'information about social and environmental consequences' had a lower effect size $(\bar{g}=-0.029$, CI $[-0.222 ; 0.164])$ than the interventions without this BCT $(\bar{g}=0.268$, CI $[0.165 ; 0.372])$. No other BCTs had a significant effect on self-efficacy. 


\section{Do any BCTs in combination amplify (or attenuate) the effect on self-efficacy?}

Random effects meta-CART was used to examine interaction effects between the fifteen BCTs. No interaction effects were detected.

\section{Risk of Bias}

Of the 20 included studies, one had a low risk of bias (Keller, Motter, Motter, \& Schwarzer, 2018), seven had a moderate risk of bias (Anderson et al., 2001; Bowen, Horvath, \& Williams, 2007; Dadaczynski, Schiemann, \& Backhaus, 2017; Irvine et al., 2011; Muller, Khoo, \& Morris, 2016; Powell et al., 2016; Prestwich et al., 2017), and twelve had a high risk of bias. Plots of the risk of bias assessment by domain and by study can be found in the online supplemental material (supplemental material 9). The domain contributing most frequently to a high risk of bias rating was 'selective reporting'. This domain was most frequently coded as a result of trial protocols stating planned analyses being either absent or unavailable. Other domains frequently contributing high ratings included 'random sequence generation' and 'allocation concealment'. Following removal of studies presenting a high risk of bias, the effect on self-efficacy remained significant ( $\bar{g}=0.211$, CI [0.092; 0.329].

\section{Additional moderator analysis}

The effect of interventions on self-efficacy decreased as the proportion of women included in the sample increased $(\bar{g}=-0.004$, CI $[-0.0085 ;-0.0004]$.

\section{Discussion}

\section{Principal findings}

The present study found that automated digital health behaviour change interventions have a small, significant, positive effect on self-efficacy. The effect of the interventions on self-efficacy did not vary as a function of the behaviour being addressed. Thirty nine BCTs in total were coded across the interventions. Including 
the BCT 'information about social and environmental consequences' in digital interventions led to a small significant reduction in self-efficacy. No interaction effects were detected between any of the included BCTs. There was a significant effect of gender such that as the proportion of women increased, the effect of interventions on self-efficacy decreased. There were insufficient studies to conduct additional planned analyses.

\section{Implications of findings}

The present review provides a unique insight into the effect of automated digital behaviour change interventions on self-efficacy. Whilst the overall effect on selfefficacy was small, this is commensurate with existing reviews examining the effect on self-efficacy in which the type of intervention delivery was unrestricted (Prestwich et al., 2014; Williams \& French, 2011). Given the potential for participants' preintervention levels of self-efficacy to be over-optimistic (McAuley, Jerome, Marquez, Elavsky, \& Blissmer, 2003) this finding is therefore encouraging, indicating that automated digital interventions can be used to increase this important determinant of health behaviour.

Analysis by behaviour was performed to examine the effect of digital interventions on self-efficacy within each behavioural domain. Firstly, it should be noted that the review did not identify any studies that tested the effect of interventions targeting alcohol use. Two explanations for this are that (1) target samples for alcohol interventions typically include either university students (Cameron et al., 2015; Epton et al., 2014) or treatment seeking individuals (Suffoletto, Callaway, Kristan, Kraemer, \& Clark, 2012) and therefore would not have met the eligibility criteria for the present review, and (2) within the alcohol literature there is a greater use of perceived behavioural control (Ajzen, 1991) as opposed to the conceptually similar term of self- 
efficacy (Cooke et al., 2016). For the remaining behaviours, namely healthy eating, physical activity, sexual behaviour, and smoking, the effect of interventions on selfefficacy was equivalent. This indicates that automated digital interventions can be used to successfully increase self-efficacy for healthy eating, physical activity, sexual behaviour, and smoking.

With regards to 'information about social and environmental consequences', the present review found inclusion of this BCT within interventions to lower selfefficacy. This BCT was included in analyses conducted by both Prestwich and colleagues (2014) and Williams and French (2011) but neither found it to have an effect on self-efficacy ${ }^{3}$. Why inclusion of this BCT should have a negative impact on self-efficacy is unclear. A recent exercise which aimed to elicit expert consensus on links between BCTs and mechanisms of action (MoAs) (Connell et al., 2018), found agreement that 'information on social and environmental consequences' 'definitely did not link' to 'beliefs about capability' (the MoA most closely aligned to selfefficacy). Instead, this BCT was judged as 'definitely' being linked to 'beliefs about consequences', a MoA akin to the psychological construct of 'risk appraisal'.

This finding is also at odds with theory. A number of theories of health behaviour identify risk appraisal as a primary motivator of protective action. According to Protection Motivation Theory (Rogers \& Prentice-Dunn, 1997) for example, people will be motivated to perform a protective behaviour providing their risk and efficacy appraisals are sufficiently high. Risk appraisal is typically operationalised as judgements about the likelihood and severity of a threat, whilst efficacy appraisal as the perceived effectiveness of an action in removing that threat

\footnotetext{
${ }^{3}$ These reviews both used predecessors of the 93-item taxonomy used in the present review. The 26item version used by Prestwich et al. (2014) labelled this BCT as 'provide information on consequences', whereas the 40-item version used by Williams and French (2011) labelled it as 'provide information on the consequences of behaviour in general'.
} 
(response efficacy), along with perceived ability to perform that action (self-efficacy). This theory posits an interaction between risk and efficacy, such that an effect of risk on behaviour is expected only under conditions where efficacy is high or simultaneously increased. However, whilst efficacy appraisals may modify the effect of risk on behaviour, changes in risk are not expected to modify the effect of efficacy on behaviour.

With two exceptions ('setting graded tasks' and 'prompt review of behavioural goals'), all of the BCTs identified as having an effect on self-efficacy in the reviews by either Prestwich and colleagues (2014) or Williams and French (2011) were included in the moderation analysis conducted within the present review. None of these BCTs were however found to have an effect on self-efficacy. Across the three reviews there is therefore no consensus on which BCTs have a positive or deleterious effect on self-efficacy or therefore on which should be used (or avoided) by intervention developers.

The expert consensus exercise (Connell et al., 2018) identified four BCTs that 'definitely' had a link with the MoA 'beliefs about capability', namely 'graded tasks', 'behavioural practice/rehearsal', 'verbal persuasion about capability' and 'problem solving'. A further four showed a trend towards agreement, namely 'instruction on how to perform behaviour', 'feedback on outcome(s) of behaviour', 'generalisation of target behaviour' and 'self-monitoring of outcome(s) of behaviour'. Of these eight BCTs, only three were coded in the present review with sufficient frequency to enable moderation analysis to be performed: 'verbal persuasion about capability' (coded four times), 'instruction on how to perform behaviour' (coded eleven times), and 'problem solving' (coded nine times). All other BCTs were either absent or coded just once. Neither of these three BCTs were however found to have a positive effect on self- 
efficacy, indeed no effect was observed. Given that BCTs which might be expected to be included to increase self-efficacy were coded with such low frequency across the review, and that those that were included had no effect, it should be considered whether the automated digital nature of the interventions may have precluded their optimal implementation or their use altogether.

Whilst digital interventions provide significant opportunities to interact with intervention recipients in new ways, it should be recognised that this mode of delivery may restrict the translation of some BCTs into practical strategies. Digital delivery, especially when fully automated, removes the potential for human interaction between the intervention deliverer and recipient. For some BCTs, a level of human interaction is implied in the definition. The BCT, 'verbal persuasion about capability' for example, states 'tell the person that they can perform the wanted behaviour, arguing against self-doubts and asserting that they can and will succeed'. Other BCTs, whilst not requiring human interaction per se, would arguably be enhanced by it. For the BCT 'instruction on how to perform the behaviour', for example, whilst this can be delivered via film or images as an alternative to face-to-face, this mode of delivery provides no opportunity for recipients to ask questions or for the explanation to be adapted according to recipients' level of understanding or need. Similarly for the BCT 'problem solving', input from a third person would likely enable a deeper level of insight into factors influencing behaviour and for a broader range of strategies to overcome barriers to be identified. These three BCTs were included in the moderation analysis for the present review but none were found to have an effect on self-efficacy. In line with the review protocol, parameters of effectiveness were only coded for BCTs found to have an effect on self-efficacy. This was to enable the effect of meeting these parameters (or otherwise) to be modelled. However, it would have been 
informative to code whether parameters of effectiveness had been met for all BCTs included in the moderation analysis. For the BCTs 'verbal persuasion about capability' for example, a suitable parameter would be that 'arguments are presented in response to self-doubt'. Such coding would enable tentative conclusions to be drawn about whether a failure to implement a BCT in line with its parameters of effectiveness may have contributed towards the absence of an effect. At present there is no consensus on 'parameters of effect' for BCTs. Developing such a consensus would be a worthwhile activity. Not only would it enable this important moderating factor to be examined as part of reviews attempting to isolate effective BCTs, it would also enhance the fidelity with which BCTs are translated into intervention content.

As well as automated digital systems presenting challenges for optimal delivery, it may also be the case that this context deters the use of some BCTs altogether. As described above, there were five BCTs in the present review that, whilst identified by the consensus exercise as linked to self-efficacy, were present in too low a frequency to be included in the moderation analysis. Each of these, to a varying extent, would require a level of digital sophistication if they were to be delivered by an automated intervention. The BCT 'graded tasks' for example, requires intervention recipients to be 'set increasingly difficult, but achievable tasks until the behaviour is performed'. This implies that the intervention deliverer, a) has a benchmark for the recipient's behaviour, b) is able to gauge what would be an 'easy to perform' task for that individual, and c) what increase in difficulty would render the task challenging but still within reach. Once again, this infers a degree of human interaction between intervention deliver and recipient. The advent of Artificial Intelligence (AI) however presents new possibilities to deliver this type of BCT. AI is an area of computer science involving the development of 'intelligent' systems that 
work and react like humans. Taking the above example, it would be possible to create an AI system that sought information from the recipient about current and historical levels of the targeted behaviour, and then using an algorithm, present them with sequential graded tasks. This algorithm could additionally factor in information about the typical rate and/or level of behaviour previously achieved by users. This would help to mitigate the risk of unrealistically high goals being set which has been shown to have a negative impact on subsequent performance (Brusso \& Orvis, 2013), most likely due to it deleterious effect on levels of self-efficacy (Bandura, 1977). Given that individuals' overestimation of their ability to perform a task is a key barrier to effective goal setting (Mabe \& West, 1982; Sitzmann, Ely, Brown, \& Bauer, 2010), an AI system which is able to factor in information about goal achievement from its ever-growing database may even have an advantage over human agents in setting realistic goals.

\section{Strengths and limitations}

This was a methodologically rigorous review conducted in accordance with the PRISMA guidelines and guidance provided by Peters and colleagues (2015). It is the first meta-analysis to identify the effectiveness of digitally delivered BCTs in changing self-efficacy, and adds more broadly to the growing body of evidence about which techniques work to change this important determinant of behaviour. The findings will be of practical value to interventionists seeking to develop automated digital interventions. It has isolated a technique that decreases self-efficacy in this context which should therefore be used with caution. Nonetheless, the results should be considered in light of their limitations. At the study level, these include the inadequate reporting of methods and intervention content. The quality of RCTs and their reporting could be improved through adherence to CONSORT guidelines 
(Moher, Schulz, \& Altman, 2001) and e-health CONSORT guidelines (Eysenbach, 2013). At the review level, limitations included between-study heterogeneity, the small number of studies within behavioural sub-groups, and the low incidence of some BCTs which restricted the performance of planned moderation analyses and reduces confidence in some estimates of effect size.

As cautioned by Peters and colleagues (2015), findings arising from this type of review should not be taken as definitive evidence of which BCTs do and don't work to change self-efficacy. To determine this, it is necessary to run controlled experiments that manipulate the presence of single BCTs and their parameters of effectiveness. This could include for example, studying the effect on self-efficacy of manipulating the presence of the $\mathrm{BCT}$ 'information about social and environmental consequences'. It is this further experimental work that is essential to building a robust evidence base for our toolbox of behaviour change techniques. The present review is an important starting point, generating hypotheses about which BCTs may be having an unfavourable effect on self-efficacy when delivered using digital automated interventions. Once tested, they can be used to provide definitive evidence about what works in this context. This is essential information for the development of future digital health behaviour change interventions urgently needed to reduce the burden of preventable disease.

\section{Conclusion}

The present review provides evidence that automated digital interventions can be used to increase self-efficacy, an important determinant of behaviour. This is the case for four health behaviours, namely healthy eating, physical activity, sexual behaviour, and smoking. The results have however provided little direction to intervention developers in terms of which BCTs should be used or avoid. The anomalous finding 
that the BCT 'information about social and environmental consequences' reduced the effect of interventions on self-efficacy, along with the lack of consensus across reviews with regards to which BCTs work to increase self-efficacy, implies caution in the continued use of meta-analytic evidence to isolate BCTs for targeting particular behavioural determinants. A more preferable approach would be to change direction, and instead to begin building our science from the 'bottom-up', using controlled experiments in which single BCTs are manipulated. It is this type of experiment, and indeed meta-analyses of their findings, that would provide the much needed and conclusive evidence about which BCTs work to change determinants of health behaviour.

\section{References}

Ajzen, I. (1991). The theory of planned behavior. Organizational Behavior and Human Decision Processes, 50(2), 179-211. doi:10.1016/0749-5978(91)90020-T

Anderson, E., Winett, R., Wojcik, J., Winett, S., \& Bowden, T. (2001). A computerized social cognitive intervention for nutrition behavior: Direct and mediated effects on fat, fiber, fruits, and vegetables, self-efficacy, and outcome expectations among food shoppers. Annals of Behavioral Medicine, 23(2), 88100. doi:10.1207/S15324796ABM2302_3

APA Publications and Communications Board Working Group on Journal Article Reporting Standards. (2008). Reporting standards for research in psychology: Why do we need them? What might they be? American Psychologist, 63(9), 839851. doi:10.1037/0003-066X.63.9.839 
Ashford, S., Edmunds, J., \& French, D. P. (2010). What is the best way to change self-efficacy to promote lifestyle and recreational physical activity? A systematic review with meta-analysis. British Journal of Health Psychology, 15(2), 265. doi:10.1348/135910709X461752

Bandura, A. (1977). Self-efficacy: Toward a unifying theory of behavioral change. Psychological Review, 84(2), 191-215. doi:10.1016/0146-6402(78)90002-4

Bandura, A. (1986). Social foundations of thought and action: A social cognitive theory. Englewood Cliffs, NJ: Prentice-Hall, Inc.

Bandura, A. (1997). Self-efficacy: The exercise of control. New York: W H Freeman \& Company.

Bartholomew, L. K., Parcel, G. S., Kok, G., Gottlieb, N. H., \& Fernandez, M., E. (2016). Planning health promotion programs: An intervention mapping approach (4th edition). San Fransisco, USA: Jossey-Bass.

Bauman, A. E., Reis, R. S., Sallis, J. F., Wells, J. C., Loos, R. J. F., \& Martin, B. W. (2012). Correlates of physical activity: Why are some people physically active and others not? Lancet, 380(9838), 258-271. doi:10.1016/S0140-6736(12)607351

Begg, C. B., \& Mazumdar, M. (1994). Operating characteristics of a rank correlation test for publication bias. Biometrics, 50(4), 1088-1101. doi:10.2307/2533446

Borenstein, M., Hedges, L. V., Higgins, J. P., \& Rothstein, H. R. (2009). Introduction to meta-analysis. West Sussex, UK: John Wiley \& Sons, Ltd. 
Bowen, A., Horvath, K., \& Williams, M. (2007). A randomized control trial of internet-delivered HIV prevention targeting rural MSM. Health Education Research, 22(1), 120-7. doi:10.1093/her/cyl057

Breiman, L. (1983). Classification and regression trees. Boca Raton, USA: Wadsworth.

Bridle, C., Spanjers, K., Patel, S., Atherton, N. M., \& Lamb, S. E. (2012). Effect of exercise on depression severity in older people: Systematic review and metaanalysis of randomised controlled trials. The British Journal of Psychiatry, 201(3), 180-185. doi:10.1192/bjp.bp.111.095174

Brown, T. C. (2016). Impact of a theory-guided encouragement intervention on an employee walking pilot program. Journal of Applied Sport Psychology, 28(4), 452-468. doi:10.1080/10413200.2016.1187687

Brusso, R. C., \& Orvis, K. A. (2013). The impeding role of initial unrealistic goalsetting on videogame-based training performance: Identifying underpinning processes and a solution. Computers in Human Behavior, 29(4), 1686-1694. doi:10.1016/j.chb.2013.01.006

Buller, M., Kane, I., Dunn, A., Edwards, E., Buller, D., \& Liu, X. (2009). Marketing fruit and vegetable intake with interactive games on the internet. Social Marketing Quarterly, 15, 136-154. doi:10.1080/15245000903038316

Burke, V., Beilin, L. J., Cutt, H. E., Mansour, J., \& Mori, T. A. (2008). Moderators and mediators of behaviour change in a lifestyle program for treated 
hypertensives: A randomized controlled trial (ADAPT). Health Education Research, 23(4), 583-591. doi:10.1093/her/cym047

Cameron, D., Epton, T., Norman, P., Sheeran, P., Harris, P. R., Webb, T. L. Sheeran, P., Julious, S.A., Ciravegna, F., Brennan, A., Meier, P.S., Naughton, D., Petroczi, A., Kruger, J., \& Shah, I. (2015). A theory-based online health behaviour intervention for new university students (U@Uni): Results from a repeat randomized controlled trial. Trials, 16(1), 1-15. doi:10.1186/s13063-015-1092-4

Cohen, J. (1992). A power primer. Psychological Bulletin, 112(1), 155-159. doi: 10.1037//0033-2909.112.1.155

Connell, L. E., Carey, R. N., de Bruin, M., Rothman, A. J., Johnston, M., Kelly, M. P., \& Michie, S. (2018). Links between behavior change techniques and mechanisms of action: An expert consensus study. Annals of Behavioral Medicine, 53(8), 708-720. doi:10.1093/abm/kay082

Cooke, R., Dahdah, M., Norman, P., \& French, D. P. (2016). How well does the theory of planned behaviour predict alcohol consumption? A systematic review and meta-analysis. Health Psychology Review, 10(2), 148-167. doi:10.1080/17437199.2014.947547

Cortis, C., Puggina, A., Pesce, C., Aleksovska, K., Buck, C., Burns, C. Cardon, G., Carlin, A., Simon, C., Ciarapica, D., Condello, G., Coppinger, T., D'Haese, S., De Craemer, M., Di Blasio, A., Hansen, S., Iacoviello, L., Issartel, J., Izzicupo, P., Jaeschke, L., Kanning, M., Kennedy, A., Ling, F.C.M., Luzak, A., Napolitano, G., Nazare, J.A., O'Donoghue, G., Perchoux, C., Pischon, T., Polito, A., Sannella, A., Schulz, H., Sohun, R., Steinbrecher, A., Schlicht, 
W., Ricciardi, W., Castellani, L., MacDonncha, C., Capranica, L., Boccia, S. (2017). Psychological determinants of physical activity across the life course: A "DEterminants of DIet and physical ACtivity" (DEDIPAC) umbrella systematic literature review. Plos One, 12(8), e0182709. doi:10.1371/journal.pone.0182709

Dadaczynski, K., Schiemann, S., \& Backhaus, O. (2017). Promoting physical activity in worksite settings: Results of a german pilot study of the online intervention healingo fit.(report). BMC Public Health, 17(1) doi:10.1186/s12889-017-4697-6

Dusseldorp, E., van Genugten, L., van Buuren, S., Verheijden, M. W., \& van Empelen, P. (2014). Combinations of techniques that effectively change health behavior: Evidence from meta-CART analysis. Health Psychology, 33(12), 15301540. doi: $10.1037 /$ hea0000018

Egger, M., Smith, G. D., Schneider, M., \& Minder, C. (1997). Bias in meta-analysis detected by a simple, graphical test. BMJ, 315(7109), 629-634. doi:10.1136/bmj.315.7109.629

Epton, T., Norman, P., Dadzie, A., Harris, P. R., Webb, T. L., Sheeran, P Julious, S.A., Ciravegna, F., Brennan, A., Meier, P.S., Naughton, D., Petroczi, A., Kruger, J., Shah, I. (2014). A theory-based online health behaviour intervention for new university students (U@Uni): Results from a randomised controlled trial. BMC Public Health, 14, 563. doi:10.1186/1471-2458-14-563

Eysenbach, G. (2013). CONSORT-EHEALTH: Implementation of a checklist for authors and editors to improve reporting of web-based and mobile randomized controlled trials. Studies in Health Technology and Informatics, 192(1), 657-661. doi:10.3233/978-1-61499-289-9-657 
Fuemmeler, B. F., Mקsse, L. C., Yaroch, A. L., Resnicow, K., Campbell, M. K., Carr, C., Wang, T., \& Williams, A. (2006). Psychosocial mediation of fruit and vegetable consumption in the body and soul effectiveness trial. Health Psychology, 25(4), 474-483. doi:10.1037/0278-6133.25.4.474

Gwaltney, C. J., Metrik, J., Kahler, C. W., \& Shiffman, S. (2009). Self-efficacy and smoking cessation: A meta-analysis. Psychology of Addictive Behaviors, 23(1), 56-66. doi:10.1037/a0013529

Hageman, P., \& Pullen, C. (2005). Tailored versus standard internet-delivered interventions to promote physical activity in older women. Journal of Geriatric Physical Therapy, 28(1), 28-33. doi:10.1519/00139143-200504000-00005

Higgins, J., \& Green, S. (2011). Cochrane handbook for systematic reviews of interventions (5.1.0 edition). The Cochrane Collaboration.

Irvine, A. B., Philips, L., Seeley, J., Wyant, S., Duncan, S., \& Moore, R. W. (2011). Get moving: A web site that increases physical activity of sedentary employees. American Journal of Health Promotion, 25(3), 199-206. doi:10.4278/ajhp.04121736

Kelders, S. M., van Gemert-Pijnen, J. E. W. C, Werkman, A., \& Seydel, E. R. (2010). Usage and effect of a web-based intervention for the prevention of overweight; a randomized controlled trial. Studies in Health Technology and Informatics, 160(1), 28-32. doi:10.1109/eTELEMED.2010.22 
Keller, J., Motter, S., Motter, M., \& Schwarzer, R. (2018). Augmenting fruit and vegetable consumption by an online intervention: Psychological mechanisms. Appetite, 120, 348-355. doi:10.1016/j.appet.2017.09.019

Langenberg, P., Ballesteros, M., Feldman, R., Damron, D., Anliker, J., \& Havas, S. (2000). Psychosocial factors and intervention-associated changes in those factors as correlates of change in fruit and vegetable consumption in the maryland WIC 5 a day promotion program. Annals of Behavioral Medicine, 22(4), 307-315. doi:10.1007/BF02895667

Li, X., Dusseldorp, E., \& Meulman, J. J. (2017). Meta-CART: A tool to identify interactions between moderators in meta-analysis. The British Journal of Mathematical and Statistical Psychology, 70(1), 118-136. doi:10.1111/bmsp. 12088

Luszczynska, A., Tryburcy, M., \& Schwarzer, R. (2007). Improving fruit and vegetable consumption: A self-efficacy intervention compared with a combined self-efficacy and planning intervention. Health Education Research, 22(5), 630638. doi:10.1093/her/cyl133

Mabe, P. A., \& West, S. G. (1982). Validity of self-evaluation of ability: A review and meta-analysis. Journal of Applied Psychology, 67(3), 280-296. doi:10.1037/0021-9010.67.3.280

McAuley, E., Jerome, G., Marquez, D., Elavsky, S., \& Blissmer, B. (2003). Exercise self-efficacy in older adults: Social, affective, and behavioral influences. Annals of Behavioral Medicine, 25(1), 1-7. doi:10.1207/S15324796ABM2501_01 
Michie, S., Abraham, C., Whittington, C., McAteer, J., \& Gupta, S. (2009). Effective techniques in healthy eating and physical activity interventions: A metaregression. Health Psychology, 28(6), 690-701. doi:10.1037/a0016136; 10.1037/a0016136.supp

Michie, S., Richardson, M., Johnston, M., Abraham, C., Francis, J., Hardeman, W., Eccles, M. P., Cane, J., Wood, C. E. (2013). The behavior change technique taxonomy (v1) of 93 hierarchically clustered techniques: Building an international consensus for the reporting of behavior change interventions. Annals of Behavioral Medicine, 46(1), 81. doi:10.1007/s12160-013-9486-6

Michie, S., West, R., Sheals, K., \& Godinho, C. A. (2018). Evaluating the effectiveness of behavior change techniques in health-related behavior: A scoping review of methods used. Translational Behavioral Medicine, 8(2), 212224. doi: $10.1093 / \mathrm{tbm} / \mathrm{ibx} 019$

Moher, D., Liberati, A., Tetzlaff, J., \& Altman, D. G. (2009). Preferred reporting items for systematic reviews and meta-analyses: The PRISMA statement. Journal of Clinical Epidemiology, 62(10), 1006-1012. doi:10.1016/j.jclinepi.2009.06.005

Moher, D., Schulz, K. F., \& Altman, D. (2001). The CONSORT statement: Revised recommendations for improving the quality of reports of parallel-group randomized trials. BMC Medical Research Methodology, 1(2), doi:10.1186/1471$2288-1-2$ 
Mokdad, A. H., Marks, J. S., Stroup, D. F., \& Gerberding, J. L. (2004). Actual causes of death in the united states, 2000. JAMA: Journal of the American Medical Association, 291(10), 1238-1245. doi:10.1001/jama.291.10.1238

Muller, A. M., Khoo, S., \& Morris, T. (2016). Text messaging for exercise promotion in older adults from an upper-middle-income country: Randomized controlled trial. Journal of Medical Internet Research, 18(1), e5. doi:10.2196/jmir.5235

Murray, E., Hekler, E. B., Andersson, G., Collins, L. M., Doherty, A., Hollis, C., . . Wyatt, J. C. (2016). Evaluating digital health interventions: Key questions and approaches. American Journal of Preventive Medicine, 51(5), 843-851. doi:10.1016/j.amepre.2016.06.008

Office for National Statistics. (2017). Internet access - households and individuals, Great Britain: 2017

Olander, E. K., Fletcher, H., Williams, S., Atkinson, L., Turner, A., \& French, D. P. (2013). What are the most effective techniques in changing obese individuals' physical activity self-efficacy and behaviour: A systematic review and metaanalysis. International Journal of Behavioral Nutrition \& Physical Activity, 10, 29-43. doi:10.1186/1479-5868-10-29

Peters, G. Y., de Bruin, M., \& Crutzen, R. (2015). Everything should be as simple as possible, but no simpler: Towards a protocol for accumulating evidence regarding the active content of health behaviour change interventions. Health Psychology Review, 9(1), 1-14. doi:10.1080/17437199.2013.848409 
Powell, J., Newhouse, N., Martin, A., Jawad, S., Yu, L., Davoudianfar, M., Locock, L., \& Ziebland, S. (2016). A novel experience-based internet intervention for smoking cessation: Feasibility randomised controlled trial. BMC Public Health, 16(1), 1156. doi:10.1186/s12889-016-3821-3

Prestwich, A., Conner, M., Morris, B., Finlayson, G., Sykes-Muskett, B., \& Hurling, R. (2017). Do web-based competitions promote physical activity? randomized controlled trial. Psychology of Sport \& Exercise, 29, 1-9. doi:10.1016/j.psychsport.2016.11.003

Prestwich, A., Kellar, I., Parker, R., MacRae, S., Learmonth, M., Sykes, B., . . . Castle, H. (2014). How can self-efficacy be increased? meta-analysis of dietary interventions. Health Psychology Review, 8(3), 270-285. doi:10.1080/17437199.2013.813729

Prochaska, J. O., \& DiClemente, C. C. (1982). Transtheoretical therapy: Toward a more integrative model of change. Psychotherapy: Theory, Research \& Practice, 19(3), 276-288. doi:10.1037/h0088437

Proudfoot, J., Klein, B., Barak, A., Carlbring, P., Cuijpers, P., Lange, A., Ritterband, L., \& Andersson, G. (2011). Establishing guidelines for executing and reporting internet intervention research. Cognitive Behaviour Therapy, 40(2), 82-97. doi:10.1080/16506073.2011.573807

Ritterband, L. M., \& Tate, D. F. (2009). The science of internet interventions. Annals of Behavioral Medicine, 38(1), 1-3. doi:10.1007/s12160-009-9132-5 
Rogers, R. W., \& Prentice-Dunn, S. (1997). Protection motivation theory. In D. S. Gochman (Ed.), Handbook of health behavior research 1: Personal and social determinants (pp. 113-132). New York, NY: Plenum.

Schwarzer, R. (1992). Self-efficacy in the adoption and maintenance of health behaviors: Theoretical approaches and a new model. In R. Schwarzer (Ed.), Self-efficacy: Thought control of action (pp. 217243). Washington, DC: Hemisphere.

Sheeran, P., Maki, A., Montanaro, E., Avishai-Yitshak, A., Bryan, A., Klein, W. M. P., Miles, E., \& Rothman, A. J. (2016). The impact of changing attitudes, norms, and self-efficacy on health-related intentions and behavior: A meta-analysis. Health Psychology, 35(11), 1178-1188. doi:10.1037/hea0000387; 10.1037/hea0000387.supp (Supplemental)

Sheeran, P., \& Taylor, S. (1999). Predicting intentions to use condoms: A metaanalysis and comparison of the theories of reasoned action and planned behavior. Journal of Applied Social Psychology, 29(8), 1624-1675. doi:10.1111/j.15591816.1999.tb02045.x

Sitzmann, T., Ely, K., Brown, K. G., \& Bauer, K. N. (2010). Self-assessment of knowledge: A cognitive learning or affective measure? Academy of Management Learning \& Education, 9(2), 169-191. doi:10.5465/AMLE.2010.51428542

Suffoletto, B., Callaway, C., Kristan, J., Kraemer, K., \& Clark, D. B. (2012). Textmessage-based drinking assessments and brief interventions for young adults discharged from the emergency department. Alcoholism: Clinical and Experimental Research, 36(3), 552-560. doi:10.1111/j.1530-0277.2011.01646.x 
Swartz, L. H. G., Noell, J. W., Schroeder, S. W., \& Ary, D. V. (2006). A randomised control study of a fully automated internet based smoking cessation programme. Tobacco Control, 15(1), 7-12. doi:10.1136/tc.2003.006189

Uechi, H., \& Tan, N. (2015). The effects of internet-delivered intervention for promoting physical activity. Japanese Journal of Health Psychology, 28(2), 6572. doi:10.11560/jahp.28.2_65

van Genugten, L., Dusseldorp, E., Massey, E. K., \& van Empelen, P. (2017). Effective self-regulation change techniques to promote mental wellbeing among adolescents: A meta-analysis. Health Psychology Review, 11(1), 53-71. doi:10.1080/17437199.2016.1252934

van Genugten, L., Dusseldorp, E., Webb, T. L., \& van Empelen, P. (2016). Which combinations of techniques and modes of delivery in internet-based interventions effectively change health behavior? A meta-analysis. Journal of Medical Internet Research, 18(6), 1-14. doi: 10.2196/jmir.4218.

Williams, S. L., \& French, D. P. (2011). What are the most effective intervention techniques for changing physical activity self-efficacy and physical activity behaviour--and are they the same? Health Education Research, 26(2), 308-322. doi:10.1093/her/cyr005 


\section{Figures}

Figure 1: Flowchart of included papers

Figure 2: Forest plot for self-efficacy of automated digital interventions versus no/usual treatment

\section{Tables}

Table 1: Summary characteristics of studies included in the meta-analysis 


\section{Supplemental Materials}

Supplemental material 1: List of search terms

Supplemental material 2: List of reviews in the area

Supplemental material 3: Data extraction sheet

Supplemental material 4: List of studies included in the review

Supplemental material 5: Study characteristics

Supplemental material 6: Incidence of BCTs across interventions along with associated dose

Supplemental material 7: Modes of delivery, BCTs and associated practical strategies coded for interventions included in the meta-analysis

Physical Activity Interventions

Healthy Eating Interventions

Smoking Interventions

Sexual Behaviour Interventions

Supplemental material 8: Forest plot for self-efficacy of automated digital interventions versus no/usual treatment by behavioural domain

Supplemental material 9: Risk of bias plots of ratings by domain and by study

Supplemental material 10: PRISMA Checklist 
Supplemental material 1: List of search terms

First filter; study design:

experiment OR randomi?ed OR controlled OR trial* OR manipulated OR evaluation OR follow-up stud* OR experiment OR program* OR intervention OR intervene*behaviour change OR health promotion OR preven*

Second filter; outcome measures:

Self-efficacy OR social cognitive theory OR vicarious learning OR vicarious experience OR mastery experience OR persuasion OR protection motivation theory

Third filter; intervention type

Digital OR mobile phone OR smartphone OR cell* phone OR email OR e-mail OR messaging service OR videogame OR video game OR website OR podcast OR social media OR app OR text* OR SMS OR computer OR television OR TV OR tablet OR DVD OR virtual reality OR VR OR wearable sensor OR internet OR web-based OR online OR blog OR vlog OR ehealth OR electronic health OR e-health OR mhealth OR m-health OR mobile health

Fourth filter; behaviour:

Condom* OR safe sex OR unsafe sex OR contracepti* OR safer sex OR smok* OR tobacco OR healthy eating OR nutrition OR food consumption OR healthy diet OR dietary behav* OR eating behav* OR physical activity OR physical exercise OR sport OR exercise OR alcohol OR heavy drinking OR binge drink* OR harmful drinking OR episodic drinking 
Supplemental material 2: List of reviews in the area

Bailey, J. V., Murray, E., Rait, G., Mercer, C. H., Morris, R. W., Peacock, R....Nazareth, I. (2012). Computer-based interventions for sexual health promotion: Systematic review and meta-analyses. Int.J.STD AIDS, 23(6), 408-413. doi:10.1258/ijsa.2011.011221.

Black, N., Mullan, B. \& Sharpe, L. (2016). Computer-delivered interventions for reducing alcohol consumption: meta-analysis and meta-regression using behaviour change techniques and theory. Health Psychol Rev, 10(3), 341-357. doi:10.1080/17437199.2016.1168268.

Bort-Roig, J., Gilson, N. D., Puig-Ribera, A., Contreras, R. S. \& Trost, S. G. (2014). Measuring and influencing physical activity with smartphone technology: a systematic review. Sports Med., 44(5), 671-686. doi:10.1007/s40279-014-0142-5.

Brannon, E. E. \& Cushing, C. C. (2015). A systematic review: Is there an app for that? translational science of pediatric behavior change for physical activity and dietary interventions. J.Pediatr.Psychol., 40(4), 373-384. doi:10.1093/jpepsy/jsu108.

Buchholz, S. W., Wilbur, J., Ingram, D. \& Fogg, L. (2013). Physical activity text messaging interventions in adults: A systematic review. Worldviews Evid Based Nurs, 10(3), 163-173. doi:10.1111/wvn.12002..

Carlos Merino-Campos \& Héctor Del, C. F. (2016). The Benefits of Active Video Games for Educational and Physical Activity Approaches: A Systematic Review. Journal of New Approaches in Educational Research, 5(2), 115-122. doi:10.7821/naer.2016.7.164. 
Coughlin, S. S., Whitehead, M., Sheats, J. Q., Mastromonico, J. \& Smith, S. (2016). A Review of Smartphone Applications for Promoting Physical Activity. Jacobs J Community Med, 2(1).

Direito, A., Carraça, E., Rawstorn, J., Whittaker, R. \& Maddison, R. (2017). mHealth technologies to influence physical activity and sedentary behaviors: Behavior change techniques, systematic review and meta-analysis of randomized controlled trials. Ann.Behav.Med., 51(2), 226-239. doi:10.1007/s12160-016-9846-0.

Hamel, L. M. \& Robbins, L. B. (2013). Computer- and web-based interventions to promote healthy eating among children and adolescents: A systematic review. J.Adv.Nurs., 69(1), 1630. doi:10.1111/j.1365-2648.2012.06086.x.

Haug, S., Sannemann, J., Meyer, C. \& John, U. (2012). [Internet and mobile phone interventions to decrease alcohol consumption and to support smoking cessation in adolescents: a review]. Gesundheitswesen, 74(3), 160-177. doi:10.1055/s-0030-1268446.

Haug, S. \& Schaub, M. (2011). Wirksamkeit internetbasierter programme zum tabakrauchen: Eine systematische literaturübersicht. = Efficacy of Internet programs for tobacco smoking: A systematic review. Zeitschrift für Gesundheitspsychologie, 19(4), 181-196. doi:10.1026/09438149/a000052.

Huang, E. T., Williams, H., Hocking, J. S. \& Lim, M. S. (2016). Safe Sex Messages Within Dating and Entertainment Smartphone Apps: A Review. JMIR Mhealth Uhealth, 4(4), e124. Knight, E., Stuckey, M. I., Prapavessis, H. \& Petrella, R. J. (2015). Public health guidelines for physical activity: is there an app for that? A review of android and apple app stores. JMIR Mhealth Uhealth, 3(2), e43. doi:10.2196/mhealth.4003. 
LaPlante, C. \& Peng, W. (2011). A systematic review of e-health interventions for physical activity: An analysis of study design, intervention characteristics, and outcomes.

Telemedicine and e-Health, 17(7), 509-523. doi:10.1089/tmj.2011.0013.

Muller, A. M., Alley, S., Schoeppe, S. \& Vandelanotte, C. (2016). The effectiveness of e-\& mHealth interventions to promote physical activity and healthy diets in developing countries: A systematic review. Int J Behav Nutr Phys Act, 13. doi:10.1186/s12966-016-0434-2.

Matthews, J., Win, K. T., Oinas-Kukkonen, H. \& Freeman, M. (2016). Persuasive Technology in Mobile Applications Promoting Physical Activity: a Systematic Review. J.Med.Syst., 40(3), 72. doi:10.1007/s10916-015-0425-x.

Middelweerd, A., Mollee, J. S., van, d. W., Brug, J. \& te Velde, S. J. (2014). Apps to promote physical activity among adults: A review and content analysis. Int J Behav Nutr Phys Act, 11 .

Miller, K. J., Adair, B. S., Pearce, A. J., Said, C. M., Ozanne, E. \& Morris, M. M. (2014). Effectiveness and feasibility of virtual reality and gaming system use at home by older adults for enabling physical activity to improve health-related domains: a systematic review. Age Ageing, 43(2), 188-195. doi:10.1093/ageing/aft194.

Monroe, C. M., Thompson, D. L., Bassett, D. R., Fitzhugh, E. C. \& Raynor, H. A. (2015). Usability of Mobile Phones in Physical Activity-Related Research: A Systematic Review. American Journal of Health Education, 46(4), 196-206.

doi:10.1080/19325037.2015.1044141.

Nair, N. K., Newton, N. C., Shakeshaft, A., Wallace, P. \& Teesson, M. (2015). A Systematic Review of Digital and Computer-Based Alcohol Intervention Programs in Primary Care. Curr Drug Abuse Rev, 8(2), 111-118. 
Norman, G. J., Zabinski, M. F., Adams, M. A., Rosenberg, D. E., Yaroch, A. L. \& Atienza, A. A. (2007). A review of eHealth interventions for physical activity and dietary behavior change. Am.J.Prev.Med., 33(4), 336-345. doi:10.1016/j.amepre.2007.05.007.

Park, E. \& Drake, E. (2015). Systematic review: Internet-based program for youth smoking prevention and cessation. J.Nurs.Scholarsh., 47(1), 43-50. doi:10.1111/jnu.12104.

Scott-Sheldon, L., Lantini, R., Jennings, E. G., Thind, H., Rosen, R. K., Salmoirago-Blotcher, E. \& Bock, B. C. (2016). Text Messaging-Based Interventions for Smoking Cessation: A Systematic Review and Meta-Analysis. JMIR Mhealth Uhealth, 4(2), e49. doi:10.2196/mhealth.5436.

Spohr, S. A., Nandy, R., Gandhiraj, D., Vemulapalli, A., Anne, S. \& Walters, S. T. (2015). Efficacy of SMS text message interventions for smoking cessation: A meta-analysis. J.Subst.Abuse Treat., 56, 1-10. doi:10.1016/j.jsat.2015.01.011.

Sundstrom, C., Blankers, M. \& Khadjesari, Z. (2017). Computer-based interventions for problematic alcohol use: A review of systematic reviews. Int.J.Behav.Med., 24(5), 646-658. doi:10.1007/s12529-016-9601-8.

Tebb, K. P., Erenrich, R. K., Jasik, C. B., Berna, M. S., Lester, J. C. \& Ozer, E. M. (2016). Use of theory in computer-based interventions to reduce alcohol use among adolescents and young adults: a systematic review. BMC Public Health, 16, 517. doi:10.1186/s12889-0163183-x.

Walters, S. T., Wright, J. A. \& Shegog, R. (2006). A review of computer and Internet-based interventions for smoking behavior. Addict.Behav., 31(2), 264-277. doi:10.1016/j.addbeh.2005.05.002. 
White, A., Kavanagh, D., Stallman, H., Klein, B., Kay-Lambkin, F., Proudfoot, J....Young, R. (2010). Online alcohol interventions: A systematic review. J Med Internet Res, 12(5), 160171. doi:10.2196/jmir.1479.

Williams, G., Hamm, M. P., Shulhan, J., Vandermeer, B. \& Hartling, L. (2014). Social media interventions for diet and exercise behaviours: a systematic review and meta-analysis of randomised controlled trials. BMJ Open, 4(2), e003926. doi:10.1136/bmjopen-2013-003926. 
Supplemental material 3: Data extraction sheet

\begin{tabular}{|l|l|}
\hline Paper Title: & \\
\hline Author Surnames: & \\
\hline Year of Publication: & \\
\hline Journal: & \\
\hline Volume \& Pages: & \\
\hline
\end{tabular}

\begin{tabular}{|l|l|}
\hline Study Design: & RCT or Quasi-RCT \\
\hline Sample Size in Analysis: & \\
\hline No. of Female Participants in & \\
Analysis: & \\
\hline Income Level of Study & high, middle or low \\
Country: & \\
& \\
\hline
\end{tabular}




\begin{tabular}{|l|l|}
\hline Age range of Sample: & $\begin{array}{l}8-24 \text { years } \\
25-34 \text { years } \\
35-64 \text { years } \\
65+\text { years }\end{array}$ \\
\hline
\end{tabular}

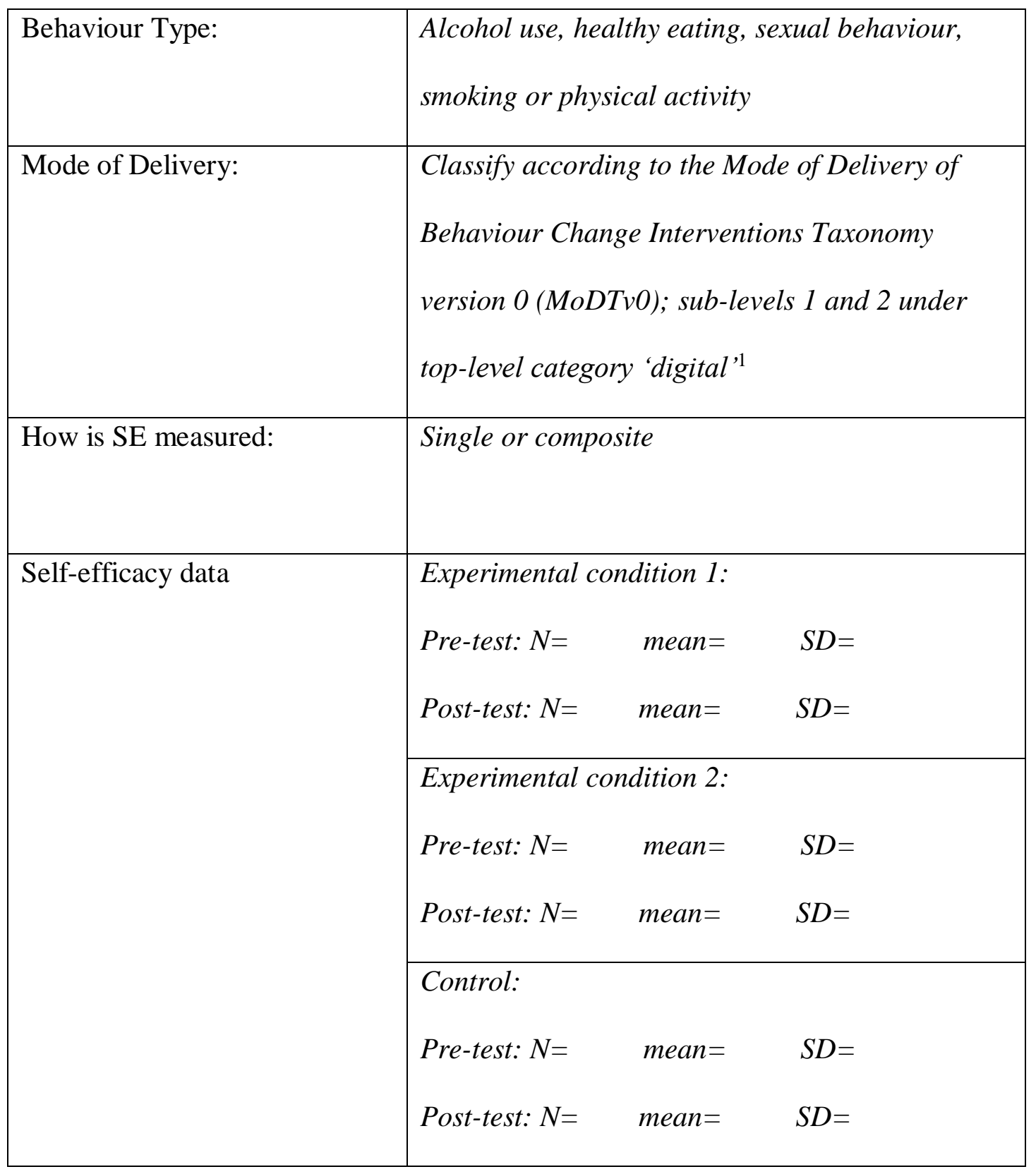




\begin{tabular}{|l|lll|}
\hline Quality of Intervention & Co-design: & Yes & No/Not Reported \\
Development: & Systematic: & Yes & No/Not Reported \\
& Theory: & Yes & No/Not Reported \\
& & & \\
\hline
\end{tabular}

${ }^{1}$ The MoDTv0 has four major categories (human, printed material, digital and somatic) and within each of these, a further three sub-levels. For the major category 'digital' there are four level one categories (phone, computer/television, wearable and environmental sensor). Within each of these level one categories there are between zero and seven level two categories. Within the level one category 'phone' for example, there are the following level two categories: email, website, video game, podcast, social media, app, automated text message. In the present study, modes of delivery were categorised down to the sub-level two. 
Supplemental material 4: List of studies included in the review

Anderson, E., Winett, R., Wojcik, J., Winett, S., \& Bowden, T. (2001). A computerized social cognitive intervention for nutrition behavior: Direct and mediated effects on fat, fiber, fruits, and vegetables, self-efficacy, and outcome expectations among food shoppers. Annals of Behavioral Medicine, 23(2), 88-100. doi:10.1207/S15324796ABM2302_3

Bowen, A., Horvath, K., \& Williams, M. (2007). A randomized control trial of internetdelivered HIV prevention targeting rural MSM. Health Education Research, 22(1), 1207. doi:10.1093/her/cyl057

Brendryen, H., Drozd, F., \& Kraft, P. (2008). A digital smoking cessation program delivered through internet and cell phone without nicotine replacement (happy ending): Randomized controlled trial. Journal of Medical Internet Research, 10(5), e51. doi:10.2196/jmir.1005

Brendryen, H., \& Kraft, P. (2008). Happy ending: A randomized controlled trial of a digital multi-media smoking cessation intervention.(author abstract)(medical condition overview)(report). Addiction, 103(3), 478. doi:10.1111/j.1360-0443.2007.02119.x

Brown, T. C. (2016). Impact of a theory-guided encouragement intervention on an employee walking pilot program. Journal of Applied Sport Psychology, 28(4), 452-468. doi:10.1080/10413200.2016.1187687

Cook, R. F., Billings, D. W., Hersch, R. K., Back, A. S., \& Hendrickson, A. (2007). A field test of a web-based workplace health promotion program to improve dietary practices, 
reduce stress, and increase physical activity: Randomized controlled trial. Journal of Medical Internet Research, 9(2), e17. doi:10.2196/jmir.9.2.e17

Dadaczynski, K., Schiemann, S., \& Backhaus, O. (2017). Promoting physical activity in worksite settings: Results of a german pilot study of the online intervention healingo fit.(report). BMC Public Health, 17(1) doi:10.1186/s12889-017-4697-6

Dunton, G. F., \& Robertson, T. P. (2008). A tailored internet-plus-email intervention for increasing physical activity among ethnically-diverse women. Preventive Medicine, 47(6), 605-611. doi:10.1016/j.ypmed.2008.10.004

Gell, N. M., \& Wadsworth, D. D. (2015). The use of text messaging to promote physical activity in working women: A randomized controlled trial. Journal of Physical Activity \& Health, 12(6), 756. doi:10.1123/jpah.2013-0144

Hageman, P., \& Pullen, C. (2005). Tailored versus standard internet-delivered interventions to promote physical activity in older women. Journal of Geriatric Physical Therapy, 28(1), 28-33.

Hager, R. L., Hardy, A., Aldana, S. G., \& George, J. D. (2002). Evaluation of an internet, stage-based physical activity intervention. Journal of Health Education, 33(6), 329-337. doi:10.1080/19325037.2002.10604755

Irvine, A. B., Ary, D., Grove, D., \& Gilfillan-Morton, L. (2004). The effectiveness of an interactive multimedia program to influence eating habits. Health Education Research, 19(3), 290-305. doi:10.1093/her/cyg027 
Irvine, A. B., Philips, L., Seeley, J., Wyant, S., Duncan, S., \& Moore, R. W. (2011). Get moving: A web site that increases physical activity of sedentary employees. American Journal of Health Promotion, 25(3), 199-206. doi:10.4278/ajhp.04121736

Keller, J., Motter, S., Motter, M., \& Schwarzer, R. (2018). Augmenting fruit and vegetable consumption by an online intervention: Psychological mechanisms. Appetite; Appetite, 120, 348-355. doi:10.1016/j.appet.2017.09.019

Klein, C. H., Kuhn, T., Altamirano, M., \& Lomonaco, C. (2017). C-SAFE: A computerdelivered sexual health promotion program for latinas. Health Promotion Practice, 18(4), 516-525. doi:10.1177/1524839917707791

Mavrot, C., Stucki, I., Sager, F., \& Etter, J. (2017). Efficacy of an internet-based, individually tailored smoking cessation program: A randomized-controlled trial. Journal of Telemedicine and Telecare, 23(5), 521-528. doi:10.1177/1357633X16655476

Muller, A. M., Khoo, S., \& Morris, T. (2016). Text messaging for exercise promotion in older adults from an upper-middle-income country: Randomized controlled trial. Journal of Medical Internet Research, 18(1), e5. doi:10.2196/jmir.5235

Powell, J., Newhouse, N., Martin, A., Jawad, S., Yu, L., Davoudianfar, M., . . Ziebland, S. (2016). A novel experience-based internet intervention for smoking cessation: Feasibility randomised controlled trial.(report). BMC Public Health, 16(1) doi:10.1186/s12889-016$3821-3$

Prestwich, A., Conner, M., Morris, B., Finlayson, G., Sykes-Muskett, B., \& Hurling, R. (2017). Do web-based competitions promote physical activity? randomized controlled trial. Psychology of Sport \& Exercise, 29, 1-9. doi:10.1016/j.psychsport.2016.11.003 
Swartz, L. H. G., Sherman, C. A., Harvey, S. M., Blanchard, J., Vawter, F., \& Gau, J. (2011). Midlife women online: Evaluation of an internet-based program to prevent unintended pregnancy \& STIs. Journal of Women \& Aging, 23(4), 342-359. doi:10.1080/08952841.2011.613255

Supplemental material 5: Study characteristics

\begin{tabular}{|c|c|c|c|c|c|c|c|c|}
\hline $\begin{array}{l}\text { Lead } \\
\text { author/ } \\
\text { year }\end{array}$ & $\begin{array}{l}\text { Tota } \\
1 \\
\text { sam } \\
\text { ple } \\
\text { size }\end{array}$ & $\begin{array}{l}\text { Stu } \\
\text { dy } \\
\text { desi } \\
\text { gn }\end{array}$ & $\begin{array}{l}\% \\
\text { fema } \\
\text { le }\end{array}$ & $\begin{array}{l}\text { Age } \\
\text { grou } \\
\text { p } \\
\text { (whe } \\
\text { re } \\
\text { mean } \\
\text { of } \\
\text { samp } \\
\text { le } \\
\text { resid } \\
\text { es) }\end{array}$ & $\begin{array}{l}\text { Health } \\
\text { behavi } \\
\text { our }\end{array}$ & $\begin{array}{l}\text { Study } \\
\text { country } \\
\text { (and } \\
\text { high or } \\
\text { medium } \\
\text { / low } \\
\text { income } \\
\text { country } \\
\text { ) }\end{array}$ & $\begin{array}{l}\text { Compo } \\
\text { site or } \\
\text { single } \\
\text { measur } \\
\text { e of } \\
\text { self- } \\
\text { efficac } \\
y ?\end{array}$ & $\begin{array}{l}\text { Quality of intervention } \\
\text { development }\end{array}$ \\
\hline
\end{tabular}




\begin{tabular}{|c|c|c|c|c|c|c|c|c|c|c|}
\hline & & & & & & & & $\begin{array}{l}\text { Theo } \\
\text { ry- } \\
\text { base } \\
\text { d }\end{array}$ & $\begin{array}{l}\text { Develo } \\
\text { ped } \\
\text { using a } \\
\text { system } \\
\text { atic } \\
\text { approa } \\
\text { ch }\end{array}$ & $\begin{array}{l}\text { Co- } \\
\text { design } \\
\text { ed } \\
\text { with } \\
\text { the } \\
\text { target } \\
\text { popula } \\
\text { tion }\end{array}$ \\
\hline $\begin{array}{l}\text { Anders } \\
\text { on, } \\
\text { Winnet } \\
\& \\
\text { Wojcik } \\
\text { (2001) }\end{array}$ & 296 & $\begin{array}{l}\mathrm{RC} \\
\mathrm{T}\end{array}$ & $\begin{array}{l}96.0 \\
\%\end{array}$ & $\begin{array}{l}\text { Mean } \\
\text { not } \\
\text { repor } \\
\text { ted }\end{array}$ & $\begin{array}{l}\text { Health } \\
\mathrm{y} \\
\text { Eating }\end{array}$ & $\begin{array}{l}\text { USA } \\
\text { (High } \\
\text { Income } \\
\text { ) }\end{array}$ & $\begin{array}{l}\text { Compo } \\
\text { site }\end{array}$ & Yes & $\begin{array}{l}\text { No/not } \\
\text { reporte } \\
\text { d }\end{array}$ & $\begin{array}{l}\text { No/not } \\
\text { reporte } \\
\text { d }\end{array}$ \\
\hline $\begin{array}{l}\text { Bowen, } \\
\text { Horvat } \\
\text { h and } \\
\text { Willia } \\
\text { ms } \\
\text { (2007) }\end{array}$ & 90 & $\begin{array}{l}\mathrm{RC} \\
\mathrm{T}\end{array}$ & $0 \%$ & $\begin{array}{l}25- \\
34\end{array}$ & $\begin{array}{l}\text { Sexual } \\
\text { Behavi } \\
\text { our }\end{array}$ & $\begin{array}{l}\text { USA } \\
\text { (High } \\
\text { Income } \\
\text { ) }\end{array}$ & $\begin{array}{l}\text { Compo } \\
\text { site }\end{array}$ & Yes & $\begin{array}{l}\text { No/not } \\
\text { reporte } \\
\text { d }\end{array}$ & $\begin{array}{l}\text { No/not } \\
\text { reporte } \\
\text { d }\end{array}$ \\
\hline $\begin{array}{l}\text { Brendr } \\
\text { yen \& } \\
\text { Kraft } \\
\text { (2008) }\end{array}$ & 400 & $\begin{array}{l}\mathrm{RC} \\
\mathrm{T}\end{array}$ & $\begin{array}{l}50.2 \\
5 \%\end{array}$ & $\begin{array}{l}35- \\
64 \\
\text { years }\end{array}$ & $\begin{array}{l}\text { Smoki } \\
\text { ng }\end{array}$ & $\begin{array}{l}\text { Norway } \\
\text { (High } \\
\text { income) }\end{array}$ & $\begin{array}{l}\text { Compo } \\
\text { site }\end{array}$ & No & $\begin{array}{l}\text { No/not } \\
\text { reporte } \\
\text { d }\end{array}$ & $\begin{array}{l}\text { No/not } \\
\text { reporte } \\
\text { d }\end{array}$ \\
\hline
\end{tabular}




\begin{tabular}{|c|c|c|c|c|c|c|c|c|c|c|}
\hline $\begin{array}{l}\text { Brendy } \\
\text { ren et al } \\
\text { (2008) }\end{array}$ & 296 & $\begin{array}{l}\mathrm{RC} \\
\mathrm{T}\end{array}$ & $\begin{array}{l}50.0 \\
\%\end{array}$ & $\begin{array}{l}35- \\
64\end{array}$ & $\begin{array}{l}\text { Smoki } \\
\text { ng }\end{array}$ & $\begin{array}{l}\text { Norway } \\
\text { (High } \\
\text { Income }\end{array}$ & $\begin{array}{l}\text { Compo } \\
\text { site }\end{array}$ & Yes & $\begin{array}{l}\text { No/not } \\
\text { reporte } \\
\text { d }\end{array}$ & $\begin{array}{l}\text { No/not } \\
\text { reporte } \\
\text { d }\end{array}$ \\
\hline $\begin{array}{l}\text { Brown } \\
(2016)\end{array}$ & 106 & $\begin{array}{l}\mathrm{RC} \\
\mathrm{T}\end{array}$ & $\begin{array}{l}84.9 \\
\%\end{array}$ & $\begin{array}{l}35- \\
64\end{array}$ & $\begin{array}{l}\text { Physic } \\
\text { al } \\
\text { Activit } \\
\text { y }\end{array}$ & $\begin{array}{l}\text { USA } \\
\text { (High } \\
\text { Income } \\
\text { ) }\end{array}$ & $\begin{array}{l}\text { Compo } \\
\text { site }\end{array}$ & Yes & $\begin{array}{l}\text { No/not } \\
\text { reporte } \\
\text { d }\end{array}$ & $\begin{array}{l}\text { No/not } \\
\text { reporte } \\
\text { d }\end{array}$ \\
\hline $\begin{array}{l}\text { Cook et } \\
\text { al } \\
\text { (2007) }\end{array}$ & 419 & $\begin{array}{l}\mathrm{RC} \\
\mathrm{T}\end{array}$ & $\begin{array}{l}72.0 \\
\%\end{array}$ & $\begin{array}{l}35- \\
64\end{array}$ & $\begin{array}{l}\text { Health } \\
\mathrm{y} \\
\text { Eating }\end{array}$ & $\begin{array}{l}\text { USA } \\
\text { (High } \\
\text { Income }\end{array}$ & $\begin{array}{l}\text { Compo } \\
\text { site }\end{array}$ & Yes & $\begin{array}{l}\text { No/not } \\
\text { reporte } \\
\text { d }\end{array}$ & $\begin{array}{l}\text { No/not } \\
\text { reporte } \\
\text { d }\end{array}$ \\
\hline $\begin{array}{l}\text { Dadacy } \\
\text { nski et } \\
\text { al } \\
\text { (2017) }\end{array}$ & 176 & $\begin{array}{l}\mathrm{RC} \\
\mathrm{T}\end{array}$ & $\begin{array}{l}35.4 \\
\%\end{array}$ & $\begin{array}{l}35- \\
64\end{array}$ & $\begin{array}{l}\text { Physic } \\
\text { al } \\
\text { Activit } \\
\text { y }\end{array}$ & $\begin{array}{l}\text { German } \\
\mathrm{y} \\
\text { (High } \\
\text { Income }\end{array}$ & $\begin{array}{l}\text { Compo } \\
\text { site }\end{array}$ & Yes & $\begin{array}{l}\text { No/not } \\
\text { reporte } \\
\text { d }\end{array}$ & $\begin{array}{l}\text { No/not } \\
\text { reporte } \\
\text { d }\end{array}$ \\
\hline $\begin{array}{l}\text { Dunton } \\
\& \\
\text { Roberts } \\
\text { on } \\
\text { (2008) }\end{array}$ & 156 & $\begin{array}{l}\mathrm{RC} \\
\mathrm{T}\end{array}$ & $\begin{array}{l}100 \\
\%\end{array}$ & $\begin{array}{l}35- \\
64\end{array}$ & $\begin{array}{l}\text { Physic } \\
\text { al } \\
\text { Activit } \\
\text { y }\end{array}$ & $\begin{array}{l}\text { USA } \\
\text { (High } \\
\text { Income } \\
\text { ) }\end{array}$ & $\begin{array}{l}\text { Compo } \\
\text { site }\end{array}$ & Yes & $\begin{array}{l}\text { No/not } \\
\text { reporte } \\
\text { d }\end{array}$ & $\begin{array}{l}\text { No/not } \\
\text { reporte } \\
\text { d }\end{array}$ \\
\hline
\end{tabular}




\begin{tabular}{|c|c|c|c|c|c|c|c|c|c|c|}
\hline $\begin{array}{l}\text { Gell \& } \\
\text { Wadsw } \\
\text { orth } \\
(2015)\end{array}$ & 87 & $\begin{array}{l}\mathrm{RC} \\
\mathrm{T}\end{array}$ & $\begin{array}{l}100 \\
\%\end{array}$ & $\begin{array}{l}35- \\
64\end{array}$ & $\begin{array}{l}\text { Physic } \\
\text { al } \\
\text { Activit } \\
\text { y }\end{array}$ & $\begin{array}{l}\text { USA } \\
\text { (High } \\
\text { Income } \\
\text { ) }\end{array}$ & $\begin{array}{l}\text { Compo } \\
\text { site }\end{array}$ & Yes & $\begin{array}{l}\text { No/not } \\
\text { reporte } \\
\text { d }\end{array}$ & $\begin{array}{l}\text { No/not } \\
\text { reporte } \\
\text { d }\end{array}$ \\
\hline $\begin{array}{l}\text { Hagem } \\
\text { an, } \\
\text { Walker } \\
\& \\
\text { Pullen } \\
(2005)\end{array}$ & 31 & $\begin{array}{l}\mathrm{RC} \\
\mathrm{T}\end{array}$ & $\begin{array}{l}100 \\
\%\end{array}$ & $\begin{array}{l}35- \\
64\end{array}$ & $\begin{array}{l}\text { Physic } \\
\text { al } \\
\text { Activit } \\
\text { y }\end{array}$ & $\begin{array}{l}\text { USA } \\
\text { (High } \\
\text { Income } \\
\text { ) }\end{array}$ & $\begin{array}{l}\text { Compo } \\
\text { site }\end{array}$ & Yes & $\begin{array}{l}\text { No/not } \\
\text { reporte } \\
\text { d }\end{array}$ & $\begin{array}{l}\text { No/not } \\
\text { reporte } \\
\text { d }\end{array}$ \\
\hline $\begin{array}{l}\text { Hager } \\
\text { et al } \\
(2002)\end{array}$ & 525 & $\begin{array}{l}\mathrm{RC} \\
\mathrm{T}\end{array}$ & $\begin{array}{l}54.8 \\
\%\end{array}$ & $\begin{array}{l}35- \\
64\end{array}$ & $\begin{array}{l}\text { Physic } \\
\text { al } \\
\text { Activit } \\
\text { y }\end{array}$ & $\begin{array}{l}\text { USA } \\
\text { (High } \\
\text { Income } \\
\text { ) }\end{array}$ & $\begin{array}{l}\text { Compo } \\
\text { site }\end{array}$ & Yes & $\begin{array}{l}\text { No/not } \\
\text { reporte } \\
\text { d }\end{array}$ & $\begin{array}{l}\text { No/not } \\
\text { reporte } \\
\text { d }\end{array}$ \\
\hline $\begin{array}{l}\text { Irvine } \\
\text { et al } \\
(2004)\end{array}$ & 517 & $\begin{array}{l}\mathrm{RC} \\
\mathrm{T}\end{array}$ & $\begin{array}{l}73.0 \\
\%\end{array}$ & $\begin{array}{l}35- \\
64\end{array}$ & $\begin{array}{l}\text { Health } \\
\mathrm{y} \\
\text { Eating }\end{array}$ & $\begin{array}{l}\text { USA } \\
\text { (High } \\
\text { Income }\end{array}$ & Single & Yes & $\begin{array}{l}\text { No/not } \\
\text { reporte } \\
\text { d }\end{array}$ & $\begin{array}{l}\text { No/not } \\
\text { reporte } \\
\text { d }\end{array}$ \\
\hline $\begin{array}{l}\text { Irvine } \\
\text { et al } \\
(2011)\end{array}$ & 228 & $\begin{array}{l}\mathrm{RC} \\
\mathrm{T}\end{array}$ & $\begin{array}{l}42.2 \\
\%\end{array}$ & $\begin{array}{l}35- \\
64\end{array}$ & $\begin{array}{l}\text { Physic } \\
\text { al } \\
\text { Activit } \\
\text { y }\end{array}$ & $\begin{array}{l}\text { USA } \\
\text { (High } \\
\text { Income } \\
\text { ) }\end{array}$ & $\begin{array}{l}\text { Compo } \\
\text { site }\end{array}$ & Yes & $\begin{array}{l}\text { No/not } \\
\text { reporte } \\
\text { d }\end{array}$ & $\begin{array}{l}\text { No/not } \\
\text { reporte } \\
\text { d }\end{array}$ \\
\hline
\end{tabular}




\begin{tabular}{|c|c|c|c|c|c|c|c|c|c|c|}
\hline $\begin{array}{l}\text { Keller } \\
\text { et al } \\
\text { (2018) }\end{array}$ & 279 & $\begin{array}{l}\mathrm{RC} \\
\mathrm{T}\end{array}$ & $\begin{array}{l}75.2 \\
\%\end{array}$ & $\begin{array}{l}25- \\
34\end{array}$ & $\begin{array}{l}\text { Health } \\
\text { y } \\
\text { Eating }\end{array}$ & $\begin{array}{l}\text { USA } \\
\text { (High } \\
\text { Income }\end{array}$ & $\begin{array}{l}\text { Compo } \\
\text { site }\end{array}$ & Yes & $\begin{array}{l}\text { No/not } \\
\text { reporte } \\
\text { d }\end{array}$ & $\begin{array}{l}\text { No/not } \\
\text { reporte } \\
\text { d }\end{array}$ \\
\hline $\begin{array}{l}\text { Klein et } \\
\text { al } \\
\text { (2017) }\end{array}$ & 321 & $\begin{array}{l}\mathrm{RC} \\
\mathrm{T}\end{array}$ & $\begin{array}{l}100 \\
\%\end{array}$ & $\begin{array}{l}25- \\
34\end{array}$ & $\begin{array}{l}\text { Sexual } \\
\text { Behavi } \\
\text { our }\end{array}$ & $\begin{array}{l}\text { USA } \\
\text { (High } \\
\text { Income }\end{array}$ & $\begin{array}{l}\text { Compo } \\
\text { site }\end{array}$ & Yes & $\begin{array}{l}\text { No/not } \\
\text { reporte } \\
\text { d }\end{array}$ & Yes \\
\hline $\begin{array}{l}\text { Mavrot } \\
(2016)\end{array}$ & $\begin{array}{l}116 \\
0\end{array}$ & $\begin{array}{l}\mathrm{RC} \\
\mathrm{T}\end{array}$ & $\begin{array}{l}65.7 \\
\%\end{array}$ & $\begin{array}{l}35- \\
64\end{array}$ & $\begin{array}{l}\text { Smoki } \\
\text { ng }\end{array}$ & $\begin{array}{l}\text { Switzer } \\
\text { land } \\
\text { (High } \\
\text { Income }\end{array}$ & $\begin{array}{l}\text { Compo } \\
\text { site }\end{array}$ & Yes & $\begin{array}{l}\text { No/not } \\
\text { reporte } \\
\text { d }\end{array}$ & $\begin{array}{l}\text { No/not } \\
\text { reporte } \\
\text { d }\end{array}$ \\
\hline $\begin{array}{l}\text { Muller, } \\
\text { Khoo } \\
\& \\
\text { Morris } \\
\text { (2016) }\end{array}$ & 43 & $\begin{array}{l}\mathrm{RC} \\
\mathrm{T}\end{array}$ & $\begin{array}{l}74.4 \\
\%\end{array}$ & $\begin{array}{l}35- \\
64\end{array}$ & $\begin{array}{l}\text { Physic } \\
\text { al } \\
\text { Activit } \\
\text { y }\end{array}$ & $\begin{array}{l}\text { Malaysi } \\
\mathrm{a} \\
\text { (Middle } \\
\text { Income } \\
\text { ) }\end{array}$ & $\begin{array}{l}\text { Compo } \\
\text { site }\end{array}$ & No & $\begin{array}{l}\text { No/not } \\
\text { reporte } \\
\text { d }\end{array}$ & $\begin{array}{l}\text { No/not } \\
\text { reporte } \\
\text { d }\end{array}$ \\
\hline $\begin{array}{l}\text { Powell } \\
\text { (2016) }\end{array}$ & 87 & $\begin{array}{l}\mathrm{RC} \\
\mathrm{T}\end{array}$ & $\begin{array}{l}52.0 \\
\%\end{array}$ & $\begin{array}{l}35- \\
64\end{array}$ & $\begin{array}{l}\text { Smoki } \\
\text { ng }\end{array}$ & $\begin{array}{l}\text { Englan } \\
\mathrm{d} \\
\text { (High } \\
\text { Income } \\
\text { ) }\end{array}$ & $\begin{array}{l}\text { Compo } \\
\text { site }\end{array}$ & Yes & $\begin{array}{l}\text { No/not } \\
\text { reporte } \\
\text { d }\end{array}$ & $\begin{array}{l}\text { No/not } \\
\text { reporte } \\
\text { d }\end{array}$ \\
\hline
\end{tabular}




\begin{tabular}{|c|c|c|c|c|c|c|c|c|c|c|}
\hline $\begin{array}{l}\text { Prestwi } \\
\text { ch et al } \\
\text { (2017) }\end{array}$ & 281 & $\begin{array}{l}\mathrm{RC} \\
\mathrm{T}\end{array}$ & $\begin{array}{l}75.7 \\
\%\end{array}$ & $\begin{array}{l}18- \\
24\end{array}$ & $\begin{array}{l}\text { Physic } \\
\text { al } \\
\text { Activit } \\
\text { y }\end{array}$ & $\begin{array}{l}\text { Englan } \\
\mathrm{d} \\
\text { (High } \\
\text { Income }\end{array}$ & $\begin{array}{l}\text { Compo } \\
\text { site }\end{array}$ & Yes & $\begin{array}{l}\text { No/not } \\
\text { reporte } \\
\text { d }\end{array}$ & $\begin{array}{l}\text { No/not } \\
\text { reporte } \\
\text { d }\end{array}$ \\
\hline $\begin{array}{l}\text { Swartz } \\
\text { et al } \\
\text { (2011) }\end{array}$ & 422 & $\begin{array}{l}\mathrm{RC} \\
\mathrm{T}\end{array}$ & $\begin{array}{l}100 \\
\%\end{array}$ & $\begin{array}{l}35- \\
64\end{array}$ & $\begin{array}{l}\text { Sexual } \\
\text { Behavi } \\
\text { our }\end{array}$ & $\begin{array}{l}\text { USA } \\
\text { (High } \\
\text { Income }\end{array}$ & $\begin{array}{l}\text { Compo } \\
\text { site }\end{array}$ & Yes & $\begin{array}{l}\text { No/not } \\
\text { reporte } \\
\text { d }\end{array}$ & Yes \\
\hline
\end{tabular}


Supplemental material 6: Incidence of BCTs across interventions along with associated dose

\begin{tabular}{|c|c|c|c|c|c|}
\hline \multirow{2}{*}{\multicolumn{2}{|c|}{$\mathrm{BCT}$}} & \multirow{3}{*}{$\begin{array}{l}\text { Incidence of BCT } \\
\text { across interventions } \\
11\end{array}$} & \multicolumn{3}{|c|}{$\begin{array}{l}\text { Dose of BCT present } \\
\text { across interventions }\end{array}$} \\
\hline & & & Low & Medium & High \\
\hline 1.1 & $\begin{array}{l}\text { Goal setting } \\
\text { (behaviour) }\end{array}$ & & 3 & 1 & 7 \\
\hline 1.2 & Problem solving & 9 & 3 & 3 & 3 \\
\hline 1.4 & Action planning & 5 & 3 & 0 & 2 \\
\hline 1.5 & $\begin{array}{l}\text { Review } \\
\text { Behavioural } \\
\text { Goal }\end{array}$ & 2 & 1 & 0 & 1 \\
\hline 1.6 & $\begin{array}{l}\text { Discrepancy } \\
\text { between current } \\
\text { behaviour and } \\
\text { goal }\end{array}$ & 2 & 0 & 0 & 2 \\
\hline 1.9 & Commitment & 1 & 0 & 0 & 1 \\
\hline 2.1 & $\begin{array}{l}\text { Monitoring of } \\
\text { Behaviour by } \\
\text { others Without } \\
\text { Feedback }\end{array}$ & 3 & 1 & 0 & 2 \\
\hline 2.2 & Feedback on & 5 & 2 & 0 & 3 \\
\hline
\end{tabular}




\begin{tabular}{|c|c|c|c|c|c|}
\hline & Behaviour & & & & \\
\hline 2.3 & $\begin{array}{l}\text { Self-monitoring } \\
\text { of behaviour }\end{array}$ & 9 & 3 & 1 & 5 \\
\hline 2.4 & $\begin{array}{l}\text { Self-Monitoring } \\
\text { of outcome of } \\
\text { behaviour }\end{array}$ & 1 & 1 & 0 & 0 \\
\hline 2.7 & $\begin{array}{l}\text { Feedback on } \\
\text { outcome(s) of } \\
\text { Behaviour }\end{array}$ & 2 & 2 & 0 & 0 \\
\hline 3.1 & $\begin{array}{l}\text { Social Support } \\
\text { (unspecified) }\end{array}$ & 3 & 1 & 0 & 2 \\
\hline 4.1 & $\begin{array}{l}\text { Instruction on } \\
\text { How to Perform } \\
\text { Behaviour }\end{array}$ & 11 & 3 & 3 & 5 \\
\hline 4.2 & $\begin{array}{l}\text { Information } \\
\text { about } \\
\text { antecedents }\end{array}$ & 3 & 2 & 1 & 0 \\
\hline 5.1 & $\begin{array}{l}\text { Information } \\
\text { about Health } \\
\text { Consequences }\end{array}$ & 5 & 3 & 0 & 2 \\
\hline 5.2 & $\begin{array}{l}\text { Salience of } \\
\text { consequences }\end{array}$ & 1 & 1 & 0 & 0 \\
\hline 5.3 & Information & 4 & 4 & 0 & 0 \\
\hline
\end{tabular}




\begin{tabular}{|c|c|c|c|c|c|}
\hline & $\begin{array}{l}\text { about Social and } \\
\text { Environmental } \\
\text { consequences }\end{array}$ & & & & \\
\hline 5.5 & $\begin{array}{l}\text { Anticipated } \\
\text { regret }\end{array}$ & 2 & 2 & 0 & 0 \\
\hline 6.1 & $\begin{array}{l}\text { Demonstration } \\
\text { of Behaviour }\end{array}$ & 4 & 1 & 0 & 3 \\
\hline 6.2 & $\begin{array}{l}\text { Social } \\
\text { Comparison }\end{array}$ & 3 & 0 & 0 & 3 \\
\hline 7.1 & Prompts/Cues & 1 & 0 & 0 & 1 \\
\hline 8.1 & $\begin{array}{l}\text { Behavioural } \\
\text { practice/ } \\
\text { rehearsal }\end{array}$ & 1 & 0 & 1 & 0 \\
\hline 8.2 & $\begin{array}{l}\text { Behavioural } \\
\text { Substitution }\end{array}$ & 4 & 4 & 0 & 0 \\
\hline 8.7 & Graded Tasks & 1 & 1 & 0 & 0 \\
\hline 9.1 & Credible source & 1 & 1 & 0 & 0 \\
\hline 10.1 & $\begin{array}{l}\text { Material } \\
\text { incentive } \\
\text { (behaviour) }\end{array}$ & 1 & 0 & 0 & 1 \\
\hline 10.4 & Social Reward & 4 & 0 & 0 & 4 \\
\hline 11.1 & $\begin{array}{l}\text { Pharmacological } \\
\text { Support }\end{array}$ & 2 & 0 & 0 & 2 \\
\hline
\end{tabular}




\begin{tabular}{|c|c|c|c|c|c|}
\hline 11.2 & $\begin{array}{l}\text { Reduce Negative } \\
\text { Emotions }\end{array}$ & 3 & 1 & 2 & 0 \\
\hline 12.1 & $\begin{array}{l}\text { Restructuring the } \\
\text { physical } \\
\text { environment }\end{array}$ & 2 & 2 & 0 & 0 \\
\hline 12.5 & $\begin{array}{l}\text { Adding objects } \\
\text { to the } \\
\text { environment }\end{array}$ & 1 & 1 & 0 & 0 \\
\hline 13.1 & $\begin{array}{l}\text { Identification of } \\
\text { self as role } \\
\text { model }\end{array}$ & 1 & 1 & 0 & 0 \\
\hline 13.2 & $\begin{array}{l}\text { Framing re- } \\
\text { framing }\end{array}$ & 2 & 0 & 0 & 2 \\
\hline 15.1 & $\begin{array}{l}\text { Verbal } \\
\text { Persuasion } \\
\text { About Capability }\end{array}$ & 4 & 4 & 0 & 0 \\
\hline 15.2 & $\begin{array}{l}\text { Mental rehearsal } \\
\text { of successful } \\
\text { performance }\end{array}$ & 1 & 1 & 0 & 0 \\
\hline 15.3 & $\begin{array}{l}\text { Focus on past } \\
\text { success }\end{array}$ & 1 & 0 & 1 & 0 \\
\hline 15.4 & Self-talk & 1 & 1 & 0 & 0 \\
\hline 16.1 & Imaginary & 1 & 1 & 0 & 0 \\
\hline
\end{tabular}




\begin{tabular}{|l|l|c|c|c|c|}
\hline & punishment & & & & \\
\hline 16.3 & Vicarious & 1 & 1 & 0 & 0 \\
& consequences & & & & \\
\hline
\end{tabular}


Supplemental material 7: Modes of delivery, BCTs and associated practical strategies coded for interventions included in the meta-analysis

Physical Activity Interventions

Brown (2016)

Intervention description: a workplace intervention designed to increase walking. Two intervention types were tested compared to a control (neutral emails with no encouragement): Task/care emails - encouragement stressed individual effort and improvement, and provided suggestions for how to encourage fellow co-workers to walk, and Ego emails: encouragement stressed competing with fellow co-workers to achieve the most steps in the group.

\begin{tabular}{llll}
\hline & Top level & Sub-level 1 & Sub-level 2 \\
\hline Mode of delivery & Digital & Unspecified & Email
\end{tabular}

Task/care intervention

BCT BCT name Practical strategy

number

\begin{tabular}{lll}
\hline 3.1 & Social & Users were encouraged to provide social support to each other e.g. \\
support & 'if you see a fellow walker today, why not give him or her a high \\
& (unspecified) & five? Tell them that they are doing a great job' \\
10.4 & Social & Users received updated step counts for the entire cohort via email
\end{tabular}


reward

e.g. 'congratulations, as a group, we've walked a daily average of 354,203 steps. That's like walking from here to our states capital'

$15.1 \quad$ Verbal e.g. 'Remember- the hardest step you're going to take in this is persuasion just getting out the door. Every step you take today counts. Every about single one. You can do this!'

capability

Ego intervention

BCT BCT name Practical strategy

number comparison week Chris walked the most steps with 140,302 and Ann walked the least steps with only 2,103. Looks like everyone below Chris needs to step it up!' and, 'now's the time to ask yourself- who's the best here? Don't you want it to be you? Take a look at the list of walkers this week. Where is your name? If you're not at the top, remind yourself that you can do better. Don't let someone out walk you!'

15.1 Verbal e.g. 'Everyone has a million excuses for why they can't do persuasion something. But if you want to be top of the walking group, you've about got to keep pushing yourself no matter what. Just put one foot in capability front of the other. If you didn't find yourself top of the walking group this week, remember you can always push yourself harder. 


\section{Don't let yourself slack'}

Dadaczynski et al (2017)

Intervention description: an intervention that aimed to increase low-level physical activity such as walking. The intervention included tracking of physical activity using a pedometer and also access to online content containing quizzes, goal setting/tracking features, and the facility to compare progress with others.

\begin{tabular}{llll}
\hline & Top level & Sub-level 1 & Sub-level 2 \\
\hline Mode of delivery & Digital & Desktop computer & Website \\
& Mobile device & Website \\
& Wearable accessory & Digital accessory
\end{tabular}

\section{BCT BCT name Practical strategy}

number

\begin{tabular}{lll}
\hline 1.1 & Goal setting & A daily step goal was implemented \\
& (behaviour) & \\
1.5 & Review & Individual tailored step goals were calculated \\
behaviour & each day based on logged data of the pedometer for \\
& goal(s) & each user of the last four days \\
& Feedback & Users received daily emails with information about their current \\
& & \\
& on & step goal as well as the results of the previous day
\end{tabular}

12.5 Adding Users were given a Fitbit pedometer to measure their physical 


\begin{tabular}{ll}
\hline $\begin{array}{l}\text { objects to } \\
\text { the } \\
\text { environment }\end{array}$ \\
$\begin{array}{ll}\text { Social } & \text { Users could join in team or individual challenges against each } \\
\text { comparison } & \text { other. Additionally, game features were implemented to increase } \\
& \text { participation e.g. rankings (leader boards) }\end{array}$
\end{tabular}

Dunton et al (2008)

Intervention description: this intervention aimed to increase physical activity amongst women. The website included an interactive computer programme that produced individualised physical activity feedback, images of women exercising (matched to age and type of activity), and tailored messages for overcoming barriers to exercising. Follow-up emails over 10 weeks provided encouragement and tips.

\begin{tabular}{llll}
\hline & Top level & Sub-level 1 & Sub-level 2 \\
\hline Mode of delivery & Digital & Unspecified & Website \\
& & Unspecified & Email
\end{tabular}

BCT BCT name Practical strategy

number

\begin{tabular}{lll}
\hline 1.1 & Goal setting & Email newsletter: 'addressed topics such as goal setting' \\
& (behaviour) & \\
1.2 & Problem & Webpage: provided suggestions for overcoming barriers to
\end{tabular}




\section{solving physical activity}

2.2 Feedback on Webpage: after the information was entered, the computer behaviour programme generated a graph displaying each respondent's selfreported current level of activity compared to the 2005 USDA Dietary guidelines for physical activity

2.3 Self- Email newsletter: link to a downloadable log provided monitoring of behaviour

4.1 Instruction on Email newsletter: information about appropriate portion sizes how to Email newsletter: number of recommended minutes of activity perform the behaviour

5.3 Information Webpage: a tailored message provided either the consequences about social of inactivity, or reinforcement for meeting activity levels, based and on self-reported number of minutes of physical activity environmental consequences

Gell et al (2015)

Intervention description: a text-message workplace-based intervention targeted at women aiming to increase physical activity. Text messages aimed to be informational and motivational. Three were sent per week for 24 weeks. All women received the same messages. 


Top level Sub-level $1 \quad$ Sub-level 2

\begin{tabular}{llll}
\hline Mode of delivery & Digital Phone & Automated text
\end{tabular}

BCT BCT name Practical strategy

number

\begin{tabular}{lll}
\hline 1.1 & Goal & Text messages included 'goal setting' e.g. 'people who write down a
\end{tabular}

setting goal are much more likely to achieve it than those who don't.

(behaviour) What's your exercise goal for the next 3 months?'

1.2 Problem Text messages included 'self-regulation strategies such as relapse

solving prevention' and 'strategies to address the most common barriers to physical activity’

2.3 Self- $\quad$ Text messages included 'self-regulation strategies such as self-

monitoring monitoring'

of

behaviour

4.1 Instruction Text messages included 'specific suggestions for ways to meet

on how to physical activity guidelines' e.g.

perform 'Add steps to your day: use the restroom on another floor and use

behaviour they steps to get there' and 'try interval training while walking: spot

something in the distance and walk fast, walk normal, pick another

object and repeat'

Hageman et al (2005) 
Intervention description: this intervention consisted of a series of three tailored newsletters accessed via the internet that aimed to increase physical activity among older women. Tailored content was created automatically from a library of 350 messages selected according to individuals' responses to their baseline survey.

\begin{tabular}{llll}
\hline & Top level & Sub-level 1 & Sub-level 2 \\
\hline Mode of delivery & Digital & Unspecified & Website \\
& & & \\
& & & \\
BCT & BCT name & Practical strategy & \\
& & & \\
\hline
\end{tabular}

No unique BCTs were coded for this intervention

Hager et al (2002)

Intervention description: This intervention aimed to increase physical activity and was offered within the workplace. The 'stage-based' version provided users with an initial exercise message tailored to their individual readiness to change. This was followed by email messages for five consecutive weeks.

\begin{tabular}{llll}
\hline & Top level & Sub-level 1 & Sub-level 2 \\
\hline Mode of delivery & Digital & Unspecified & Website \\
& & Unspecified & Email
\end{tabular}


BCT BCT name Practical strategy

number

1.1 Goal setting The email 'be precise about what you plan to achieve, and when and how it will happen. Write down the details'

1.2 Problem The email 'exercise is not for me, but I think about it' contained a solving 'barrier identification and solution exercise'

1.4 Action $\quad$ Email: 'be precise about what you plan to achieve, and when and planning how it will happen. Write down the details'

2.3 Self- Email: Goals: Include a way to gauge your success- time spent monitoring of exercising, number of workout sessions, or drop in cholesterol or behaviour blood pressure

2.4 Self- $\quad$ Email: 'Goals: include a way to gauge your success - time spent monitoring of exercising, number of workout sessions, or drop in cholesterol or outcome blood pressure'

behaviour

4.1 Instruction on Email: 'a good fitness program includes three elements': Aerobic how to activity, exercises that increase your heart rate through nonstop perform activity. Fast walking, jogging, swimming, cycling, and roller behaviour skating

Email: 'a good fitness program includes three elements':

Stretching exercises that enable your joints to move through a full range of motion. Stretch after your body is warmed up and breathe naturally while you stretch. Hold each stretch comfortably for 30 seconds and never bounce 


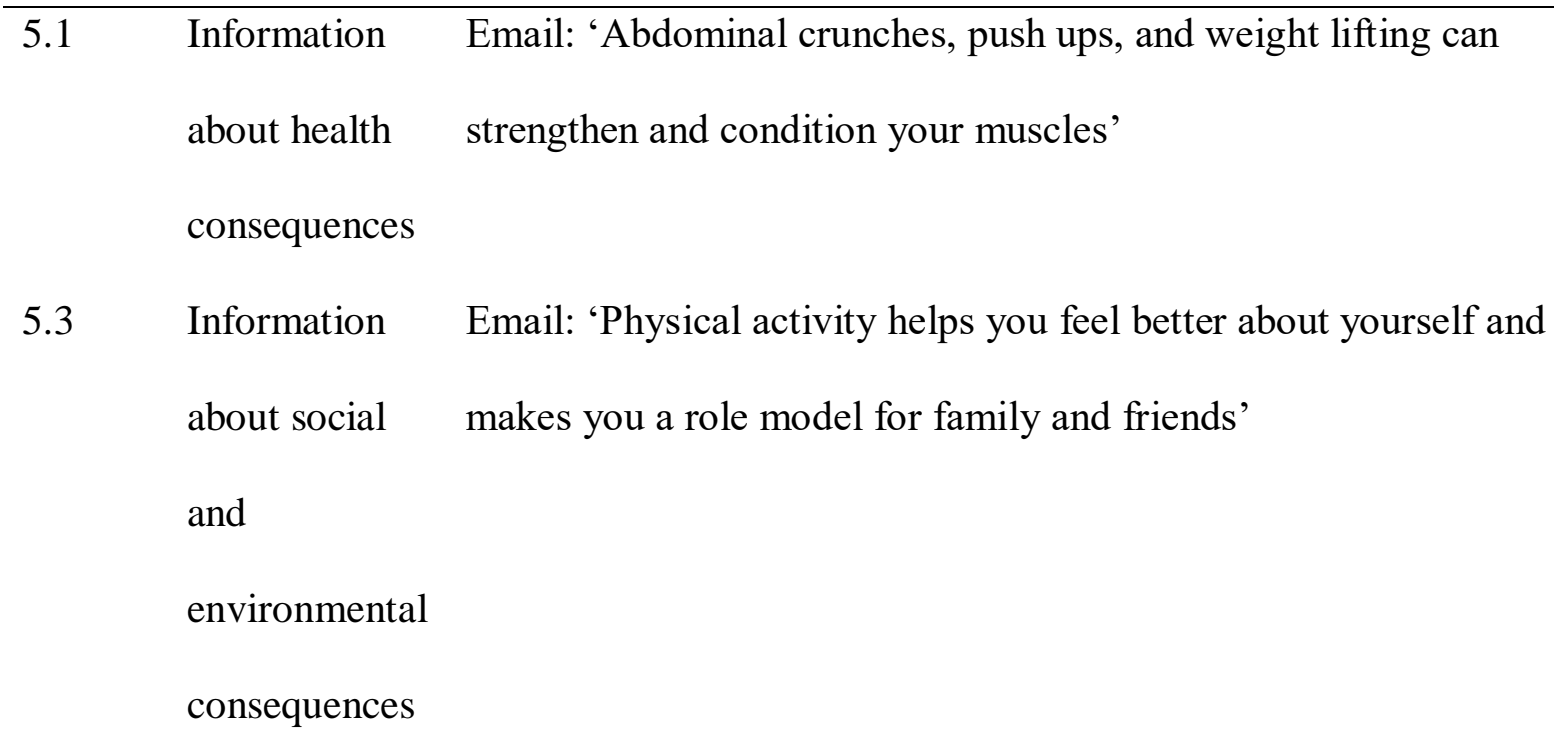

13.1 Identification Email: 'Physical activity helps you feel better about yourself and as self as role makes you a role model for family and friends' model

15.2 Mental Email: 'Picture yourself exercising- healthier and more energetic rehearsal of than you've ever been-looking forward to the day with enthusiasm successful and optimism for what lies ahead' performance

Irvine et al 2011

Intervention description: an automated internet-based work-place intervention (Get Moving) designed to improve the physical activity of sedentary workers. Content aimed to provide education, support and guidance using on-screen text, video, and animations. Employees were able to access the website using workstations located within their workplace computer lab. 


Mode of delivery Digital Computer/television Website

BCT BCT name Practical strategies

number

1.1 Goal setting The Web site helped users to set physical activity goals on a

(behaviour) weekly basis. On each weekly return to the website, users were

encouraged to set the same or an amended goal. Users were

told that the goal was to make physical activity a habit over a

period of months by building gradually to nationally

recommended levels of 30 minutes of moderate intensity

1.2 Problem solving Text and video messages were tailored to users' perceived

personal barriers to PA. For example, they received

encouragement to overcome self-perceived barriers to physical

activity (e.g., too tired, no will power, self-conscious, not fun)

and could view up to six different video testimonials offering

tips in the form of personal stories about overcoming specified

barriers

Users could print tips for overcoming anticipated barriers; they

were encouraged to review common barriers and address the

previous week's obstacles on each return to website

1.4 Action planning The website helped users to create an activity schedule,

including day, time and type of activity they would perform

1.5 Review When users returned to the website, they were queried about

behavioural physical activity since previous visit. The programme 
$\operatorname{goal}(\mathrm{s})$

compared the responses with their stored physical activity data from the previous visit and then provided tailored positive support even if their goals had not been met. Whether users chose the same or amended goal for the following week, a new physical activity schedule for the following week could be created

8.7 Graded tasks The Web site helped users to set physical activity goals on a weekly basis. On each weekly return to the website, users were encouraged to set the same or an amended goal. Users were told that the ultimate goal was to make physical activity a habit over a period of months by building gradually to nationally recommended levels of 30 minutes of moderate intensity

Muller et al (2016)

Intervention description: this intervention aimed to increase exercise self-efficacy in inactive older adults using text messaging (60 messages over 12 weeks). Messages aimed to encourage, prompt and praise exercise behaviour.

\begin{tabular}{llll}
\hline & Top level & Sub-level 1 & Sub-level 2 \\
\hline Mode of delivery & Digital & Phone & Automated text \\
& & & \\
\hline BC & BCT & Practical strategies & \\
T & name & & \\
\hline
\end{tabular}


num

ber

7.1 Prompts/ Text message prompt: 'Please do the My Paths exercises regularly' cues

10.4 Social Text messages praise efforts made towards the exercise behaviour e.g. 'all reward your efforts will impact your health'

Prestwich et al (2017)

Intervention description: an intervention that aimed to increase physical activity measured using step counts. Two different interventions were presented ('self-monitoring' and 'competition'). In both, users were asked to meet a daily step count goal and to track their physical activity using a pedometer. An online website allowed them to observe their stepcount over time. In the competition intervention, users were additionally able to see how their step-count compared to other users.

Self-monitoring intervention

\begin{tabular}{llll}
\hline & Top level & Sub-level 1 & Sub-level 2 \\
\hline Mode of delivery & Digital & Unspecified & Website \\
& & Wearable accessory & Digital accessory \\
& & & \\
\hline BCT & BCT name & Practical strategy & \\
number & & & \\
\hline 1.1 & Goal setting & Users were asked to perform a minimum of 10,000 steps per day
\end{tabular}


(behaviour)

1.6 Discrepancy Tailored message via website: You reported that you have between achieved 11,000 steps so far. The daily target is to achieve at current least 10,000 , thus within the next 24 hours your pedometer behaviour should read at least 120,0000 steps and goal

$2.3 \quad$ Self- $\quad$ Users were asked to log onto study website and record their monitoring number of pedometer steps (at least once every 7 days for 5 of weeks). They were also asked to log any activity done whilst not behaviour wearing the pedometer

2.2 Feedback Users tracked changes in their pedometer steps over the course of the on study via graphical and tabular feedback (at least once every 7 days for behaviour 5 weeks)

Competition intervention

BCT BCT name Practical strategy

number

1.1 Goal setting Users were asked to perform a minimum of 10,000 steps per day (behaviour)

1.6 Discrepancy Tailored message via website: You reported that you have between achieved 11,000 steps so far. The daily target is to achieve at current least 10,000 , thus within the next 24 hours your pedometer behaviour should read at least 120,0000 steps 
and goal

2.3 Self- Users were asked to log onto study website and record their

monitoring number of pedometer steps (at least once every 7 days for 5

of weeks). They were also asked to log any activity done whilst not

behaviour wearing the pedometer

2.2 Feedback Users tracked changes in their pedometer steps over the course of the

on study via graphical and tabular feedback (at least once every 7 days for

behaviour 5 weeks)

6.2 Social Users received feedback relating to how their pedometer steps comparison compared to others (at least once every 7 days for 5 weeks). This was presented in the form of a league table.

Healthy Eating Interventions

Anderson et al (2001)

Intervention description: this intervention aimed to encourage users to decrease dietary fat and increase fruit, vegetables and fibre in their food purchases and consumption. Booths, containing computers hosting the intervention, were situated within supermarkets. The intervention consisted of 15 weekly segments containing pictures, graphics and audio, and the provision of food coupons to be used in the supermarket to buy healthy foods (nature/value of coupon was dependant on the focus of the weekly segment). Vouchers could be printed in the booth and redeemed within one week of printing. 


\begin{tabular}{llll}
\hline & Top level & Sub-level 1 & Sub-level 2 \\
\hline Mode of delivery & Digital & Computer/television & DVD
\end{tabular}

BCT BCT name Practical strategies

number

1.1 Goal The intervention 'provided opportunities for personalised goal

setting setting'

(behaviour)

2.3 Self- $\quad$ Each segment 'provided prescriptive information, suggested

monitoring strategies for monitoring and planning food purchases and meal

of preparation'

behaviour

4.1 Instruction Strategies for monitoring and planning food purchases and meal

on how to preparation were provided

perform

behaviour

10.1 Material Targeted food coupons were provided; type, order, and value of these incentive coupons was dependent on the programme segment's content, a products cost, and a weekly coupon allocation

Cook et al (2007) 
Intervention description: this was a workplace intervention ('Health Connection') delivered via a website. Graphics, audio and video were used to provide 'information and guidance' on three health topics: stress management, nutrition/weight management, and physical activity.

\begin{tabular}{llll}
\hline & Top level & Sub-level 1 & Sub-level 2 \\
\hline Mode of delivery & Digital & Unspecified & Website
\end{tabular}

BCT BCT name Practical strategies

number

1.1 Goal setting Goals are set based on personal assessment information

1.2 Problem Includes a printable 'tracker' for tracking obstacles and strategies

solving that work

1.4 Action Interactive daily meal planning exercises

planning

2.1 Monitoring of An interactive assessment of daily calorie and fat intake

behaviours by

others without

feedback

2.3 Self- A printable smart goal planner and progress tracker

monitoring of

behaviour

4.1 Instruction on Tips for making healthy choices (protein, fats, beverages), 
how to

perform the

behaviour

5.3

Information

information and training in reading nutritional facts labels and

down on alcohol use

about social

Video testimonials highlighting the benefits of good nutrition and

and

environmental

consequences

6.1 Demonstration A demonstration of using the label to check fat content of foods is of behaviour provided

Video demonstrations of: planning ahead for healthy snacks, refusing unwanted drinks or food, using portion control with favourite rich foods, selecting the most healthful cooking method

8.2 Behaviour Advice on replacing alcohol with positive alternatives

substitution

11.2 Reduce Education and training in the 5 steps of effective stress

negative management'

emotions

Irvine et al (2004)

Intervention description: A computer programme which aimed to reduce dietary fat consumption and increase consumption of fruit and vegetables. Content (on-screen text and videos) was tailored according to users' gender, ethnicity, age and interest in content. It was 
made available to employees of two large organisations via temporary computer workstations.

\begin{tabular}{llll}
\hline & Top level & Sub-level 1 & Sub-level 2 \\
\hline Mode of delivery & Digital & Computer/television & DVD
\end{tabular}

BCT BCT name Practical strategies

number

1.1 Goal setting Users were asked to identify which of the recommended

(behaviour) behaviours they were not currently doing and to commit to

those which they would be willing to try in the next week

1.2 Problem solving Users were asked to identify potential barriers to achieving these weekly goals from a total of 24 potential barriers. For chosen barriers, video models delivered short testimonial describing how they overcame the selected barriers

1.9 Commitment Users were asked to 'commit' to the behaviours that they are willing to try in the next week

4.1 Instruction on $\quad$ On screen text was used to present practical steps for how to how to perform perform the behaviours e.g. 'add fruit \& veggies when you the behaviour pack your lunch'

Video vignettes were used to model recommended eating behaviours e.g. the fork-dip method, ordering low-fat menu items 
The recipe section contained over 1500 low-fat recipes - users selected different criteria for recipes and the ones meeting these criteria were displayed and could be printed

$5.1 \quad$ Information The importance and health benefits of eating less dietary fat about health were stressed

consequences

6.1 Demonstration of Video vignettes were used to model recommended eating the behaviour behaviours e.g. the fork-dip method, ordering low-fat menu items

Keller et al (2018)

Intervention description: an intervention that aimed to increase fruit and vegetable consumption. Via a website, users were presented with age and gender matched testimonials by others who had successfully increased their fruit and vegetable consumption and encouraged to focus on past success.

Self-monitoring intervention

Top level Sub-level $1 \quad$ Sub-level 2

\begin{tabular}{llll}
\hline Mode of delivery & Digital Unspecified
\end{tabular}

BCT BCT name Practical strategy

number

8.2 Behaviour Testimonial: 'Until recently I was a real sweet tooth! Chocolate


substitution and cookies in the evening in front of the TV were just a must. I then got the tip from a friend to simply replace sweets with fruit. I'm always nibbling on grapes and dry fruits. Never thought how delicious that is! If I can do that, you can do it!'

15.3 Focus on Users were asked to recall their own experiences of success with past success fruit and veg by checking against some example statements or by documenting their own success stories

15.4 Self-talk Users were encouraged to generate a self-motivating phrase that they could recall when being tempted to snack or otherwise being unmotivated to eat fruit and veg

Smoking Interventions

Brendryen \& Kraft (2008) and Brendryen et al (2008)

Intervention description: The intervention ('Happy Ending') is a 1-year smoking cessation programme. The same intervention was examined in both studies. It has preparation, quitting and follow-up phases during which content, messages and support differ. Access to a website is prompted via email. Users are encouraged to call an Interactive Voice Response (IVR) helpline during the quitting phase whenever they experience an urge to smoke (just-in-time intervention). During this phase, users are additionally contacted by the IVR system daily and prompted to report whether they have smoked; reports of smoking trigger relapse prevention (a 'therapy regimen'). Text messages are used to remind users to contact the IVR helpline when needed. 


\begin{tabular}{llll}
\hline & Top level & Sub-level 1 & Sub-level 2 \\
\hline Mode of delivery & Digital & Unspecified & Website \\
& Unspecified & Email \\
& Phone & Automated text \\
& Phone & Interactive Voice
\end{tabular}

${ }^{1}$ IVR is not currently categorised within the Mode of Delivery of Behaviour Change Interventions Taxonomy Version 0 (MoDTv0) (Carey et al., 20016) as a mode of delivery

\begin{tabular}{|c|c|c|}
\hline $\begin{array}{l}\text { BCT } \\
\text { number }\end{array}$ & BCT name & Practical strategies \\
\hline 1.2 & Problem solving & $\begin{array}{l}\text { Users were encouraged to make concrete 'coping plans' } \\
\text { regarding how to stay smoke free in the immediate future } \\
\text { Automated IVR based 'relapse prevention' system is } \\
\text { incorporated in Happy Ending. }\end{array}$ \\
\hline 1.4 & Action planning & $\begin{array}{l}\text { Users are encouraged to make concrete 'implementation } \\
\text { intentions' regarding how to stay smoke free in the immediate } \\
\text { future } \\
\text { Users who have a 'slip' are encouraged to prepare an } \\
\text { 'implementation intention' regarding how and when to resume } \\
\text { the quit attempt } \\
\text { Repeatedly encouraged to make a plan to call the hotline every } \\
\text { time they are tempted to have a cigarette }\end{array}$ \\
\hline 2.1 & Monitoring of & Users' were contacted every night by the IVR system and asked \\
\hline
\end{tabular}


behaviour by whether they had smoked during the day

others without

feedback

2.3 Self-monitoring The preparation stage contains elements of behavioural skills

of behaviour training. These consist of techniques related to the acquisition of new skills, such as self-stopping, the use of substitutions, self-monitoring and foresight

2.7 Feedback on IVR message: today your blood pressure has been reduced to outcome(s) of that of a non-smoker

behaviour

3.1 Social support The intervention contains an IVR based craving helpline. Users (unspecified) were instructed (repeatedly by text message) to call the helpline every time they are tempted to have a cigarette.

Users were repeatedly encouraged via website messages to call the IVR helpline when experiencing cravings

4.1 Instruction on The preparation stage contains elements of 'behavioural skills how to perform training'. These consist of techniques related to the acquisition behaviour of new skills, such as self-stopping, the use of substitutions, self-monitoring and foresight

4.2 Information Website message: 'what it is that distinguishes your smoking about pattern? I often smoke... after a meal/ on the way to work/ antecedents when I have a coffee break ....?'

5.1 Information Each morning during the quitting phase, users receive a preabout health recorded message via the IVR system about one of the short 
consequences term positive consequences of quitting e.g. 'today your blood pressure has been reduced to that of a non-smoker'

5.5 Anticipated IVR relapse prevention message: 'How will you feel in a regret month's time if you decide to start smoking again now?'

8.2 Behaviour Website message: use some of the smoking breaks you used to substitution have at work to go for a brisk walk instead

10.4 Social reward Website message: 'you will see that you already have a much improved overall state of health - congratulations' Text message: 'congrats - smoke free for a whole work week' and, 'Bravo - it's now a full working week since you stopped'

11.1 Pharmacological Seven text messages are sent to users related to nicotine support replacement therapy (NRT); reminders are sent about obtaining it, wearing it, and to use it regularly

11.2 Reduce negative Users are encouraged to attribute a 'slip' to situational factors, emotions 'thereby preventing negative emotions and a full-blown relapse'

12.1 Restructuring Website message: "clear away all ash tray and anything else that the physical remind you of smoking- look through drawers and cupboards, environment throw away anything you find'

13.2 Framing/ re- Website messages: 'even if you've had a few cigarettes it's not framing a disaster' and, 'a slip up is no great catastrophe, look on any slip up as a little step backwards before you continue ahead at full speed'

15.1 Verbal Email message: 'your first weekend as a non-smoker is nearly persuasion here.... You won't destroy it now by being careless this 
about capability weekend ... you are over the worst cravings and you will have soon managed a whole week as a non-smoker'

Mavrot et al (2016)

Intervention description: this intervention ('Coach'), designed for both current and former smokers (both motivated and unmotivated to quit), aimed to increase smoking cessation and prevent relapse. Website content is tailored and provides 'counselling' through personalised messages (information, encouragement, advice, feedback).

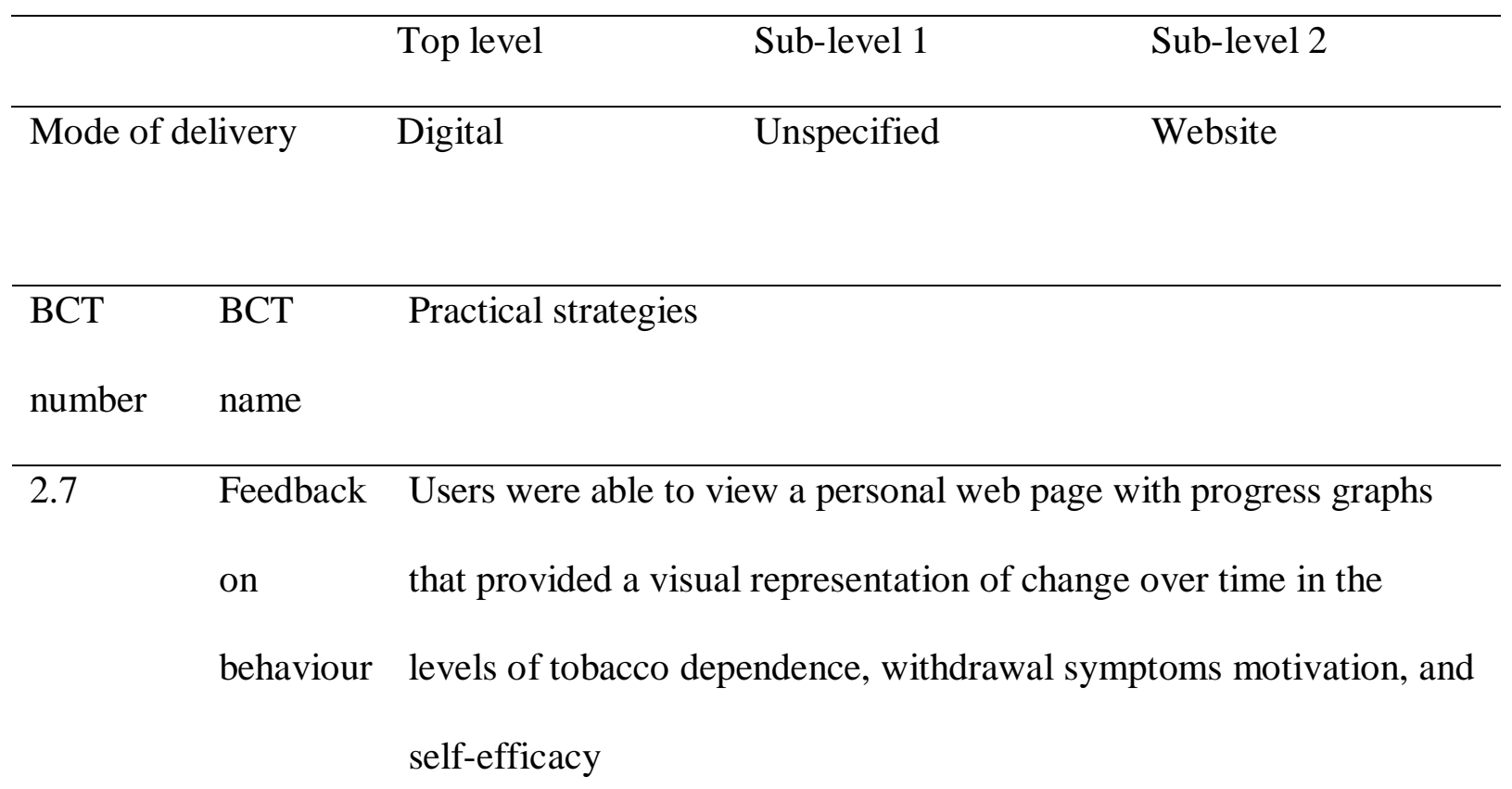

Powell et al (2016) 
Intervention description: A website designed to increase smoking cessation, containing audio, video and on-screen text extracts of ex-smoker's experiences of quitting smoking, organised into topic groups. Users were able to navigate and browse content as they wished.

\begin{tabular}{llll}
\hline & Top level & Sub-level 1 & Sub-level 2 \\
\hline Mode of delivery & Digital & Unspecified & Website \\
& & & \\
\hline BCT $\quad$ BCT & Practical strategies & & \\
number & name & & \\
\end{tabular}

No unique BCTs were coded for this intervention

Sexual Behaviour Interventions

Bowen et al (2007)

Intervention description: A HIV risk-reduction intervention for men who have sex with men (MSM). HIV prevention messages were conveyed through video conversations between an HIV-positive man ('expert') and an HIV-negative man ('inexperienced'; engaging in high risk activities); dialogue was interspersed with interactive activities and graphics emphasising key points.

\begin{tabular}{llll}
\hline & Top level & Sub-level 1 & Sub-level 2 \\
\hline Mode of delivery & Digital & Unspecified & Website
\end{tabular}




\begin{tabular}{lll}
\hline BCT & BCT & Practical strategies \\
number & name & \\
\hline 4.1 & Instruction & The content focused on how the inexperienced man might maintain his \\
& on how to & HIV-negative status, including safe sex options, condom types, and \\
& perform & correct condom application \\
& behaviour
\end{tabular}

Klein et al (2017)

Intervention description: a 2-hour long programme delivered within a sexual health setting.

Users could stop at any point, resume where they left off, and if they wanted to, repeat already completed activities. Each session combines audio narration, visual presentations, interactive components, games, and a series of soap opera-style videos.

Self-monitoring intervention

\begin{tabular}{llll}
\hline & Top level & Sub-level 1 & Sub-level 2 \\
\hline Mode of delivery & Digital & Unspecified & Website
\end{tabular}

BCT BCT name Practical strategy

number

\begin{tabular}{|c|c|c|}
\hline 1.1 & $\begin{array}{l}\text { Goal setting } \\
\text { (behaviour) }\end{array}$ & 'Think about it' activity - for which goal setting is outcome \\
\hline 1.2 & Problem solving & Presentation on ways of getting past barriers to condom use, \\
\hline
\end{tabular}


game'

4.1 Instruction on Interactive review of correct condom use steps; 'Andrea how to perform demonstrates correct condom use'; 'salsa dancing game:

behaviour user negotiates each step of the encounter (sexual

communication) until the dance is complete'

4.2 Information $\quad$ Unsafe sex triggers - video of workshop women discussing

about their own unsafe sex triggers and then 'what are your

antecedents triggers' exercise

5.1 Information Consequences of risky sex = STIs; Interactive activity 'you

about social and and Ramon'- animated chart depicting how Ramon's sexual

environmental experiences translate into a larger sexual history than spans

consequences nearly 100 people

5.2 Salience of Interactive activity 'you and Ramon' - animated chart

consequences depicting how Ramon's sexual experiences translate into a

larger sexual history than spans nearly 100 people

6.1 Demonstration of Video demonstration of communication role play and of

behaviour $\quad$ condom use: 'Andrea demonstrates correct condom use';

video of workshop women practicing putting on condoms

on penis proxies; video demo of communication role-play

8.1 Behaviour Activity- Users negotiates each step of sexual encounter

practice/rehearsal until dance is complete; if he says/ you can say' activity-

communication role-play activity

9.1 Credible source Video of health educator Andrea demonstrating correct 


\section{condom use}

16.1 Imaginary Exercise- visualise the impact of contracting HIV on

punishment family, friends and their quality of life

16.3 Vicarious $\quad$ Video of women's experiences of contracting an STI

consequences multiple times from their partners

Swartz et al (2011)

Intervention description: this intervention aimed to reduce unwanted pregnancy and sexually transmitted infections (STIs) amongst middle-aged women. The website had five modules and included on-screen text, animations, quizzes, and videos (including those presented by midwife and testimonials from other women).

\begin{tabular}{llll}
\hline & Top level & Sub-level 1 & Sub-level 2 \\
\hline Mode of delivery & Digital & Unspecified & Website
\end{tabular}

\section{BCT BCT name Practical strategies}

number

\begin{tabular}{ll}
\hline Instruction on & $\begin{array}{l}\text { The 'talking to your partner' module presents information and } \\
\text { how to }\end{array}$ \\
skill-building techniques for talking with sexual partners about \\
behaviour & how best to initiate and conduct discussions regarding risk- \\
& condoms, or being tested for STI's) \\
& Tip sheets and video modelling are presented to help build \\
& communication skills, and include a) effective communication
\end{tabular}


with your health care provider b) helpful information to bring to an appointment and c) sample questions to ask your health care provider

5.1 Information Information is presented on the benefits and limits of commonly about health used prevention strategies (e.g. condoms) in preventing specific consequences STI's

6.1 Demonstration Tip sheets and video modelling are presented to help build of behaviour communication skills, and include a) effective communication with your health care provider b) helpful information to bring to an appointment and c) sample questions to ask your health care provider 
Supplemental material 8: Forest plot for self-efficacy of automated digital interventions versus no/usual treatment by behavioural domain

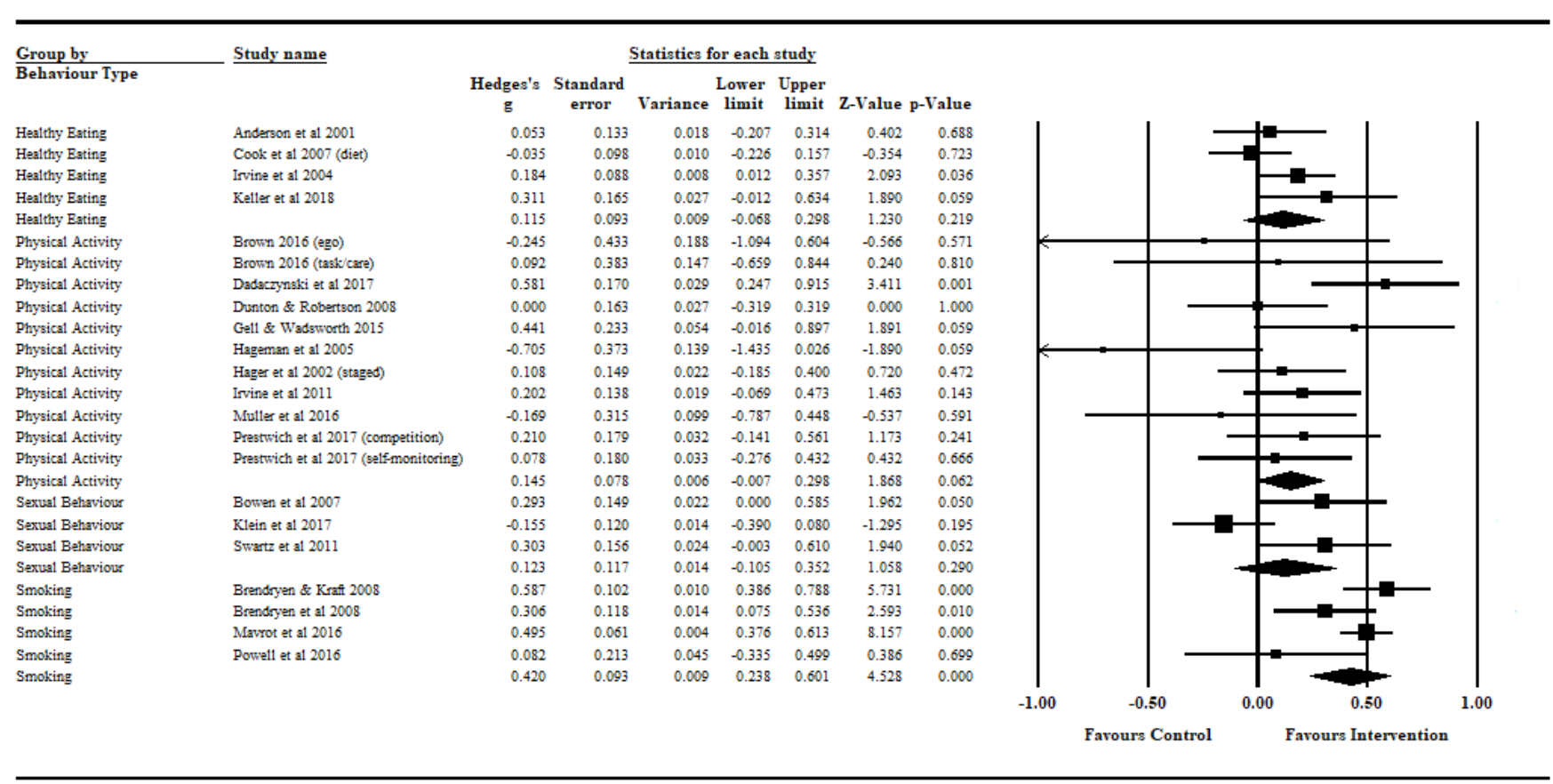


Supplemental material 9: Risk of bias plots of ratings by domain and by study

Risk of bias ratings by domain

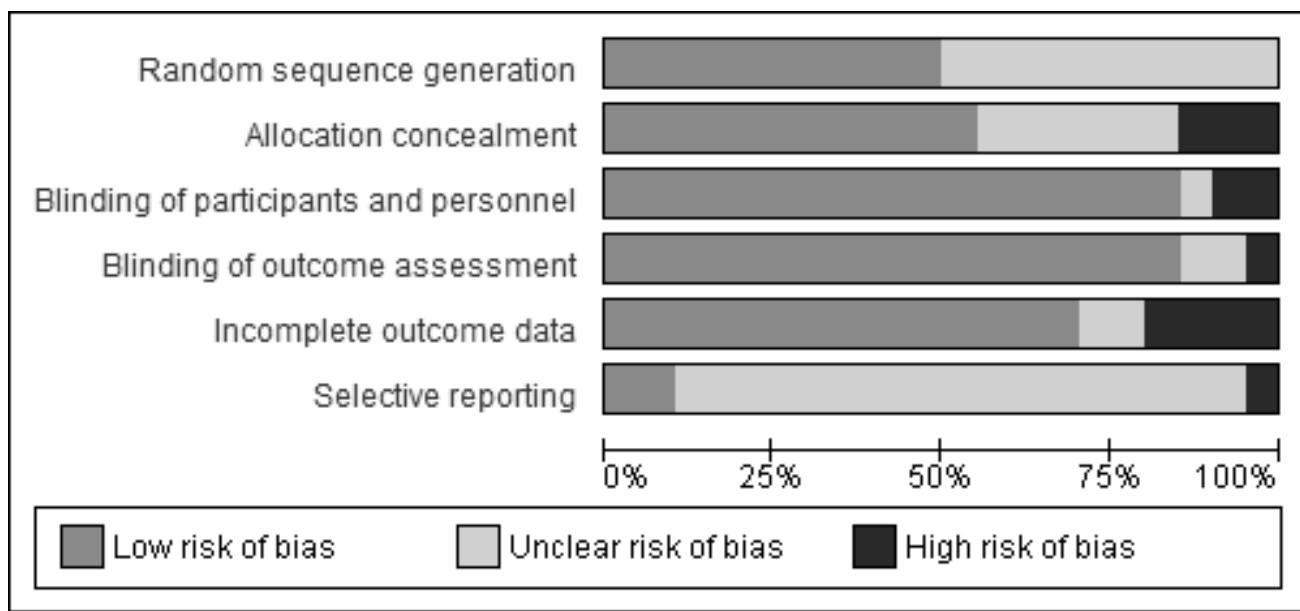


Risk of bias ratings by study

\begin{tabular}{|c|c|c|c|c|c|c|}
\hline & 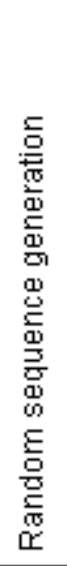 & 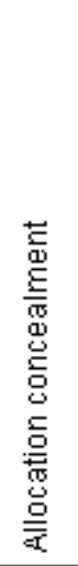 & 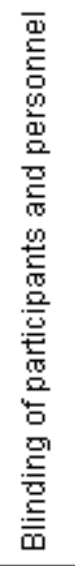 & 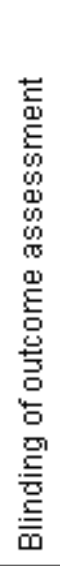 & 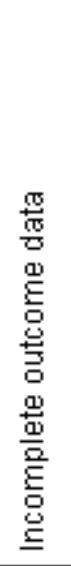 & 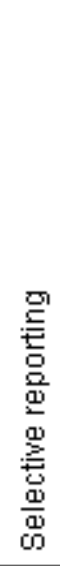 \\
\hline Anderson et al 2001 & $?$ & + & + & + & + & $?$ \\
\hline Bowen et al 2007 & 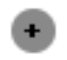 & + & + & + & $\oplus$ & $?$ \\
\hline Brendryen \& Kraft 2008 & $\odot$ & + & + & + & $\odot$ & ? \\
\hline Brendryen et al 2008 & + & + & + & + & $\odot$ & $?$ \\
\hline Brown 2016 & $?$ & + & + & $?$ & $\oplus$ & $?$ \\
\hline Cook et al 2007 & ? & $?$ & + & + & 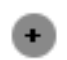 & - \\
\hline Dadaczynski et al 2017 & + & + & + & + & 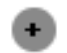 & ? \\
\hline Dunton \& Robertson & + & $?$ & + & + & $?$ & ? \\
\hline Gell \& Wadsworth 2015 & $?$ & $?$ & + & + & + & $?$ \\
\hline Hager et al 2002 & $?$ & ? & + & + & $?$ & ? \\
\hline Hagerman et al 2005 & $?$ & $?$ & + & + & + & $?$ \\
\hline Irvine et al 2004 & $?$ & $?$ & + & + & ? & $?$ \\
\hline Irvine et al 2011 & $?$ & + & + & + & + & ? \\
\hline Keller et al 2018 & 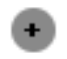 & + & + & + & + & + \\
\hline Klein et al 2017 & $?$ & - & $\odot$ & - & + & $?$ \\
\hline Mavrot et al 2016 & + & - & $O$ & ? & $O$ & ? \\
\hline Muller et al 2016 & + & - & + & + & + & + \\
\hline Powell et al 2016 & + & + & + & + & + & $?$ \\
\hline Prestwich et al 2017 & + & + & + & + & + & ? \\
\hline Swart et al 2011 & $?$ & + & ? & + & + & $?$ \\
\hline
\end{tabular}


$\rightarrow$ High risk of bias

+ Low risk of bias

$?$ Unclear risk of bias 
Supplemental material 10: PRISMA Checklist

\begin{tabular}{|c|c|c|c|}
\hline Section/topic & $\#$ & Checklist item & $\begin{array}{l}\text { Reported on } \\
\text { page \# }\end{array}$ \\
\hline \multicolumn{4}{|l|}{ TITLE } \\
\hline Title & 1 & Identify the report as a systematic review, meta-analysis, or both. & 1 \\
\hline \multicolumn{4}{|l|}{ ABSTRACT } \\
\hline Structured summary & 2 & $\begin{array}{l}\text { Provide a structured summary including, as applicable: background; objectives; data sources; study } \\
\text { eligibility criteria, participants, and interventions; study appraisal and synthesis methods; results; } \\
\text { limitations; conclusions and implications of key findings; systematic review registration number. }\end{array}$ & 3 \\
\hline \multicolumn{4}{|l|}{ INTRODUCTION } \\
\hline Rationale & 3 & Describe the rationale for the review in the context of what is already known. & $4-7$ \\
\hline Objectives & 4 & $\begin{array}{l}\text { Provide an explicit statement of questions being addressed with reference to participants, interventions, } \\
\text { comparisons, outcomes, and study design (PICOS). }\end{array}$ & 7 \\
\hline METHODS & & & \\
\hline
\end{tabular}




\begin{tabular}{|c|c|c|c|}
\hline Protocol and registration & 5 & $\begin{array}{l}\text { Indicate if a review protocol exists, if and where it can be accessed (e.g., Web address), and, if available, } \\
\text { provide registration information including registration number. }\end{array}$ & 7 \\
\hline Eligibility criteria & 6 & $\begin{array}{l}\text { Specify study characteristics (e.g., PICOS, length of follow-up) and report characteristics (e.g., years } \\
\text { considered, language, publication status) used as criteria for eligibility, giving rationale. }\end{array}$ & $7-8$ \\
\hline Information sources & 7 & $\begin{array}{l}\text { Describe all information sources (e.g., databases with dates of coverage, contact with study authors to } \\
\text { identify additional studies) in the search and date last searched. }\end{array}$ & 8 \\
\hline Search & 8 & $\begin{array}{l}\text { Present full electronic search strategy for at least one database, including any limits used, such that it } \\
\text { could be repeated. }\end{array}$ & $\begin{array}{l}\text { Supplemental } \\
\text { material } 2\end{array}$ \\
\hline Study selection & 9 & $\begin{array}{l}\text { State the process for selecting studies (i.e., screening, eligibility, included in systematic review, and, if } \\
\text { applicable, included in the meta-analysis). }\end{array}$ & $9-10$ \\
\hline Data collection process & 10 & $\begin{array}{l}\text { Describe method of data extraction from reports (e.g., piloted forms, independently, in duplicate) and any } \\
\text { processes for obtaining and confirming data from investigators. }\end{array}$ & $10-13$ \\
\hline Data items & 11 & $\begin{array}{l}\text { List and define all variables for which data were sought (e.g., PICOS, funding sources) and any } \\
\text { assumptions and simplifications made. }\end{array}$ & $10-13$ \\
\hline
\end{tabular}




\begin{tabular}{|c|c|c|c|}
\hline $\begin{array}{l}\text { Risk of bias in individual } \\
\text { studies }\end{array}$ & 12 & $\begin{array}{l}\text { Describe methods used for assessing risk of bias of individual studies (including specification of whether } \\
\text { this was done at the study or outcome level), and how this information is to be used in any data synthesis. }\end{array}$ & 13 \\
\hline Summary measures & 13 & State the principal summary measures (e.g., risk ratio, difference in means). & $13-14$ \\
\hline Synthesis of results & 14 & $\begin{array}{l}\text { Describe the methods of handling data and combining results of studies, if done, including measures of } \\
\text { consistency (e.g., } \mathrm{I}^{2} \text { ) for each meta-analysis. }\end{array}$ & $13-14$ \\
\hline Risk of bias across studies & 15 & $\begin{array}{l}\text { Specify any assessment of risk of bias that may affect the cumulative evidence (e.g., publication bias, } \\
\text { selective reporting within studies). }\end{array}$ & 14 \\
\hline Additional analyses & 16 & $\begin{array}{l}\text { Describe methods of additional analyses (e.g., sensitivity or subgroup analyses, meta-regression), if } \\
\text { done, indicating which were pre-specified. }\end{array}$ & $14-15$ \\
\hline \multicolumn{4}{|l|}{ RESULTS } \\
\hline Study selection & 17 & $\begin{array}{l}\text { Give numbers of studies screened, assessed for eligibility, and included in the review, with reasons for } \\
\text { exclusions at each stage, ideally with a flow diagram. }\end{array}$ & 10 (figure 1), \\
\hline Study characteristics & 18 & $\begin{array}{l}\text { For each study, present characteristics for which data were extracted (e.g., study size, PICOS, follow-up } \\
\text { period) and provide the citations. }\end{array}$ & $\begin{array}{l}\text { 16-17, } \\
\text { Supplemental }\end{array}$ \\
\hline
\end{tabular}




\begin{tabular}{|c|c|c|c|}
\hline & & & material 4-7 \\
\hline Risk of bias within studies & 19 & Present data on risk of bias of each study and, if available, any outcome level assessment (see item 12). & $\begin{array}{c}18, \\
\text { supplemental } \\
\text { material } 9\end{array}$ \\
\hline $\begin{array}{l}\text { Results of individual } \\
\text { studies }\end{array}$ & 20 & $\begin{array}{l}\text { For all outcomes considered (benefits or harms), present, for each study: (a) simple summary data for } \\
\text { each intervention group (b) effect estimates and confidence intervals, ideally with a forest plot. }\end{array}$ & 17 (Figure 2) \\
\hline Synthesis of results & 21 & Present results of each meta-analysis done, including confidence intervals and measures of consistency. & 17 \\
\hline Risk of bias across studies & 22 & Present results of any assessment of risk of bias across studies (see Item 15). & $\begin{array}{c}18, \\
\text { supplemental } \\
\text { material } 9\end{array}$ \\
\hline Additional analysis & 23 & $\begin{array}{l}\text { Give results of additional analyses, if done (e.g., sensitivity or subgroup analyses, meta-regression [see } \\
\text { Item 16]). }\end{array}$ & $17-18$ \\
\hline \multicolumn{4}{|l|}{ DISCUSSION } \\
\hline Summary of evidence & 24 & $\begin{array}{l}\text { Summarize the main findings including the strength of evidence for each main outcome; consider their } \\
\text { relevance to key groups (e.g., healthcare providers, users, and policy makers). }\end{array}$ & $18-19$ \\
\hline
\end{tabular}




\begin{tabular}{|c|c|c|c|}
\hline Limitations & 25 & $\begin{array}{l}\text { Discuss limitations at study and outcome level (e.g., risk of bias), and at review-level (e.g., incomplete } \\
\text { retrieval of identified research, reporting bias). }\end{array}$ & $24-25$ \\
\hline Conclusions & 26 & $\begin{array}{l}\text { Provide a general interpretation of the results in the context of other evidence, and implications for future } \\
\text { research. }\end{array}$ & $25-26$ \\
\hline \multicolumn{4}{|l|}{ "FUNDING } \\
\hline Funding & 27 & $\begin{array}{l}\text { Describe sources of funding for the systematic review and other support (e.g., supply of data); role of } \\
\text { funders for the systematic review. }\end{array}$ & 2 \\
\hline
\end{tabular}

From: Moher D, Liberati A, Tetzlaff J, Altman DG, The PRISMA Group (2009). Preferred Reporting Items for Systematic Reviews and MetaAnalyses: The PRISMA Statement. PLoS Med 6(7): e1000097. doi:10.1371/journal.pmed1000097

For more information, visit: www.prisma-statement.org 
Do automated digital health behaviour change interventions have a positive effect on selfefficacy? A systematic review and meta-analysis

\section{Supplemental Materials}

Supplemental material 1: List of search terms

Supplemental material 2: List of reviews in the area

Supplemental material 3: Data extraction sheet

Supplemental material 4: List of studies included in the review

Supplemental material 5: Study characteristics

Supplemental material 6: Incidence of BCTs across interventions along with associated dose

Supplemental material 7: Modes of delivery, BCTs and associated practical strategies coded for interventions included in the meta-analysis

Physical Activity Interventions

Healthy Eating Interventions

Smoking Interventions

Sexual Behaviour Interventions

Supplemental material 8: Forest plot for self-efficacy of automated digital interventions versus no/usual treatment by behavioural domain

Supplemental material 9: Risk of bias plots of ratings by domain and by study

Supplemental material 10: PRISMA Checklist 
Do automated digital health behaviour change interventions have a positive effect on selfefficacy? A systematic review and meta-analysis

Supplemental material 1: List of search terms

First filter; study design:

experiment OR randomi?ed OR controlled OR trial* OR manipulated OR evaluation OR follow-up stud* OR experiment OR program* OR intervention OR intervene*behaviour change OR health promotion OR preven*

Second filter; outcome measures:

Self-efficacy OR social cognitive theory OR vicarious learning OR vicarious experience OR mastery experience OR persuasion OR protection motivation theory

Third filter; intervention type

Digital OR mobile phone OR smartphone OR cell* phone OR email OR e-mail OR messaging service OR videogame OR video game OR website OR podcast OR social media OR app OR text* OR SMS OR computer OR television OR TV OR tablet OR DVD OR virtual reality OR VR OR wearable sensor OR internet OR web-based OR online OR blog OR vlog OR ehealth OR electronic health OR e-health OR mhealth OR m-health OR mobile health

Fourth filter; behaviour:

Condom* OR safe sex OR unsafe sex OR contracepti* OR safer sex OR smok* OR tobacco OR healthy eating OR nutrition OR food consumption OR healthy diet OR dietary behav* OR eating behav* OR physical activity OR physical exercise OR sport OR exercise OR alcohol OR heavy drinking OR binge drink* OR harmful drinking OR episodic drinking 
Do automated digital health behaviour change interventions have a positive effect on selfefficacy? A systematic review and meta-analysis

Supplemental material 2: List of reviews in the area

Bailey, J. V., Murray, E., Rait, G., Mercer, C. H., Morris, R. W., Peacock, R....Nazareth, I. (2012). Computer-based interventions for sexual health promotion: Systematic review and meta-analyses. Int.J.STD AIDS, 23(6), 408-413. doi:10.1258/ijsa.2011.011221.

Black, N., Mullan, B. \& Sharpe, L. (2016). Computer-delivered interventions for reducing alcohol consumption: meta-analysis and meta-regression using behaviour change techniques and theory. Health Psychol Rev, 10(3), 341-357. doi:10.1080/17437199.2016.1168268.

Bort-Roig, J., Gilson, N. D., Puig-Ribera, A., Contreras, R. S. \& Trost, S. G. (2014). Measuring and influencing physical activity with smartphone technology: a systematic review. Sports Med., 44(5), 671-686. doi:10.1007/s40279-014-0142-5.

Brannon, E. E. \& Cushing, C. C. (2015). A systematic review: Is there an app for that? translational science of pediatric behavior change for physical activity and dietary interventions. J.Pediatr.Psychol., 40(4), 373-384. doi:10.1093/jpepsy/jsu108.

Buchholz, S. W., Wilbur, J., Ingram, D. \& Fogg, L. (2013). Physical activity text messaging interventions in adults: A systematic review. Worldviews Evid Based Nurs, 10(3), 163-173. doi:10.1111/wvn.12002..

Carlos Merino-Campos \& Héctor Del, C. F. (2016). The Benefits of Active Video Games for Educational and Physical Activity Approaches: A Systematic Review. Journal of New Approaches in Educational Research, 5(2), 115-122. doi:10.7821/naer.2016.7.164. 
Do automated digital health behaviour change interventions have a positive effect on selfefficacy? A systematic review and meta-analysis

Coughlin, S. S., Whitehead, M., Sheats, J. Q., Mastromonico, J. \& Smith, S. (2016). A Review of Smartphone Applications for Promoting Physical Activity. Jacobs J Community Med, 2(1).

Direito, A., Carraça, E., Rawstorn, J., Whittaker, R. \& Maddison, R. (2017). mHealth technologies to influence physical activity and sedentary behaviors: Behavior change techniques, systematic review and meta-analysis of randomized controlled trials. Ann.Behav.Med., 51(2), 226-239. doi:10.1007/s12160-016-9846-0.

Hamel, L. M. \& Robbins, L. B. (2013). Computer- and web-based interventions to promote healthy eating among children and adolescents: A systematic review. J.Adv.Nurs., 69(1), 1630. doi:10.1111/j.1365-2648.2012.06086.x.

Haug, S., Sannemann, J., Meyer, C. \& John, U. (2012). [Internet and mobile phone interventions to decrease alcohol consumption and to support smoking cessation in adolescents: a review]. Gesundheitswesen, 74(3), 160-177. doi:10.1055/s-0030-1268446.

Haug, S. \& Schaub, M. (2011). Wirksamkeit internetbasierter programme zum tabakrauchen: Eine systematische literaturübersicht. = Efficacy of Internet programs for tobacco smoking: A systematic review. Zeitschrift für Gesundheitspsychologie, 19(4), 181-196. doi:10.1026/0943$8149 / \mathrm{a} 000052$.

Huang, E. T., Williams, H., Hocking, J. S. \& Lim, M. S. (2016). Safe Sex Messages Within Dating and Entertainment Smartphone Apps: A Review. JMIR Mhealth Uhealth, 4(4), e124. Knight, E., Stuckey, M. I., Prapavessis, H. \& Petrella, R. J. (2015). Public health guidelines for physical activity: is there an app for that? A review of android and apple app stores. JMIR Mhealth Uhealth, 3(2), e43. doi:10.2196/mhealth.4003. 
Do automated digital health behaviour change interventions have a positive effect on selfefficacy? A systematic review and meta-analysis

LaPlante, C. \& Peng, W. (2011). A systematic review of e-health interventions for physical activity: An analysis of study design, intervention characteristics, and outcomes.

Telemedicine and e-Health, 17(7), 509-523. doi:10.1089/tmj.2011.0013.

Muller, A. M., Alley, S., Schoeppe, S. \& Vandelanotte, C. (2016). The effectiveness of e-\& mHealth interventions to promote physical activity and healthy diets in developing countries: A systematic review. Int J Behav Nutr Phys Act, 13. doi:10.1186/s12966-016-0434-2.

Matthews, J., Win, K. T., Oinas-Kukkonen, H. \& Freeman, M. (2016). Persuasive Technology in Mobile Applications Promoting Physical Activity: a Systematic Review. J.Med.Syst., 40(3), 72. doi:10.1007/s10916-015-0425-х.

Middelweerd, A., Mollee, J. S., van, d. W., Brug, J. \& te Velde, S. J. (2014). Apps to promote physical activity among adults: A review and content analysis. Int J Behav Nutr Phys Act, 11 .

Miller, K. J., Adair, B. S., Pearce, A. J., Said, C. M., Ozanne, E. \& Morris, M. M. (2014). Effectiveness and feasibility of virtual reality and gaming system use at home by older adults for enabling physical activity to improve health-related domains: a systematic review. Age Ageing, 43(2), 188-195. doi:10.1093/ageing/aft194.

Monroe, C. M., Thompson, D. L., Bassett, D. R., Fitzhugh, E. C. \& Raynor, H. A. (2015). Usability of Mobile Phones in Physical Activity-Related Research: A Systematic Review. American Journal of Health Education, 46(4), 196-206.

doi:10.1080/19325037.2015.1044141.

Nair, N. K., Newton, N. C., Shakeshaft, A., Wallace, P. \& Teesson, M. (2015). A Systematic Review of Digital and Computer-Based Alcohol Intervention Programs in Primary Care. Curr Drug Abuse Rev, 8(2), 111-118. 
Do automated digital health behaviour change interventions have a positive effect on selfefficacy? A systematic review and meta-analysis

Norman, G. J., Zabinski, M. F., Adams, M. A., Rosenberg, D. E., Yaroch, A. L. \& Atienza, A. A. (2007). A review of eHealth interventions for physical activity and dietary behavior change. Am.J.Prev.Med., 33(4), 336-345. doi:10.1016/j.amepre.2007.05.007.

Park, E. \& Drake, E. (2015). Systematic review: Internet-based program for youth smoking prevention and cessation. J.Nurs.Scholarsh., 47(1), 43-50. doi:10.1111/jnu.12104.

Scott-Sheldon, L., Lantini, R., Jennings, E. G., Thind, H., Rosen, R. K., Salmoirago-Blotcher, E. \& Bock, B. C. (2016). Text Messaging-Based Interventions for Smoking Cessation: A Systematic Review and Meta-Analysis. JMIR Mhealth Uhealth, 4(2), e49. doi:10.2196/mhealth.5436.

Spohr, S. A., Nandy, R., Gandhiraj, D., Vemulapalli, A., Anne, S. \& Walters, S. T. (2015). Efficacy of SMS text message interventions for smoking cessation: A meta-analysis. J.Subst.Abuse Treat., 56, 1-10. doi:10.1016/j.jsat.2015.01.011.

Sundstrom, C., Blankers, M. \& Khadjesari, Z. (2017). Computer-based interventions for problematic alcohol use: A review of systematic reviews. Int.J.Behav.Med., 24(5), 646-658. doi:10.1007/s12529-016-9601-8.

Tebb, K. P., Erenrich, R. K., Jasik, C. B., Berna, M. S., Lester, J. C. \& Ozer, E. M. (2016). Use of theory in computer-based interventions to reduce alcohol use among adolescents and young adults: a systematic review. BMC Public Health, 16, 517. doi:10.1186/s12889-0163183-x.

Walters, S. T., Wright, J. A. \& Shegog, R. (2006). A review of computer and Internet-based interventions for smoking behavior. Addict.Behav., 31(2), 264-277. doi:10.1016/j.addbeh.2005.05.002. 
Do automated digital health behaviour change interventions have a positive effect on selfefficacy? A systematic review and meta-analysis

White, A., Kavanagh, D., Stallman, H., Klein, B., Kay-Lambkin, F., Proudfoot, J....Young, R. (2010). Online alcohol interventions: A systematic review. J Med Internet Res, 12(5), 160171. doi:10.2196/jmir.1479.

Williams, G., Hamm, M. P., Shulhan, J., Vandermeer, B. \& Hartling, L. (2014). Social media interventions for diet and exercise behaviours: a systematic review and meta-analysis of randomised controlled trials. BMJ Open, 4(2), e003926. doi:10.1136/bmjopen-2013-003926. 
Do automated digital health behaviour change interventions have a positive effect on selfefficacy? A systematic review and meta-analysis

Supplemental material 3: Data extraction sheet

\begin{tabular}{|l|l|}
\hline Paper Title: & \\
\hline Author Surnames: & \\
\hline Year of Publication: & \\
\hline Journal: & \\
\hline Volume \& Pages: & \\
\hline
\end{tabular}

\begin{tabular}{|l|l|}
\hline Study Design: & RCT or Quasi-RCT \\
\hline Sample Size in Analysis: & \\
\hline No. of Female Participants in & \\
Analysis: & \\
\hline Income Level of Study & high, middle or low \\
Country: & \\
& \\
\hline
\end{tabular}


Do automated digital health behaviour change interventions have a positive effect on selfefficacy? A systematic review and meta-analysis

\begin{tabular}{|l|l|}
\hline Age range of Sample: & $8-24$ years \\
$25-34$ years \\
$35-64$ years \\
$65+$ years
\end{tabular}

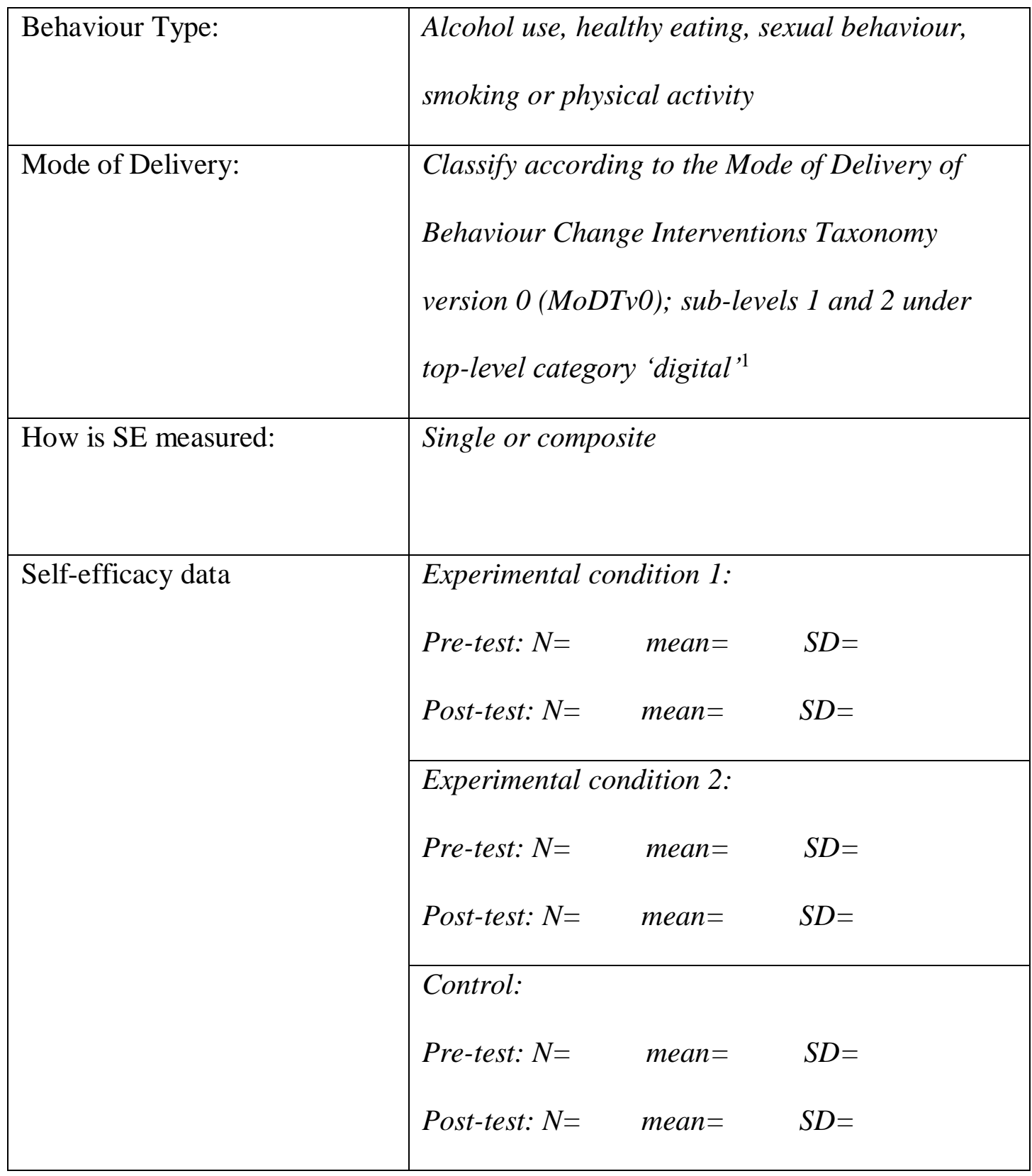


Do automated digital health behaviour change interventions have a positive effect on selfefficacy? A systematic review and meta-analysis

\begin{tabular}{|l|lll|}
\hline Quality of Intervention & Co-design: & Yes & No/Not Reported \\
Development: & Systematic: & Yes & No/Not Reported \\
& Theory: & Yes & No/Not Reported \\
& & &
\end{tabular}

${ }^{1}$ The MoDTv0 has four major categories (human, printed material, digital and somatic) and within each of these, a further three sub-levels. For the major category 'digital' there are four level one categories (phone, computer/television, wearable and environmental sensor). Within each of these level one categories there are between zero and seven level two categories. Within the level one category 'phone' for example, there are the following level two categories: email, website, video game, podcast, social media, app, automated text message. In the present study, modes of delivery were categorised down to the sub-level two. 
Do automated digital health behaviour change interventions have a positive effect on selfefficacy? A systematic review and meta-analysis

Supplemental material 4: List of studies included in the review

Anderson, E., Winett, R., Wojcik, J., Winett, S., \& Bowden, T. (2001). A computerized social cognitive intervention for nutrition behavior: Direct and mediated effects on fat, fiber, fruits, and vegetables, self-efficacy, and outcome expectations among food shoppers. Annals of Behavioral Medicine, 23(2), 88-100. doi:10.1207/S15324796ABM2302_3

Bowen, A., Horvath, K., \& Williams, M. (2007). A randomized control trial of internetdelivered HIV prevention targeting rural MSM. Health Education Research, 22(1), 1207. doi:10.1093/her/cyl057

Brendryen, H., Drozd, F., \& Kraft, P. (2008). A digital smoking cessation program delivered through internet and cell phone without nicotine replacement (happy ending): Randomized controlled trial. Journal of Medical Internet Research, 10(5), e51. doi:10.2196/jmir.1005

Brendryen, H., \& Kraft, P. (2008). Happy ending: A randomized controlled trial of a digital multi-media smoking cessation intervention.(author abstract)(medical condition overview)(report). Addiction, 103(3), 478. doi:10.1111/j.1360-0443.2007.02119.x

Brown, T. C. (2016). Impact of a theory-guided encouragement intervention on an employee walking pilot program. Journal of Applied Sport Psychology, 28(4), 452-468. doi:10.1080/10413200.2016.1187687

Cook, R. F., Billings, D. W., Hersch, R. K., Back, A. S., \& Hendrickson, A. (2007). A field test of a web-based workplace health promotion program to improve dietary practices, 
Do automated digital health behaviour change interventions have a positive effect on selfefficacy? A systematic review and meta-analysis

reduce stress, and increase physical activity: Randomized controlled trial. Journal of Medical Internet Research, 9(2), e17. doi:10.2196/jmir.9.2.e17

Dadaczynski, K., Schiemann, S., \& Backhaus, O. (2017). Promoting physical activity in worksite settings: Results of a german pilot study of the online intervention healingo fit.(report). BMC Public Health, 17(1) doi:10.1186/s12889-017-4697-6

Dunton, G. F., \& Robertson, T. P. (2008). A tailored internet-plus-email intervention for increasing physical activity among ethnically-diverse women. Preventive Medicine, 47(6), 605-611. doi:10.1016/j.ypmed.2008.10.004

Gell, N. M., \& Wadsworth, D. D. (2015). The use of text messaging to promote physical activity in working women: A randomized controlled trial. Journal of Physical Activity \& Health, 12(6), 756. doi:10.1123/jpah.2013-0144

Hageman, P., \& Pullen, C. (2005). Tailored versus standard internet-delivered interventions to promote physical activity in older women. Journal of Geriatric Physical Therapy, 28(1), 28-33.

Hager, R. L., Hardy, A., Aldana, S. G., \& George, J. D. (2002). Evaluation of an internet, stage-based physical activity intervention. Journal of Health Education, 33(6), 329-337. doi:10.1080/19325037.2002.10604755

Irvine, A. B., Ary, D., Grove, D., \& Gilfillan-Morton, L. (2004). The effectiveness of an interactive multimedia program to influence eating habits. Health Education Research, 19(3), 290-305. doi:10.1093/her/cyg027 
Do automated digital health behaviour change interventions have a positive effect on selfefficacy? A systematic review and meta-analysis

Irvine, A. B., Philips, L., Seeley, J., Wyant, S., Duncan, S., \& Moore, R. W. (2011). Get moving: A web site that increases physical activity of sedentary employees. American Journal of Health Promotion, 25(3), 199-206. doi:10.4278/ajhp.04121736

Keller, J., Motter, S., Motter, M., \& Schwarzer, R. (2018). Augmenting fruit and vegetable consumption by an online intervention: Psychological mechanisms. Appetite; Appetite, 120, 348-355. doi:10.1016/j.appet.2017.09.019

Klein, C. H., Kuhn, T., Altamirano, M., \& Lomonaco, C. (2017). C-SAFE: A computerdelivered sexual health promotion program for latinas. Health Promotion Practice, 18(4), 516-525. doi:10.1177/1524839917707791

Mavrot, C., Stucki, I., Sager, F., \& Etter, J. (2017). Efficacy of an internet-based, individually tailored smoking cessation program: A randomized-controlled trial. Journal of Telemedicine and Telecare, 23(5), 521-528. doi:10.1177/1357633X16655476

Muller, A. M., Khoo, S., \& Morris, T. (2016). Text messaging for exercise promotion in older adults from an upper-middle-income country: Randomized controlled trial. Journal of Medical Internet Research, 18(1), e5. doi:10.2196/jmir.5235

Powell, J., Newhouse, N., Martin, A., Jawad, S., Yu, L., Davoudianfar, M., . . Ziebland, S. (2016). A novel experience-based internet intervention for smoking cessation: Feasibility randomised controlled trial.(report). BMC Public Health, 16(1) doi:10.1186/s12889-016$3821-3$

Prestwich, A., Conner, M., Morris, B., Finlayson, G., Sykes-Muskett, B., \& Hurling, R. (2017). Do web-based competitions promote physical activity? randomized controlled trial. Psychology of Sport \& Exercise, 29, 1-9. doi:10.1016/j.psychsport.2016.11.003 
Do automated digital health behaviour change interventions have a positive effect on selfefficacy? A systematic review and meta-analysis

Swartz, L. H. G., Sherman, C. A., Harvey, S. M., Blanchard, J., Vawter, F., \& Gau, J. (2011). Midlife women online: Evaluation of an internet-based program to prevent unintended pregnancy \& STIs. Journal of Women \& Aging, 23(4), 342-359. doi:10.1080/08952841.2011.613255

Supplemental material 5: Study characteristics

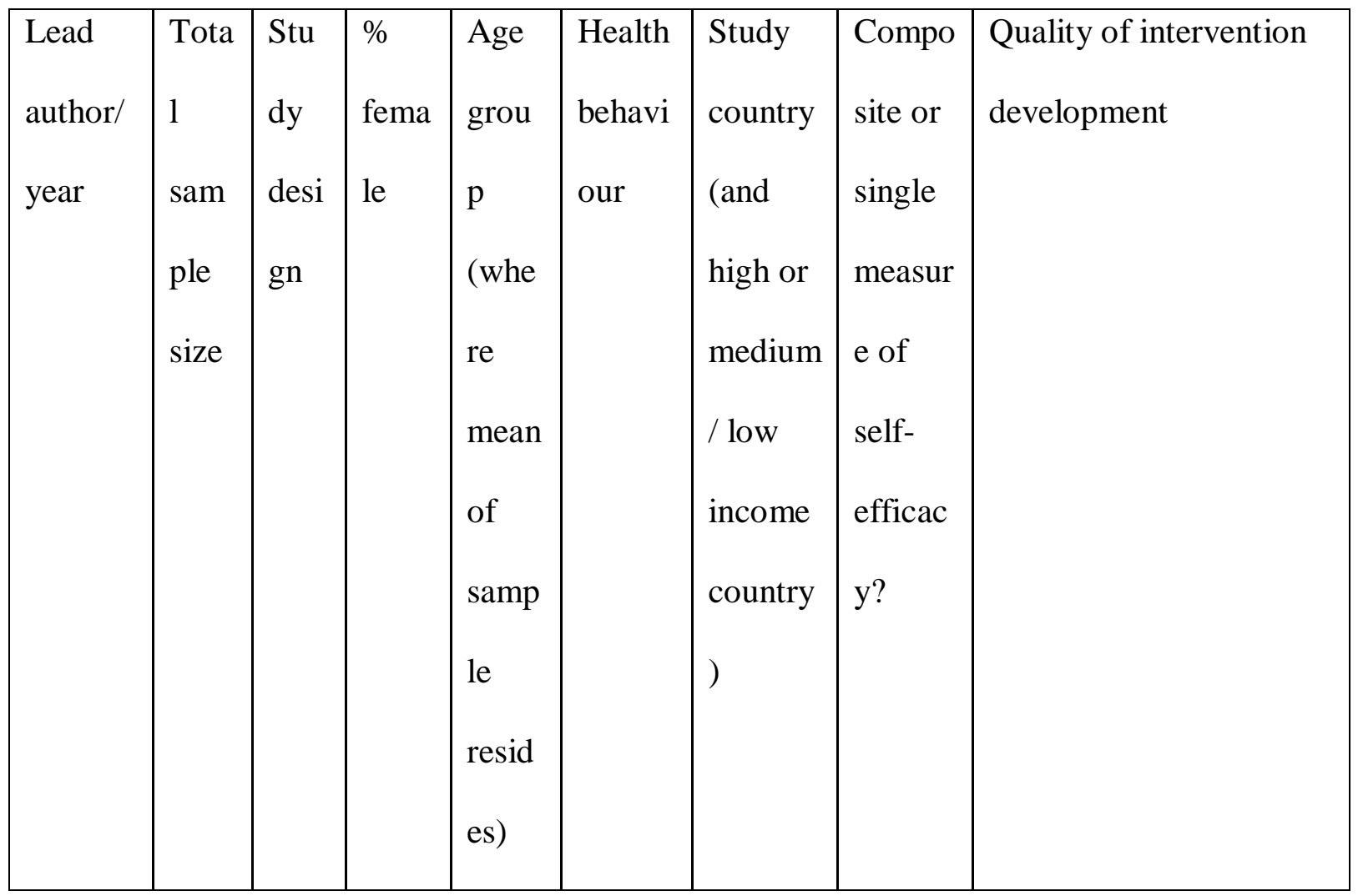


Do automated digital health behaviour change interventions have a positive effect on selfefficacy? A systematic review and meta-analysis

\begin{tabular}{|c|c|c|c|c|c|c|c|c|c|c|}
\hline & & & & & & & & $\begin{array}{l}\text { Theo } \\
\text { ry- } \\
\text { base } \\
\text { d }\end{array}$ & $\begin{array}{l}\text { Develo } \\
\text { ped } \\
\text { using a } \\
\text { system } \\
\text { atic } \\
\text { approa } \\
\text { ch }\end{array}$ & $\begin{array}{l}\text { Co- } \\
\text { design } \\
\text { ed } \\
\text { with } \\
\text { the } \\
\text { target } \\
\text { popula } \\
\text { tion }\end{array}$ \\
\hline $\begin{array}{l}\text { Anders } \\
\text { on, } \\
\text { Winnet } \\
\& \\
\text { Wojcik } \\
\text { (2001) }\end{array}$ & 296 & $\begin{array}{l}\mathrm{RC} \\
\mathrm{T}\end{array}$ & $\begin{array}{l}96.0 \\
\%\end{array}$ & $\begin{array}{l}\text { Mean } \\
\text { not } \\
\text { repor } \\
\text { ted }\end{array}$ & $\begin{array}{l}\text { Health } \\
\mathrm{y} \\
\text { Eating }\end{array}$ & $\begin{array}{l}\text { USA } \\
\text { (High } \\
\text { Income } \\
\text { ) }\end{array}$ & $\begin{array}{l}\text { Compo } \\
\text { site }\end{array}$ & Yes & $\begin{array}{l}\text { No/not } \\
\text { reporte } \\
\text { d }\end{array}$ & $\begin{array}{l}\text { No/not } \\
\text { reporte } \\
\text { d }\end{array}$ \\
\hline $\begin{array}{l}\text { Bowen, } \\
\text { Horvat } \\
\text { h and } \\
\text { Willia } \\
\text { ms } \\
(2007)\end{array}$ & 90 & $\begin{array}{l}\mathrm{RC} \\
\mathrm{T}\end{array}$ & $0 \%$ & $\begin{array}{l}25- \\
34\end{array}$ & $\begin{array}{l}\text { Sexual } \\
\text { Behavi } \\
\text { our }\end{array}$ & $\begin{array}{l}\text { USA } \\
\text { (High } \\
\text { Income } \\
\text { ) }\end{array}$ & $\begin{array}{l}\text { Compo } \\
\text { site }\end{array}$ & Yes & $\begin{array}{l}\text { No/not } \\
\text { reporte } \\
\text { d }\end{array}$ & $\begin{array}{l}\text { No/not } \\
\text { reporte } \\
\text { d }\end{array}$ \\
\hline $\begin{array}{l}\text { Brendr } \\
\text { yen \& } \\
\text { Kraft } \\
\text { (2008) }\end{array}$ & 400 & $\begin{array}{l}\mathrm{RC} \\
\mathrm{T}\end{array}$ & $\begin{array}{l}50.2 \\
5 \%\end{array}$ & $\begin{array}{l}35- \\
64 \\
\text { years }\end{array}$ & $\begin{array}{l}\text { Smoki } \\
\text { ng }\end{array}$ & $\begin{array}{l}\text { Norway } \\
\text { (High } \\
\text { income) }\end{array}$ & $\begin{array}{l}\text { Compo } \\
\text { site }\end{array}$ & No & $\begin{array}{l}\text { No/not } \\
\text { reporte } \\
\text { d }\end{array}$ & $\begin{array}{l}\text { No/not } \\
\text { reporte } \\
\text { d }\end{array}$ \\
\hline
\end{tabular}


Do automated digital health behaviour change interventions have a positive effect on selfefficacy? A systematic review and meta-analysis

\begin{tabular}{|c|c|c|c|c|c|c|c|c|c|c|}
\hline $\begin{array}{l}\text { Brendy } \\
\text { ren et al } \\
\text { (2008) }\end{array}$ & 296 & $\begin{array}{l}\mathrm{RC} \\
\mathrm{T}\end{array}$ & $\begin{array}{l}50.0 \\
\%\end{array}$ & $\begin{array}{l}35- \\
64\end{array}$ & $\begin{array}{l}\text { Smoki } \\
\text { ng }\end{array}$ & $\begin{array}{l}\text { Norway } \\
\text { (High } \\
\text { Income }\end{array}$ & $\begin{array}{l}\text { Compo } \\
\text { site }\end{array}$ & Yes & $\begin{array}{l}\text { No/not } \\
\text { reporte } \\
\text { d }\end{array}$ & $\begin{array}{l}\text { No/not } \\
\text { reporte } \\
\text { d }\end{array}$ \\
\hline $\begin{array}{l}\text { Brown } \\
(2016)\end{array}$ & 106 & $\begin{array}{l}\mathrm{RC} \\
\mathrm{T}\end{array}$ & $\begin{array}{l}84.9 \\
\%\end{array}$ & $\begin{array}{l}35- \\
64\end{array}$ & $\begin{array}{l}\text { Physic } \\
\text { al } \\
\text { Activit } \\
\text { y }\end{array}$ & $\begin{array}{l}\text { USA } \\
\text { (High } \\
\text { Income } \\
\text { ) }\end{array}$ & $\begin{array}{l}\text { Compo } \\
\text { site }\end{array}$ & Yes & $\begin{array}{l}\text { No/not } \\
\text { reporte } \\
\text { d }\end{array}$ & $\begin{array}{l}\text { No/not } \\
\text { reporte } \\
\text { d }\end{array}$ \\
\hline $\begin{array}{l}\text { Cook et } \\
\text { al } \\
\text { (2007) }\end{array}$ & 419 & $\begin{array}{l}\mathrm{RC} \\
\mathrm{T}\end{array}$ & $\begin{array}{l}72.0 \\
\%\end{array}$ & $\begin{array}{l}35- \\
64\end{array}$ & $\begin{array}{l}\text { Health } \\
\mathrm{y} \\
\text { Eating }\end{array}$ & $\begin{array}{l}\text { USA } \\
\text { (High } \\
\text { Income }\end{array}$ & $\begin{array}{l}\text { Compo } \\
\text { site }\end{array}$ & Yes & $\begin{array}{l}\text { No/not } \\
\text { reporte } \\
\text { d }\end{array}$ & $\begin{array}{l}\text { No/not } \\
\text { reporte } \\
\text { d }\end{array}$ \\
\hline $\begin{array}{l}\text { Dadacy } \\
\text { nski et } \\
\text { al } \\
\text { (2017) }\end{array}$ & 176 & $\begin{array}{l}\mathrm{RC} \\
\mathrm{T}\end{array}$ & $\begin{array}{l}35.4 \\
\%\end{array}$ & $\begin{array}{l}35- \\
64\end{array}$ & $\begin{array}{l}\text { Physic } \\
\text { al } \\
\text { Activit } \\
\text { y }\end{array}$ & $\begin{array}{l}\text { German } \\
\mathrm{y} \\
\text { (High } \\
\text { Income }\end{array}$ & $\begin{array}{l}\text { Compo } \\
\text { site }\end{array}$ & Yes & $\begin{array}{l}\text { No/not } \\
\text { reporte } \\
\text { d }\end{array}$ & $\begin{array}{l}\text { No/not } \\
\text { reporte } \\
\text { d }\end{array}$ \\
\hline $\begin{array}{l}\text { Dunton } \\
\& \\
\text { Roberts } \\
\text { on } \\
(2008)\end{array}$ & 156 & $\begin{array}{l}\mathrm{RC} \\
\mathrm{T}\end{array}$ & $\begin{array}{l}100 \\
\%\end{array}$ & $\begin{array}{l}35- \\
64\end{array}$ & $\begin{array}{l}\text { Physic } \\
\text { al } \\
\text { Activit } \\
\text { y }\end{array}$ & $\begin{array}{l}\text { USA } \\
\text { (High } \\
\text { Income } \\
\text { ) }\end{array}$ & $\begin{array}{l}\text { Compo } \\
\text { site }\end{array}$ & Yes & $\begin{array}{l}\text { No/not } \\
\text { reporte } \\
\text { d }\end{array}$ & $\begin{array}{l}\text { No/not } \\
\text { reporte } \\
\text { d }\end{array}$ \\
\hline
\end{tabular}


Do automated digital health behaviour change interventions have a positive effect on selfefficacy? A systematic review and meta-analysis

\begin{tabular}{|c|c|c|c|c|c|c|c|c|c|c|}
\hline $\begin{array}{l}\text { Gell \& } \\
\text { Wadsw } \\
\text { orth } \\
(2015)\end{array}$ & 87 & $\begin{array}{l}\mathrm{RC} \\
\mathrm{T}\end{array}$ & $\begin{array}{l}100 \\
\%\end{array}$ & $\begin{array}{l}35- \\
64\end{array}$ & $\begin{array}{l}\text { Physic } \\
\text { al } \\
\text { Activit } \\
\text { y }\end{array}$ & $\begin{array}{l}\text { USA } \\
\text { (High } \\
\text { Income } \\
\text { ) }\end{array}$ & $\begin{array}{l}\text { Compo } \\
\text { site }\end{array}$ & Yes & $\begin{array}{l}\text { No/not } \\
\text { reporte } \\
\text { d }\end{array}$ & $\begin{array}{l}\text { No/not } \\
\text { reporte } \\
\text { d }\end{array}$ \\
\hline $\begin{array}{l}\text { Hagem } \\
\text { an, } \\
\text { Walker } \\
\& \\
\text { Pullen } \\
(2005)\end{array}$ & 31 & $\begin{array}{l}\mathrm{RC} \\
\mathrm{T}\end{array}$ & $\begin{array}{l}100 \\
\%\end{array}$ & $\begin{array}{l}35- \\
64\end{array}$ & $\begin{array}{l}\text { Physic } \\
\text { al } \\
\text { Activit } \\
\text { y }\end{array}$ & $\begin{array}{l}\text { USA } \\
\text { (High } \\
\text { Income } \\
\text { ) }\end{array}$ & $\begin{array}{l}\text { Compo } \\
\text { site }\end{array}$ & Yes & $\begin{array}{l}\text { No/not } \\
\text { reporte } \\
\text { d }\end{array}$ & $\begin{array}{l}\text { No/not } \\
\text { reporte } \\
\text { d }\end{array}$ \\
\hline $\begin{array}{l}\text { Hager } \\
\text { et al } \\
(2002)\end{array}$ & 525 & $\begin{array}{l}\mathrm{RC} \\
\mathrm{T}\end{array}$ & $\begin{array}{l}54.8 \\
\%\end{array}$ & $\begin{array}{l}35- \\
64\end{array}$ & $\begin{array}{l}\text { Physic } \\
\text { al } \\
\text { Activit } \\
\text { y }\end{array}$ & $\begin{array}{l}\text { USA } \\
\text { (High } \\
\text { Income } \\
\text { ) }\end{array}$ & $\begin{array}{l}\text { Compo } \\
\text { site }\end{array}$ & Yes & $\begin{array}{l}\text { No/not } \\
\text { reporte } \\
\text { d }\end{array}$ & $\begin{array}{l}\text { No/not } \\
\text { reporte } \\
\text { d }\end{array}$ \\
\hline $\begin{array}{l}\text { Irvine } \\
\text { et al } \\
(2004)\end{array}$ & 517 & $\begin{array}{l}\mathrm{RC} \\
\mathrm{T}\end{array}$ & $\begin{array}{l}73.0 \\
\%\end{array}$ & $\begin{array}{l}35- \\
64\end{array}$ & $\begin{array}{l}\text { Health } \\
\mathrm{y} \\
\text { Eating }\end{array}$ & $\begin{array}{l}\text { USA } \\
\text { (High } \\
\text { Income } \\
\text { ) }\end{array}$ & \begin{tabular}{|l|} 
Single \\
\end{tabular} & Yes & $\begin{array}{l}\text { No/not } \\
\text { reporte } \\
\text { d }\end{array}$ & $\begin{array}{l}\text { No/not } \\
\text { reporte } \\
\text { d }\end{array}$ \\
\hline $\begin{array}{l}\text { Irvine } \\
\text { et al } \\
(2011)\end{array}$ & 228 & $\begin{array}{l}\mathrm{RC} \\
\mathrm{T}\end{array}$ & $\begin{array}{l}42.2 \\
\%\end{array}$ & $\begin{array}{l}35- \\
64\end{array}$ & $\begin{array}{l}\text { Physic } \\
\text { al } \\
\text { Activit } \\
\text { y }\end{array}$ & $\begin{array}{l}\text { USA } \\
\text { (High } \\
\text { Income } \\
\text { ) }\end{array}$ & $\begin{array}{l}\text { Compo } \\
\text { site }\end{array}$ & Yes & $\begin{array}{l}\text { No/not } \\
\text { reporte } \\
\text { d }\end{array}$ & $\begin{array}{l}\text { No/not } \\
\text { reporte } \\
\text { d }\end{array}$ \\
\hline
\end{tabular}


Do automated digital health behaviour change interventions have a positive effect on selfefficacy? A systematic review and meta-analysis

\begin{tabular}{|c|c|c|c|c|c|c|c|c|c|c|}
\hline $\begin{array}{l}\text { Keller } \\
\text { et al } \\
(2018)\end{array}$ & 279 & $\begin{array}{l}\mathrm{RC} \\
\mathrm{T}\end{array}$ & $\begin{array}{l}75.2 \\
\%\end{array}$ & $\begin{array}{l}25- \\
34\end{array}$ & $\begin{array}{l}\text { Health } \\
\mathrm{y} \\
\text { Eating }\end{array}$ & $\begin{array}{l}\text { USA } \\
\text { (High } \\
\text { Income }\end{array}$ & $\begin{array}{l}\text { Compo } \\
\text { site }\end{array}$ & Yes & $\begin{array}{l}\text { No/not } \\
\text { reporte } \\
\text { d }\end{array}$ & $\begin{array}{l}\text { No/not } \\
\text { reporte } \\
\text { d }\end{array}$ \\
\hline $\begin{array}{l}\text { Klein et } \\
\text { al } \\
\text { (2017) }\end{array}$ & 321 & $\begin{array}{l}\mathrm{RC} \\
\mathrm{T}\end{array}$ & $\begin{array}{l}100 \\
\%\end{array}$ & $\begin{array}{l}25- \\
34\end{array}$ & $\begin{array}{l}\text { Sexual } \\
\text { Behavi } \\
\text { our }\end{array}$ & $\begin{array}{l}\text { USA } \\
\text { (High } \\
\text { Income }\end{array}$ & $\begin{array}{l}\text { Compo } \\
\text { site }\end{array}$ & Yes & $\begin{array}{l}\text { No/not } \\
\text { reporte } \\
\text { d }\end{array}$ & Yes \\
\hline $\begin{array}{l}\text { Mavrot } \\
(2016)\end{array}$ & $\begin{array}{l}116 \\
0\end{array}$ & $\begin{array}{l}\mathrm{RC} \\
\mathrm{T}\end{array}$ & $\begin{array}{l}65.7 \\
\%\end{array}$ & $\begin{array}{l}35- \\
64\end{array}$ & $\begin{array}{l}\text { Smoki } \\
\text { ng }\end{array}$ & $\begin{array}{l}\text { Switzer } \\
\text { land } \\
\text { (High } \\
\text { Income }\end{array}$ & $\begin{array}{l}\text { Compo } \\
\text { site }\end{array}$ & Yes & $\begin{array}{l}\text { No/not } \\
\text { reporte } \\
\text { d }\end{array}$ & $\begin{array}{l}\text { No/not } \\
\text { reporte } \\
\text { d }\end{array}$ \\
\hline $\begin{array}{l}\text { Muller, } \\
\text { Khoo } \\
\& \\
\text { Morris } \\
\text { (2016) }\end{array}$ & 43 & $\begin{array}{l}\mathrm{RC} \\
\mathrm{T}\end{array}$ & $\begin{array}{l}74.4 \\
\%\end{array}$ & $\begin{array}{l}35- \\
64\end{array}$ & $\begin{array}{l}\text { Physic } \\
\text { al } \\
\text { Activit } \\
\text { y }\end{array}$ & $\begin{array}{l}\text { Malaysi } \\
\text { a } \\
\text { (Middle } \\
\text { Income } \\
\text { ) }\end{array}$ & $\begin{array}{l}\text { Compo } \\
\text { site }\end{array}$ & No & $\begin{array}{l}\text { No/not } \\
\text { reporte } \\
\text { d }\end{array}$ & $\begin{array}{l}\text { No/not } \\
\text { reporte } \\
\text { d }\end{array}$ \\
\hline $\begin{array}{l}\text { Powell } \\
\text { (2016) }\end{array}$ & 87 & $\begin{array}{l}\mathrm{RC} \\
\mathrm{T}\end{array}$ & $\begin{array}{l}52.0 \\
\%\end{array}$ & $\begin{array}{l}35- \\
64\end{array}$ & $\begin{array}{l}\text { Smoki } \\
\text { ng }\end{array}$ & $\begin{array}{l}\text { Englan } \\
\mathrm{d} \\
\text { (High } \\
\text { Income } \\
\text { ) }\end{array}$ & $\begin{array}{l}\text { Compo } \\
\text { site }\end{array}$ & Yes & $\begin{array}{l}\text { No/not } \\
\text { reporte } \\
\text { d }\end{array}$ & $\begin{array}{l}\text { No/not } \\
\text { reporte } \\
\text { d }\end{array}$ \\
\hline
\end{tabular}


Do automated digital health behaviour change interventions have a positive effect on selfefficacy? A systematic review and meta-analysis

\begin{tabular}{|c|c|c|c|c|c|c|c|c|c|c|}
\hline $\begin{array}{l}\text { Prestwi } \\
\text { ch et al } \\
\text { (2017) }\end{array}$ & 281 & $\begin{array}{l}\mathrm{RC} \\
\mathrm{T}\end{array}$ & $\begin{array}{l}75.7 \\
\%\end{array}$ & $\begin{array}{l}18- \\
24\end{array}$ & $\begin{array}{l}\text { Physic } \\
\text { al } \\
\text { Activit } \\
\text { y }\end{array}$ & $\begin{array}{l}\text { Englan } \\
\mathrm{d} \\
\text { (High } \\
\text { Income }\end{array}$ & $\begin{array}{l}\text { Compo } \\
\text { site }\end{array}$ & Yes & $\begin{array}{l}\text { No/not } \\
\text { reporte } \\
\text { d }\end{array}$ & $\begin{array}{l}\text { No/not } \\
\text { reporte } \\
\text { d }\end{array}$ \\
\hline $\begin{array}{l}\text { Swartz } \\
\text { et al } \\
\text { (2011) }\end{array}$ & 422 & $\begin{array}{l}\mathrm{RC} \\
\mathrm{T}\end{array}$ & $\begin{array}{l}100 \\
\%\end{array}$ & $\begin{array}{l}35- \\
64\end{array}$ & $\begin{array}{l}\text { Sexual } \\
\text { Behavi } \\
\text { our }\end{array}$ & $\begin{array}{l}\text { USA } \\
\text { (High } \\
\text { Income }\end{array}$ & $\begin{array}{l}\text { Compo } \\
\text { site }\end{array}$ & Yes & $\begin{array}{l}\text { No/not } \\
\text { reporte } \\
\text { d }\end{array}$ & Yes \\
\hline
\end{tabular}


Do automated digital health behaviour change interventions have a positive effect on self-

efficacy? A systematic review and meta-analysis

Supplemental material 6: Incidence of BCTs across interventions along with associated dose

\begin{tabular}{|c|c|c|c|c|c|}
\hline \multirow{2}{*}{\multicolumn{2}{|c|}{$\mathrm{BCT}$}} & \multirow{3}{*}{$\begin{array}{l}\text { Incidence of BCT } \\
\text { across interventions } \\
11\end{array}$} & \multicolumn{3}{|c|}{$\begin{array}{l}\text { Dose of BCT present } \\
\text { across interventions }\end{array}$} \\
\hline & & & Low & Medium & High \\
\hline 1.1 & $\begin{array}{l}\text { Goal setting } \\
\text { (behaviour) }\end{array}$ & & 3 & 1 & 7 \\
\hline 1.2 & Problem solving & 9 & 3 & 3 & 3 \\
\hline 1.4 & Action planning & 5 & 3 & 0 & 2 \\
\hline 1.5 & $\begin{array}{l}\text { Review } \\
\text { Behavioural } \\
\text { Goal }\end{array}$ & 2 & 1 & 0 & 1 \\
\hline 1.6 & $\begin{array}{l}\text { Discrepancy } \\
\text { between current } \\
\text { behaviour and } \\
\text { goal }\end{array}$ & 2 & 0 & 0 & 2 \\
\hline 1.9 & Commitment & 1 & 0 & 0 & 1 \\
\hline 2.1 & $\begin{array}{l}\text { Monitoring of } \\
\text { Behaviour by } \\
\text { others Without } \\
\text { Feedback }\end{array}$ & 3 & 1 & 0 & 2 \\
\hline 2.2 & Feedback on & 5 & 2 & 0 & 3 \\
\hline
\end{tabular}


Do automated digital health behaviour change interventions have a positive effect on selfefficacy? A systematic review and meta-analysis

\begin{tabular}{|c|c|c|c|c|c|}
\hline & Behaviour & & & & \\
\hline 2.3 & $\begin{array}{l}\text { Self-monitoring } \\
\text { of behaviour }\end{array}$ & 9 & 3 & 1 & 5 \\
\hline 2.4 & $\begin{array}{l}\text { Self-Monitoring } \\
\text { of outcome of } \\
\text { behaviour }\end{array}$ & 1 & 1 & 0 & 0 \\
\hline 2.7 & $\begin{array}{l}\text { Feedback on } \\
\text { outcome(s) of } \\
\text { Behaviour }\end{array}$ & 2 & 2 & 0 & 0 \\
\hline 3.1 & $\begin{array}{l}\text { Social Support } \\
\text { (unspecified) }\end{array}$ & 3 & 1 & 0 & 2 \\
\hline 4.1 & $\begin{array}{l}\text { Instruction on } \\
\text { How to Perform } \\
\text { Behaviour }\end{array}$ & 11 & 3 & 3 & 5 \\
\hline 4.2 & $\begin{array}{l}\text { Information } \\
\text { about } \\
\text { antecedents }\end{array}$ & 3 & 2 & 1 & 0 \\
\hline 5.1 & $\begin{array}{l}\text { Information } \\
\text { about Health } \\
\text { Consequences }\end{array}$ & 5 & 3 & 0 & 2 \\
\hline 5.2 & $\begin{array}{l}\text { Salience of } \\
\text { consequences }\end{array}$ & 1 & 1 & 0 & 0 \\
\hline 5.3 & Information & 4 & 4 & 0 & 0 \\
\hline
\end{tabular}


Do automated digital health behaviour change interventions have a positive effect on selfefficacy? A systematic review and meta-analysis

\begin{tabular}{|c|c|c|c|c|c|}
\hline & $\begin{array}{l}\text { about Social and } \\
\text { Environmental } \\
\text { consequences }\end{array}$ & & & & \\
\hline 5.5 & $\begin{array}{l}\text { Anticipated } \\
\text { regret }\end{array}$ & 2 & 2 & 0 & 0 \\
\hline 6.1 & $\begin{array}{l}\text { Demonstration } \\
\text { of Behaviour }\end{array}$ & 4 & 1 & 0 & 3 \\
\hline 6.2 & $\begin{array}{l}\text { Social } \\
\text { Comparison }\end{array}$ & 3 & 0 & 0 & 3 \\
\hline 7.1 & Prompts/Cues & 1 & 0 & 0 & 1 \\
\hline 8.1 & $\begin{array}{l}\text { Behavioural } \\
\text { practice/ } \\
\text { rehearsal }\end{array}$ & 1 & 0 & 1 & 0 \\
\hline 8.2 & $\begin{array}{l}\text { Behavioural } \\
\text { Substitution }\end{array}$ & 4 & 4 & 0 & 0 \\
\hline 8.7 & Graded Tasks & 1 & 1 & 0 & 0 \\
\hline 9.1 & Credible source & 1 & 1 & 0 & 0 \\
\hline 10.1 & $\begin{array}{l}\text { Material } \\
\text { incentive } \\
\text { (behaviour) }\end{array}$ & 1 & 0 & 0 & 1 \\
\hline 10.4 & Social Reward & 4 & 0 & 0 & 4 \\
\hline 11.1 & $\begin{array}{l}\text { Pharmacological } \\
\text { Support }\end{array}$ & 2 & 0 & 0 & 2 \\
\hline
\end{tabular}


Do automated digital health behaviour change interventions have a positive effect on selfefficacy? A systematic review and meta-analysis

\begin{tabular}{|c|c|c|c|c|c|}
\hline 11.2 & $\begin{array}{l}\text { Reduce Negative } \\
\text { Emotions }\end{array}$ & 3 & 1 & 2 & 0 \\
\hline 12.1 & $\begin{array}{l}\text { Restructuring the } \\
\text { physical } \\
\text { environment }\end{array}$ & 2 & 2 & 0 & 0 \\
\hline 12.5 & $\begin{array}{l}\text { Adding objects } \\
\text { to the } \\
\text { environment }\end{array}$ & 1 & 1 & 0 & 0 \\
\hline 13.1 & $\begin{array}{l}\text { Identification of } \\
\text { self as role } \\
\text { model }\end{array}$ & 1 & 1 & 0 & 0 \\
\hline 13.2 & $\begin{array}{l}\text { Framing re- } \\
\text { framing }\end{array}$ & 2 & 0 & 0 & 2 \\
\hline 15.1 & $\begin{array}{l}\text { Verbal } \\
\text { Persuasion } \\
\text { About Capability }\end{array}$ & 4 & 4 & 0 & 0 \\
\hline 15.2 & $\begin{array}{l}\text { Mental rehearsal } \\
\text { of successful } \\
\text { performance }\end{array}$ & 1 & 1 & 0 & 0 \\
\hline 15.3 & $\begin{array}{l}\text { Focus on past } \\
\text { success }\end{array}$ & 1 & 0 & 1 & 0 \\
\hline 15.4 & Self-talk & 1 & 1 & 0 & 0 \\
\hline 16.1 & Imaginary & 1 & 1 & 0 & 0 \\
\hline
\end{tabular}


Do automated digital health behaviour change interventions have a positive effect on selfefficacy? A systematic review and meta-analysis

\begin{tabular}{|l|l|c|c|c|c|}
\hline & punishment & & & & \\
\hline 16.3 & Vicarious & 1 & 1 & 0 & 0 \\
& consequences & & & & \\
\hline
\end{tabular}


Do automated digital health behaviour change interventions have a positive effect on selfefficacy? A systematic review and meta-analysis

Supplemental material 7: Modes of delivery, BCTs and associated practical strategies coded for interventions included in the meta-analysis

Physical Activity Interventions

Brown (2016)

Intervention description: a workplace intervention designed to increase walking. Two intervention types were tested compared to a control (neutral emails with no encouragement): Task/care emails - encouragement stressed individual effort and improvement, and provided suggestions for how to encourage fellow co-workers to walk, and Ego emails: encouragement stressed competing with fellow co-workers to achieve the most steps in the group.

\begin{tabular}{llll}
\hline & Top level & Sub-level 1 & Sub-level 2 \\
\hline Mode of delivery & Digital & Unspecified & Email
\end{tabular}

Task/care intervention

BCT BCT name Practical strategy

number

\begin{tabular}{lll}
\hline 3.1 & Social & Users were encouraged to provide social support to each other e.g. \\
support & 'if you see a fellow walker today, why not give him or her a high \\
& (unspecified) & five? Tell them that they are doing a great job' \\
10.4 & Social & Users received updated step counts for the entire cohort via email
\end{tabular}


Do automated digital health behaviour change interventions have a positive effect on selfefficacy? A systematic review and meta-analysis

reward

e.g. 'congratulations, as a group, we've walked a daily average of 354,203 steps. That's like walking from here to our states capital'

15.1 Verbal e.g. 'Remember- the hardest step you're going to take in this is persuasion just getting out the door. Every step you take today counts. Every about single one. You can do this!'

capability

Ego intervention

\begin{tabular}{|c|c|c|}
\hline $\begin{array}{l}\text { BCT } \\
\text { number }\end{array}$ & BCT name & Practical strategy \\
\hline 6.2 & $\begin{array}{l}\text { Social } \\
\text { comparison }\end{array}$ & $\begin{array}{l}\text { Users received a running tally of everyone's step count e.g. 'this } \\
\text { week Chris walked the most steps with 140,302 and Ann walked } \\
\text { the least steps with only 2,103. Looks like everyone below Chris } \\
\text { needs to step it up!' and, 'now's the time to ask yourself- who's } \\
\text { the best here? Don't you want it to be you? Take a look at the list } \\
\text { of walkers this week. Where is your name? If you're not at the top, } \\
\text { remind yourself that you can do better. Don't let someone out walk } \\
\text { you!' }\end{array}$ \\
\hline 15.1 & $\begin{array}{l}\text { Verbal } \\
\text { persuasion } \\
\text { about } \\
\text { capability }\end{array}$ & $\begin{array}{l}\text { e.g. 'Everyone has a million excuses for why they can't do } \\
\text { something. But if you want to be top of the walking group, you've } \\
\text { got to keep pushing yourself no matter what. Just put one foot in } \\
\text { front of the other. If you didn't find yourself top of the walking } \\
\text { group this week, remember you can always push yourself harder. }\end{array}$ \\
\hline
\end{tabular}


Do automated digital health behaviour change interventions have a positive effect on selfefficacy? A systematic review and meta-analysis

\section{Don't let yourself slack'}

Dadaczynski et al (2017)

Intervention description: an intervention that aimed to increase low-level physical activity such as walking. The intervention included tracking of physical activity using a pedometer and also access to online content containing quizzes, goal setting/tracking features, and the facility to compare progress with others.

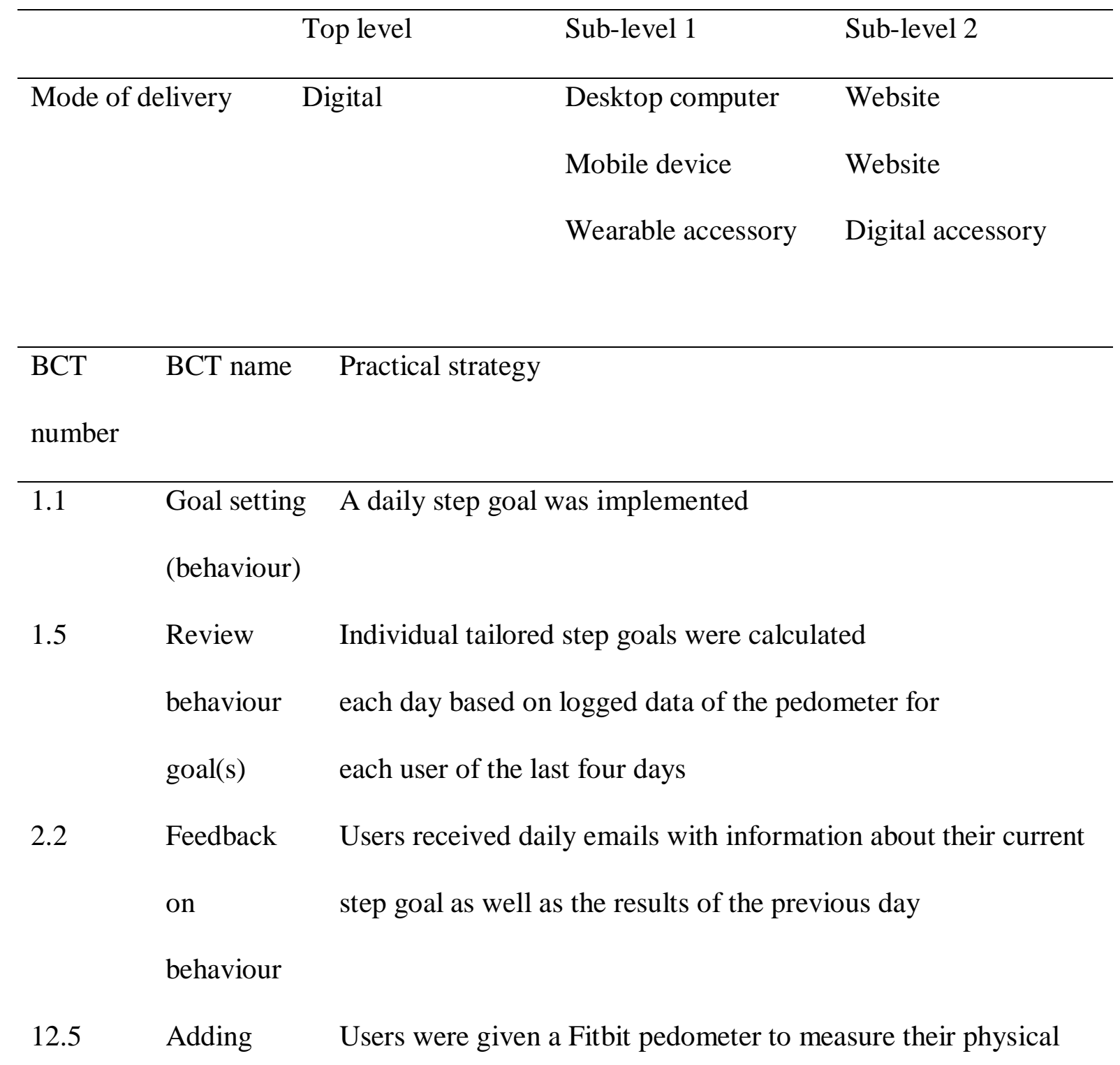


Do automated digital health behaviour change interventions have a positive effect on selfefficacy? A systematic review and meta-analysis

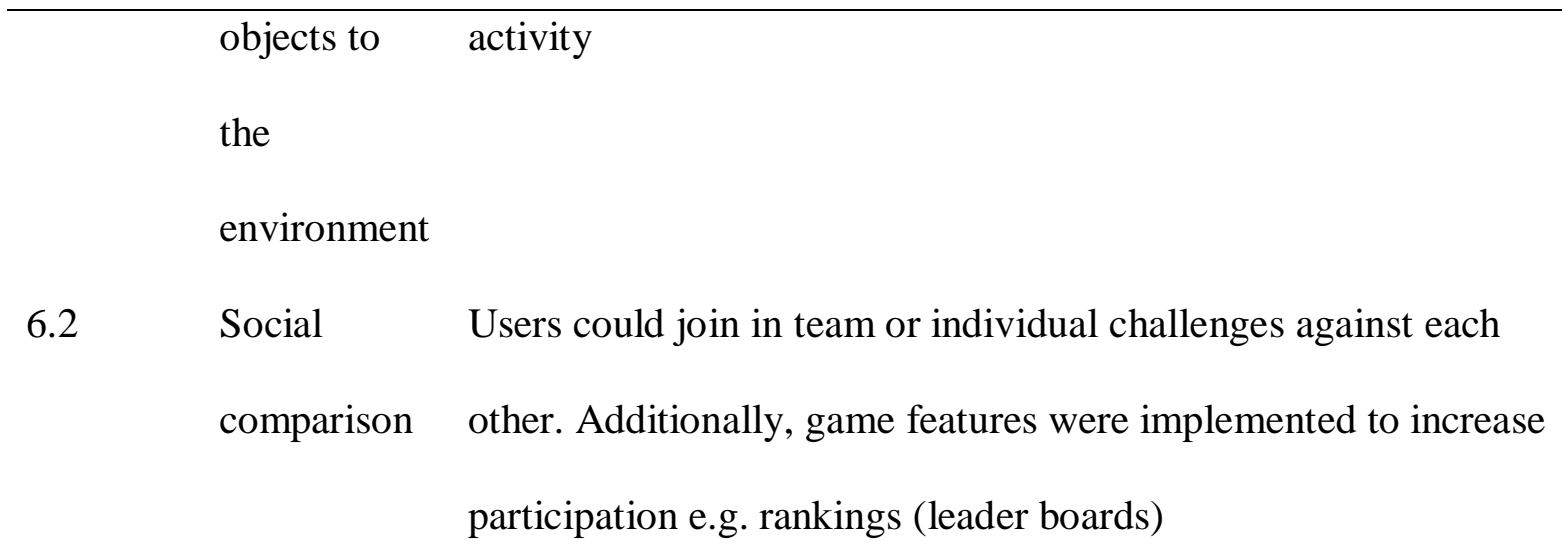

Dunton et al (2008)

Intervention description: this intervention aimed to increase physical activity amongst women. The website included an interactive computer programme that produced individualised physical activity feedback, images of women exercising (matched to age and type of activity), and tailored messages for overcoming barriers to exercising. Follow-up emails over 10 weeks provided encouragement and tips.

\begin{tabular}{llll}
\hline & Top level & Sub-level 1 & Sub-level 2 \\
\hline Mode of delivery & Digital & Unspecified & Website \\
& & Unspecified & Email
\end{tabular}

BCT BCT name Practical strategy

number

\begin{tabular}{lll}
\hline 1.1 & Goal setting & Email newsletter: 'addressed topics such as goal setting' \\
& (behaviour) & \\
1.2 & Problem & Webpage: provided suggestions for overcoming barriers to
\end{tabular}


Do automated digital health behaviour change interventions have a positive effect on selfefficacy? A systematic review and meta-analysis

solving physical activity

2.2 Feedback on Webpage: after the information was entered, the computer behaviour programme generated a graph displaying each respondent's selfreported current level of activity compared to the 2005 USDA Dietary guidelines for physical activity

2.3 Self- $\quad$ Email newsletter: link to a downloadable log provided monitoring of behaviour

4.1 Instruction on Email newsletter: information about appropriate portion sizes how to $\quad$ Email newsletter: number of recommended minutes of activity perform the behaviour

5.3 Information Webpage: a tailored message provided either the consequences about social of inactivity, or reinforcement for meeting activity levels, based and on self-reported number of minutes of physical activity environmental consequences

Gell et al (2015)

Intervention description: a text-message workplace-based intervention targeted at women aiming to increase physical activity. Text messages aimed to be informational and motivational. Three were sent per week for 24 weeks. All women received the same messages. 
Do automated digital health behaviour change interventions have a positive effect on selfefficacy? A systematic review and meta-analysis

\begin{tabular}{llll}
\hline & Top level & Sub-level 1 & Sub-level 2 \\
\hline Mode of delivery & Digital & Phone & Automated text
\end{tabular}

BCT BCT name Practical strategy

number

\begin{tabular}{lll}
\hline 1.1 & Goal & Text messages included 'goal setting' e.g. 'people who write down a
\end{tabular}

setting goal are much more likely to achieve it than those who don't.

(behaviour) What's your exercise goal for the next 3 months?'

1.2 Problem Text messages included 'self-regulation strategies such as relapse

solving prevention' and 'strategies to address the most common barriers to physical activity’

2.3 Self- Text messages included 'self-regulation strategies such as selfmonitoring monitoring'

of

behaviour

4.1 Instruction Text messages included 'specific suggestions for ways to meet

on how to physical activity guidelines' e.g.

perform 'Add steps to your day: use the restroom on another floor and use

behaviour they steps to get there' and 'try interval training while walking: spot

something in the distance and walk fast, walk normal, pick another

object and repeat'

Hageman et al (2005) 
Do automated digital health behaviour change interventions have a positive effect on selfefficacy? A systematic review and meta-analysis

Intervention description: this intervention consisted of a series of three tailored newsletters accessed via the internet that aimed to increase physical activity among older women.

Tailored content was created automatically from a library of 350 messages selected according to individuals' responses to their baseline survey.

\begin{tabular}{llll}
\hline & Top level & Sub-level 1 & Sub-level 2 \\
\hline Mode of delivery & Digital & Unspecified & Website \\
& & & \\
& & & \\
BCT & BCT name & Practical strategy & \\
& & & \\
\hline
\end{tabular}

No unique BCTs were coded for this intervention

Hager et al (2002)

Intervention description: This intervention aimed to increase physical activity and was offered within the workplace. The 'stage-based' version provided users with an initial exercise message tailored to their individual readiness to change. This was followed by email messages for five consecutive weeks.

\begin{tabular}{llll}
\hline & Top level & Sub-level 1 & Sub-level 2 \\
\hline Mode of delivery & Digital & Unspecified & Website \\
& & Unspecified & Email
\end{tabular}


Do automated digital health behaviour change interventions have a positive effect on selfefficacy? A systematic review and meta-analysis

BCT BCT name Practical strategy

number

1.1 Goal setting The email 'be precise about what you plan to achieve, and when and how it will happen. Write down the details'

1.2 Problem The email 'exercise is not for me, but I think about it' contained a solving 'barrier identification and solution exercise'

1.4 Action $\quad$ Email: 'be precise about what you plan to achieve, and when and planning how it will happen. Write down the details'

2.3 Self- Email: Goals: Include a way to gauge your success- time spent monitoring of exercising, number of workout sessions, or drop in cholesterol or behaviour blood pressure

2.4 Self- $\quad$ Email: 'Goals: include a way to gauge your success - time spent monitoring of exercising, number of workout sessions, or drop in cholesterol or outcome blood pressure'

behaviour

4.1 Instruction on Email: 'a good fitness program includes three elements': Aerobic how to activity, exercises that increase your heart rate through nonstop perform activity. Fast walking, jogging, swimming, cycling, and roller behaviour skating

Email: 'a good fitness program includes three elements':

Stretching exercises that enable your joints to move through a full range of motion. Stretch after your body is warmed up and breathe naturally while you stretch. Hold each stretch comfortably for 30 seconds and never bounce 
Do automated digital health behaviour change interventions have a positive effect on selfefficacy? A systematic review and meta-analysis

\author{
5.1 Information Email: 'Abdominal crunches, push ups, and weight lifting can \\ about health strengthen and condition your muscles' \\ consequences \\ 5.3 Information Email: 'Physical activity helps you feel better about yourself and \\ about social makes you a role model for family and friends' \\ and \\ environmental \\ consequences
}

13.1 Identification Email: 'Physical activity helps you feel better about yourself and as self as role makes you a role model for family and friends' model

15.2 Mental Email: 'Picture yourself exercising- healthier and more energetic rehearsal of than you've ever been-looking forward to the day with enthusiasm successful and optimism for what lies ahead' performance

Irvine et al 2011

Intervention description: an automated internet-based work-place intervention (Get Moving) designed to improve the physical activity of sedentary workers. Content aimed to provide education, support and guidance using on-screen text, video, and animations. Employees were able to access the website using workstations located within their workplace computer lab. 
Do automated digital health behaviour change interventions have a positive effect on selfefficacy? A systematic review and meta-analysis

Mode of delivery Digital Computer/television Website

BCT BCT name Practical strategies

number

\begin{tabular}{ll}
\hline Goal setting & The Web site helped users to set physical activity goals on a \\
(behaviour) & weekly basis. On each weekly return to the website, users were \\
& encouraged to set the same or an amended goal. Users were \\
& told that the goal was to make physical activity a habit over a \\
& period of months by building gradually to nationally \\
& recommended levels of 30 minutes of moderate intensity \\
Problem solving & Text and video messages were tailored to users' perceived \\
& personal barriers to PA. For example, they received \\
encouragement to overcome self-perceived barriers to physical & activity (e.g., too tired, no will power, self-conscious, not fun) \\
and could view up to six different video testimonials offering \\
tips in the form of personal stories about overcoming specified \\
barriers
\end{tabular}

Users could print tips for overcoming anticipated barriers; they were encouraged to review common barriers and address the previous week's obstacles on each return to website

1.4 Action planning The website helped users to create an activity schedule, including day, time and type of activity they would perform

1.5 Review When users returned to the website, they were queried about behavioural physical activity since previous visit. The programme 
Do automated digital health behaviour change interventions have a positive effect on selfefficacy? A systematic review and meta-analysis

$\operatorname{goal}(\mathrm{s})$

8.7 Graded tasks compared the responses with their stored physical activity data from the previous visit and then provided tailored positive support even if their goals had not been met. Whether users chose the same or amended goal for the following week, a new physical activity schedule for the following week could be created The Web site helped users to set physical activity goals on a weekly basis. On each weekly return to the website, users were encouraged to set the same or an amended goal. Users were told that the ultimate goal was to make physical activity a habit over a period of months by building gradually to nationally recommended levels of 30 minutes of moderate intensity

Muller et al (2016)

Intervention description: this intervention aimed to increase exercise self-efficacy in inactive older adults using text messaging (60 messages over 12 weeks). Messages aimed to encourage, prompt and praise exercise behaviour.

\begin{tabular}{llll}
\hline & Top level & Sub-level 1 & Sub-level 2 \\
\hline Mode of delivery & Digital & Phone & Automated text \\
& & & \\
\hline BC & BCT & Practical strategies & \\
T & name & & \\
\hline
\end{tabular}


Do automated digital health behaviour change interventions have a positive effect on selfefficacy? A systematic review and meta-analysis

num

ber

7.1 Prompts/ Text message prompt: 'Please do the My Paths exercises regularly' cues

10.4 Social Text messages praise efforts made towards the exercise behaviour e.g. 'all reward your efforts will impact your health'

Prestwich et al (2017)

Intervention description: an intervention that aimed to increase physical activity measured using step counts. Two different interventions were presented ('self-monitoring' and 'competition'). In both, users were asked to meet a daily step count goal and to track their physical activity using a pedometer. An online website allowed them to observe their stepcount over time. In the competition intervention, users were additionally able to see how their step-count compared to other users.

Self-monitoring intervention

\begin{tabular}{llll}
\hline & Top level & Sub-level 1 & Sub-level 2 \\
\hline Mode of delivery & Digital & Unspecified & Website \\
& & Wearable accessory & Digital accessory \\
& & & \\
\hline BCT & BCT name & Practical strategy & \\
number & & & \\
\hline 1.1 & Goal setting & Users were asked to perform a minimum of 10,000 steps per day
\end{tabular}


Do automated digital health behaviour change interventions have a positive effect on selfefficacy? A systematic review and meta-analysis

(behaviour)

1.6 Discrepancy Tailored message via website: You reported that you have between achieved 11,000 steps so far. The daily target is to achieve at current least 10,000 , thus within the next 24 hours your pedometer behaviour should read at least 120,0000 steps and goal

$2.3 \quad$ Self- $\quad$ Users were asked to log onto study website and record their monitoring number of pedometer steps (at least once every 7 days for 5 of weeks). They were also asked to log any activity done whilst not behaviour wearing the pedometer

2.2 Feedback Users tracked changes in their pedometer steps over the course of the on study via graphical and tabular feedback (at least once every 7 days for behaviour 5 weeks)

Competition intervention

BCT BCT name Practical strategy

number

1.1 Goal setting Users were asked to perform a minimum of 10,000 steps per day (behaviour)

1.6 Discrepancy Tailored message via website: You reported that you have between achieved 11,000 steps so far. The daily target is to achieve at current least 10,000 , thus within the next 24 hours your pedometer behaviour should read at least 120,0000 steps 
Do automated digital health behaviour change interventions have a positive effect on selfefficacy? A systematic review and meta-analysis

and goal

2.3 Self- Users were asked to log onto study website and record their monitoring number of pedometer steps (at least once every 7 days for 5 of weeks). They were also asked to log any activity done whilst not behaviour wearing the pedometer

2.2 Feedback Users tracked changes in their pedometer steps over the course of the on study via graphical and tabular feedback (at least once every 7 days for behaviour 5 weeks)

6.2 Social Users received feedback relating to how their pedometer steps comparison compared to others (at least once every 7 days for 5 weeks). This was presented in the form of a league table.

Healthy Eating Interventions

Anderson et al (2001)

Intervention description: this intervention aimed to encourage users to decrease dietary fat and increase fruit, vegetables and fibre in their food purchases and consumption. Booths, containing computers hosting the intervention, were situated within supermarkets. The intervention consisted of 15 weekly segments containing pictures, graphics and audio, and the provision of food coupons to be used in the supermarket to buy healthy foods (nature/value of coupon was dependant on the focus of the weekly segment). Vouchers could be printed in the booth and redeemed within one week of printing. 
Do automated digital health behaviour change interventions have a positive effect on selfefficacy? A systematic review and meta-analysis

\begin{tabular}{llll}
\hline & Top level & Sub-level 1 & Sub-level 2 \\
\hline Mode of delivery & Digital & Computer/television & DVD
\end{tabular}

BCT BCT name Practical strategies

number

1.1 Goal The intervention 'provided opportunities for personalised goal setting setting' (behaviour)

2.3 Self- $\quad$ Each segment 'provided prescriptive information, suggested monitoring strategies for monitoring and planning food purchases and meal of preparation' behaviour

4.1 Instruction Strategies for monitoring and planning food purchases and meal on how to preparation were provided perform behaviour

10.1 Material Targeted food coupons were provided; type, order, and value of these incentive coupons was dependent on the programme segment's content, a products cost, and a weekly coupon allocation

Cook et al (2007) 
Do automated digital health behaviour change interventions have a positive effect on selfefficacy? A systematic review and meta-analysis

Intervention description: this was a workplace intervention ('Health Connection') delivered via a website. Graphics, audio and video were used to provide 'information and guidance' on three health topics: stress management, nutrition/weight management, and physical activity.

\begin{tabular}{llll}
\hline & Top level & Sub-level 1 & Sub-level 2 \\
\hline Mode of delivery & Digital & Unspecified & Website
\end{tabular}

BCT BCT name Practical strategies

number

1.1 Goal setting Goals are set based on personal assessment information

1.2 Problem Includes a printable 'tracker' for tracking obstacles and strategies

solving that work

1.4 Action Interactive daily meal planning exercises

planning

2.1 Monitoring of An interactive assessment of daily calorie and fat intake

behaviours by

others without

feedback

2.3 Self- A printable smart goal planner and progress tracker

monitoring of

behaviour

4.1 Instruction on Tips for making healthy choices (protein, fats, beverages), 
Do automated digital health behaviour change interventions have a positive effect on selfefficacy? A systematic review and meta-analysis

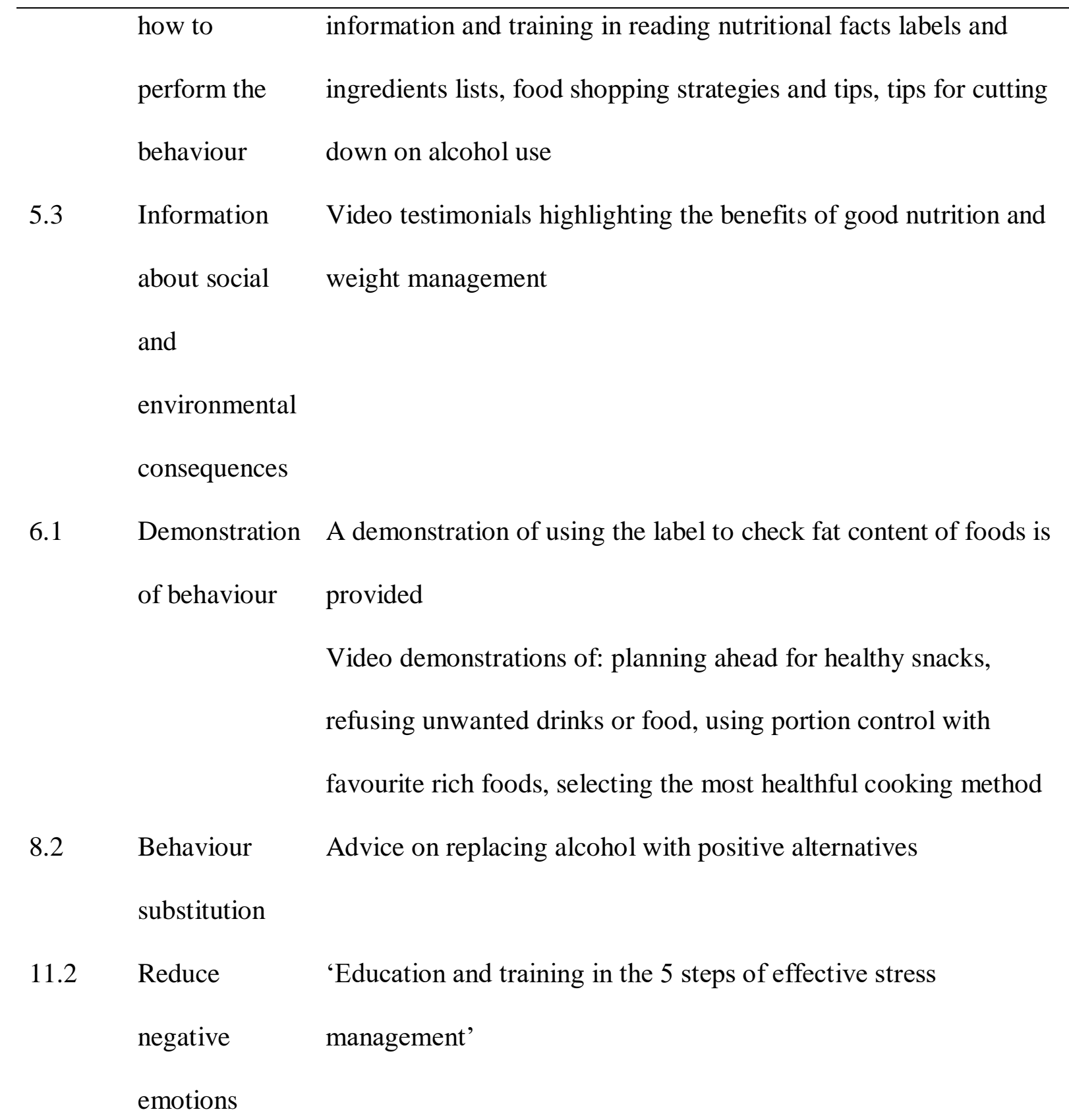

Irvine et al (2004)

Intervention description: A computer programme which aimed to reduce dietary fat consumption and increase consumption of fruit and vegetables. Content (on-screen text and videos) was tailored according to users' gender, ethnicity, age and interest in content. It was 
Do automated digital health behaviour change interventions have a positive effect on selfefficacy? A systematic review and meta-analysis

made available to employees of two large organisations via temporary computer workstations.

\begin{tabular}{llll}
\hline & Top level & Sub-level 1 & Sub-level 2 \\
\hline Mode of delivery & Digital & Computer/television & DVD
\end{tabular}

BCT BCT name Practical strategies

number

1.1 Goal setting Users were asked to identify which of the recommended

(behaviour) behaviours they were not currently doing and to commit to

those which they would be willing to try in the next week

1.2 Problem solving Users were asked to identify potential barriers to achieving these weekly goals from a total of 24 potential barriers. For chosen barriers, video models delivered short testimonial describing how they overcame the selected barriers

1.9 Commitment Users were asked to 'commit' to the behaviours that they are willing to try in the next week

4.1 Instruction on $\quad$ On screen text was used to present practical steps for how to how to perform perform the behaviours e.g. 'add fruit \& veggies when you the behaviour pack your lunch'

Video vignettes were used to model recommended eating behaviours e.g. the fork-dip method, ordering low-fat menu items 
Do automated digital health behaviour change interventions have a positive effect on selfefficacy? A systematic review and meta-analysis

The recipe section contained over 1500 low-fat recipes - users selected different criteria for recipes and the ones meeting these criteria were displayed and could be printed

5.1 Information The importance and health benefits of eating less dietary fat about health were stressed consequences

6.1 Demonstration of Video vignettes were used to model recommended eating the behaviour behaviours e.g. the fork-dip method, ordering low-fat menu items

Keller et al (2018)

Intervention description: an intervention that aimed to increase fruit and vegetable consumption. Via a website, users were presented with age and gender matched testimonials by others who had successfully increased their fruit and vegetable consumption and encouraged to focus on past success.

Self-monitoring intervention

Top level Sub-level $1 \quad$ Sub-level 2

\begin{tabular}{llll}
\hline Mode of delivery & Digital & Unspecified
\end{tabular}

BCT BCT name Practical strategy

number

8.2 Behaviour Testimonial: 'Until recently I was a real sweet tooth! Chocolate


Do automated digital health behaviour change interventions have a positive effect on selfefficacy? A systematic review and meta-analysis

substitution and cookies in the evening in front of the TV were just a must. I
then got the tip from a friend to simply replace sweets with fruit.
I'm always nibbling on grapes and dry fruits. Never thought how
delicious that is! If I can do that, you can do it!'
Focus on $\quad$ Users were asked to recall their own experiences of success with
fruit and veg by checking against some example statements or by
Self-talk
Users were encouraged to generate a self-motivating phrase that
they could recall when being tempted to snack or otherwise
being unmotivated to eat fruit and veg

Smoking Interventions

Brendryen \& Kraft (2008) and Brendryen et al (2008)

Intervention description: The intervention ('Happy Ending') is a 1-year smoking cessation programme. The same intervention was examined in both studies. It has preparation, quitting and follow-up phases during which content, messages and support differ. Access to a website is prompted via email. Users are encouraged to call an Interactive Voice Response (IVR) helpline during the quitting phase whenever they experience an urge to smoke (just-in-time intervention). During this phase, users are additionally contacted by the IVR system daily and prompted to report whether they have smoked; reports of smoking trigger relapse prevention (a 'therapy regimen'). Text messages are used to remind users to contact the IVR helpline when needed. 
Do automated digital health behaviour change interventions have a positive effect on selfefficacy? A systematic review and meta-analysis

\begin{tabular}{llll}
\hline & Top level & Sub-level 1 & Sub-level 2 \\
\hline Mode of delivery & Digital & Unspecified & Website \\
& Unspecified & Email \\
& Phone & Automated text \\
& Phone & Interactive Voice \\
& & Response (IVR) ${ }^{1}$
\end{tabular}

${ }^{1}$ IVR is not currently categorised within the Mode of Delivery of Behaviour Change Interventions Taxonomy Version 0 (MoDTv0) (Carey et al., 20016) as a mode of delivery

\begin{tabular}{|c|c|c|}
\hline $\begin{array}{l}\text { BCT } \\
\text { numbe }\end{array}$ & BCT name & Practical strategies \\
\hline 1.2 & Problem solving & $\begin{array}{l}\text { Users were encouraged to make concrete 'coping plans' } \\
\text { regarding how to stay smoke free in the immediate future } \\
\text { Automated IVR based 'relapse prevention' system is } \\
\text { incorporated in Happy Ending. }\end{array}$ \\
\hline 1.4 & Action planning & $\begin{array}{l}\text { Users are encouraged to make concrete 'implementation } \\
\text { intentions' regarding how to stay smoke free in the immediate } \\
\text { future } \\
\text { Users who have a 'slip' are encouraged to prepare an } \\
\text { 'implementation intention' regarding how and when to resume } \\
\text { the quit attempt } \\
\text { Repeatedly encouraged to make a plan to call the hotline every } \\
\text { time they are tempted to have a cigarette }\end{array}$ \\
\hline 2.1 & Monitoring of & Users' were contacted every night by the IVR system and asked \\
\hline
\end{tabular}


Do automated digital health behaviour change interventions have a positive effect on selfefficacy? A systematic review and meta-analysis

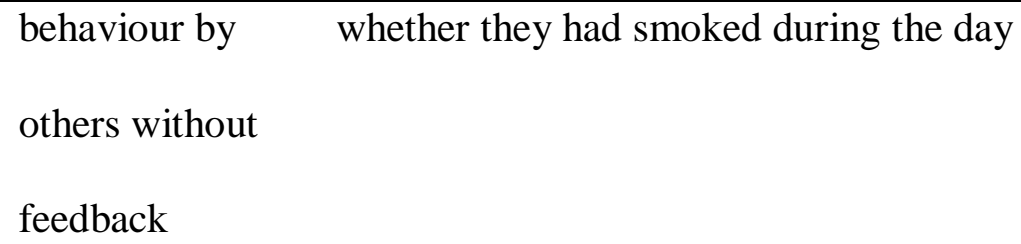

2.3 Self-monitoring The preparation stage contains elements of behavioural skills of behaviour training. These consist of techniques related to the acquisition of new skills, such as self-stopping, the use of substitutions, self-monitoring and foresight

2.7 Feedback on IVR message: today your blood pressure has been reduced to outcome(s) of that of a non-smoker behaviour

3.1 Social support The intervention contains an IVR based craving helpline. Users (unspecified) were instructed (repeatedly by text message) to call the helpline every time they are tempted to have a cigarette.

Users were repeatedly encouraged via website messages to call the IVR helpline when experiencing cravings

4.1 Instruction on The preparation stage contains elements of 'behavioural skills how to perform training'. These consist of techniques related to the acquisition behaviour of new skills, such as self-stopping, the use of substitutions, self-monitoring and foresight

4.2 Information Website message: 'what it is that distinguishes your smoking about pattern? I often smoke... after a meal/ on the way to work/ antecedents when I have a coffee break ....?'

5.1 Information Each morning during the quitting phase, users receive a preabout health recorded message via the IVR system about one of the short 
Do automated digital health behaviour change interventions have a positive effect on selfefficacy? A systematic review and meta-analysis

consequences term positive consequences of quitting e.g. 'today your blood pressure has been reduced to that of a non-smoker'

5.5 Anticipated IVR relapse prevention message: 'How will you feel in a regret month's time if you decide to start smoking again now?'

8.2 Behaviour Website message: use some of the smoking breaks you used to substitution have at work to go for a brisk walk instead

10.4 Social reward Website message: 'you will see that you already have a much improved overall state of health - congratulations' Text message: 'congrats - smoke free for a whole work week' and, 'Bravo - it's now a full working week since you stopped'

11.1 Pharmacological Seven text messages are sent to users related to nicotine support replacement therapy (NRT); reminders are sent about obtaining it, wearing it, and to use it regularly

11.2 Reduce negative Users are encouraged to attribute a 'slip' to situational factors, emotions 'thereby preventing negative emotions and a full-blown relapse'

12.1 Restructuring Website message: "clear away all ash tray and anything else that the physical remind you of smoking- look through drawers and cupboards, environment throw away anything you find'

13.2 Framing/ re- Website messages: 'even if you've had a few cigarettes it's not framing a disaster' and, 'a slip up is no great catastrophe, look on any slip up as a little step backwards before you continue ahead at full speed'

15.1 Verbal Email message: 'your first weekend as a non-smoker is nearly persuasion here... You won't destroy it now by being careless this 
Do automated digital health behaviour change interventions have a positive effect on selfefficacy? A systematic review and meta-analysis

\author{
about capability weekend ... you are over the worst cravings and you will have \\ soon managed a whole week as a non-smoker’
}

Mavrot et al (2016)

Intervention description: this intervention ('Coach'), designed for both current and former smokers (both motivated and unmotivated to quit), aimed to increase smoking cessation and prevent relapse. Website content is tailored and provides 'counselling' through personalised messages (information, encouragement, advice, feedback).

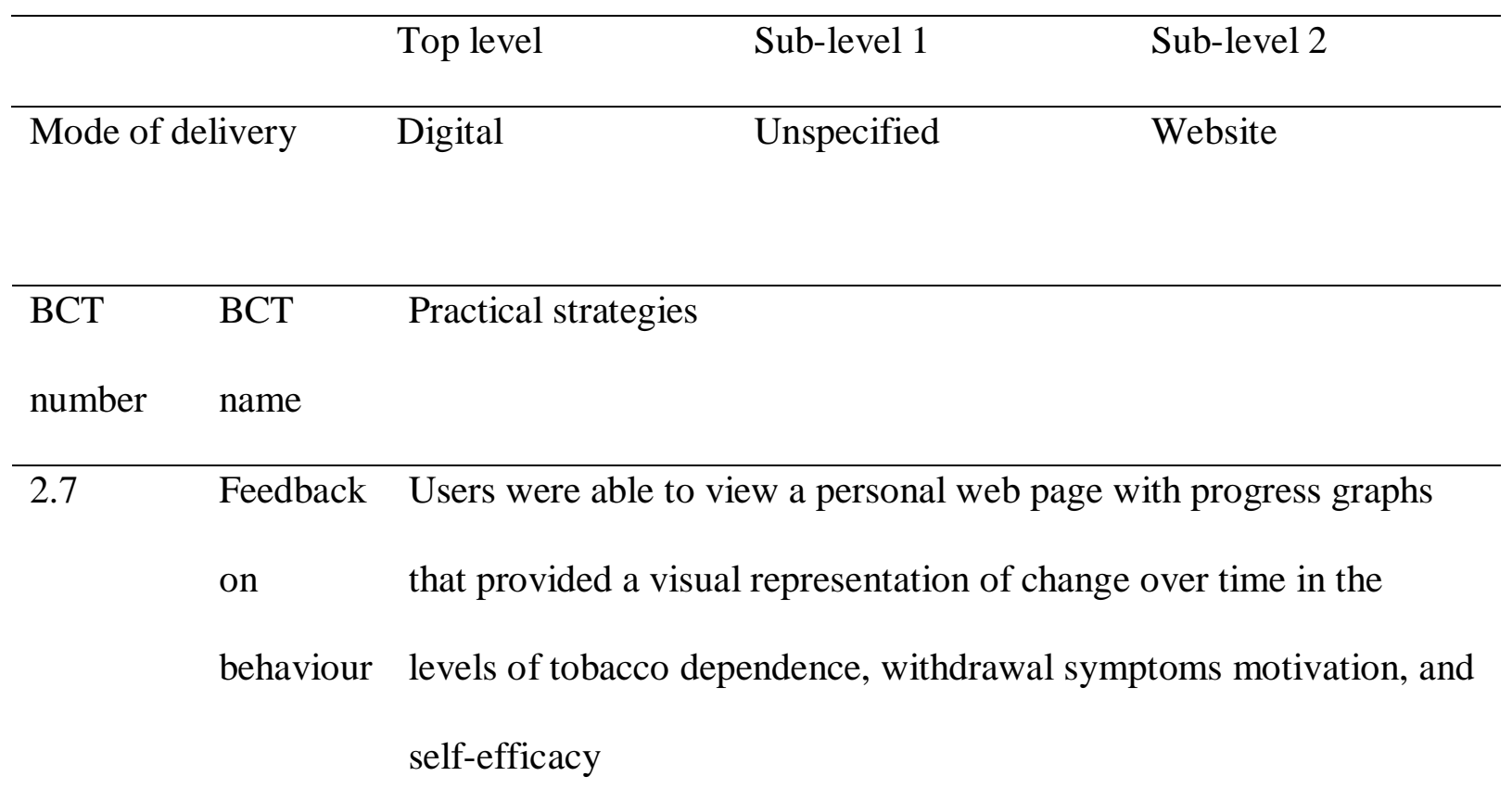

Powell et al (2016) 
Do automated digital health behaviour change interventions have a positive effect on selfefficacy? A systematic review and meta-analysis

Intervention description: A website designed to increase smoking cessation, containing audio, video and on-screen text extracts of ex-smoker's experiences of quitting smoking, organised into topic groups. Users were able to navigate and browse content as they wished.

\begin{tabular}{llll}
\hline & Top level & Sub-level 1 & Sub-level 2 \\
\hline Mode of delivery & Digital & Unspecified & Website \\
& & & \\
\hline BCT & BCT & Practical strategies & \\
number & name & & \\
\hline
\end{tabular}

No unique BCTs were coded for this intervention

Sexual Behaviour Interventions

Bowen et al (2007)

Intervention description: A HIV risk-reduction intervention for men who have sex with men (MSM). HIV prevention messages were conveyed through video conversations between an HIV-positive man ('expert') and an HIV-negative man ('inexperienced'; engaging in high risk activities); dialogue was interspersed with interactive activities and graphics emphasising key points.

\begin{tabular}{llll}
\hline & Top level & Sub-level 1 & Sub-level 2 \\
\hline Mode of delivery & Digital & Unspecified & Website
\end{tabular}


Do automated digital health behaviour change interventions have a positive effect on selfefficacy? A systematic review and meta-analysis

\begin{tabular}{lll}
\hline BCT & BCT & Practical strategies \\
number & name & \\
\hline 4.1 & Instruction & The content focused on how the inexperienced man might maintain his \\
& on how to & HIV-negative status, including safe sex options, condom types, and \\
& perform & correct condom application \\
& behaviour
\end{tabular}

Klein et al (2017)

Intervention description: a 2-hour long programme delivered within a sexual health setting. Users could stop at any point, resume where they left off, and if they wanted to, repeat already completed activities. Each session combines audio narration, visual presentations, interactive components, games, and a series of soap opera-style videos.

Self-monitoring intervention

\begin{tabular}{llll}
\hline & Top level & Sub-level 1 & Sub-level 2 \\
\hline Mode of delivery & Digital & Unspecified & Website
\end{tabular}

BCT BCT name Practical strategy

number

\begin{tabular}{lll}
\hline 1.1 & Goal setting & 'Think about it' activity - for which goal setting is outcome \\
(behaviour) & \\
1.2 & Problem solving & Presentation on ways of getting past barriers to condom use, \\
& communication strategies video, 'excuses and comebacks
\end{tabular}


Do automated digital health behaviour change interventions have a positive effect on selfefficacy? A systematic review and meta-analysis

game'

4.1 Instruction on Interactive review of correct condom use steps; 'Andrea how to perform demonstrates correct condom use'; 'salsa dancing game: behaviour user negotiates each step of the encounter (sexual communication) until the dance is complete'

4.2 Information Unsafe sex triggers - video of workshop women discussing about their own unsafe sex triggers and then 'what are your antecedents triggers' exercise

5.1 Information Consequences of risky sex = STIs; Interactive activity 'you about social and and Ramon'- animated chart depicting how Ramon's sexual environmental experiences translate into a larger sexual history than spans consequences nearly 100 people

5.2 Salience of Interactive activity 'you and Ramon' - animated chart consequences depicting how Ramon's sexual experiences translate into a larger sexual history than spans nearly 100 people

6.1 Demonstration of Video demonstration of communication role play and of behaviour condom use: 'Andrea demonstrates correct condom use'; video of workshop women practicing putting on condoms on penis proxies; video demo of communication role-play

8.1 Behaviour Activity- Users negotiates each step of sexual encounter practice/rehearsal until dance is complete; if he says/ you can say' activitycommunication role-play activity

9.1 Credible source Video of health educator Andrea demonstrating correct 
Do automated digital health behaviour change interventions have a positive effect on selfefficacy? A systematic review and meta-analysis

\section{condom use}

16.1 Imaginary Exercise- visualise the impact of contracting HIV on

punishment family, friends and their quality of life

16.3 Vicarious $\quad$ Video of women's experiences of contracting an STI

consequences multiple times from their partners

Swartz et al (2011)

Intervention description: this intervention aimed to reduce unwanted pregnancy and sexually transmitted infections (STIs) amongst middle-aged women. The website had five modules and included on-screen text, animations, quizzes, and videos (including those presented by midwife and testimonials from other women).

\begin{tabular}{llll}
\hline & Top level & Sub-level 1 & Sub-level 2 \\
\hline Mode of delivery & Digital & Unspecified & Website
\end{tabular}

BCT BCT name Practical strategies

number

\begin{tabular}{|c|c|c|}
\hline \multirow{7}{*}{4.1} & Instruction on & The 'talking to your partner' module presents information and \\
\hline & how to & skill-building techniques for talking with sexual partners about \\
\hline & perform the & how best to initiate and conduct discussions regarding risk- \\
\hline & \multirow[t]{4}{*}{ behaviour } & reduction behaviours (e.g. changing contraceptive methods, using \\
\hline & & condoms, or being tested for STI's) \\
\hline & & Tip sheets and video modelling are presented to help build \\
\hline & & communication skills, and include a) effective communication \\
\hline
\end{tabular}


Do automated digital health behaviour change interventions have a positive effect on selfefficacy? A systematic review and meta-analysis

with your health care provider b) helpful information to bring to an appointment and c) sample questions to ask your health care provider

5.1 Information Information is presented on the benefits and limits of commonly about health used prevention strategies (e.g. condoms) in preventing specific consequences STI's

6.1 Demonstration Tip sheets and video modelling are presented to help build of behaviour communication skills, and include a) effective communication with your health care provider b) helpful information to bring to an appointment and c) sample questions to ask your health care provider 
Do automated digital health behaviour change interventions have a positive effect on self-

efficacy? A systematic review and meta-analysis

Supplemental material 8: Forest plot for self-efficacy of automated digital interventions versus no/usual treatment by behavioural domain

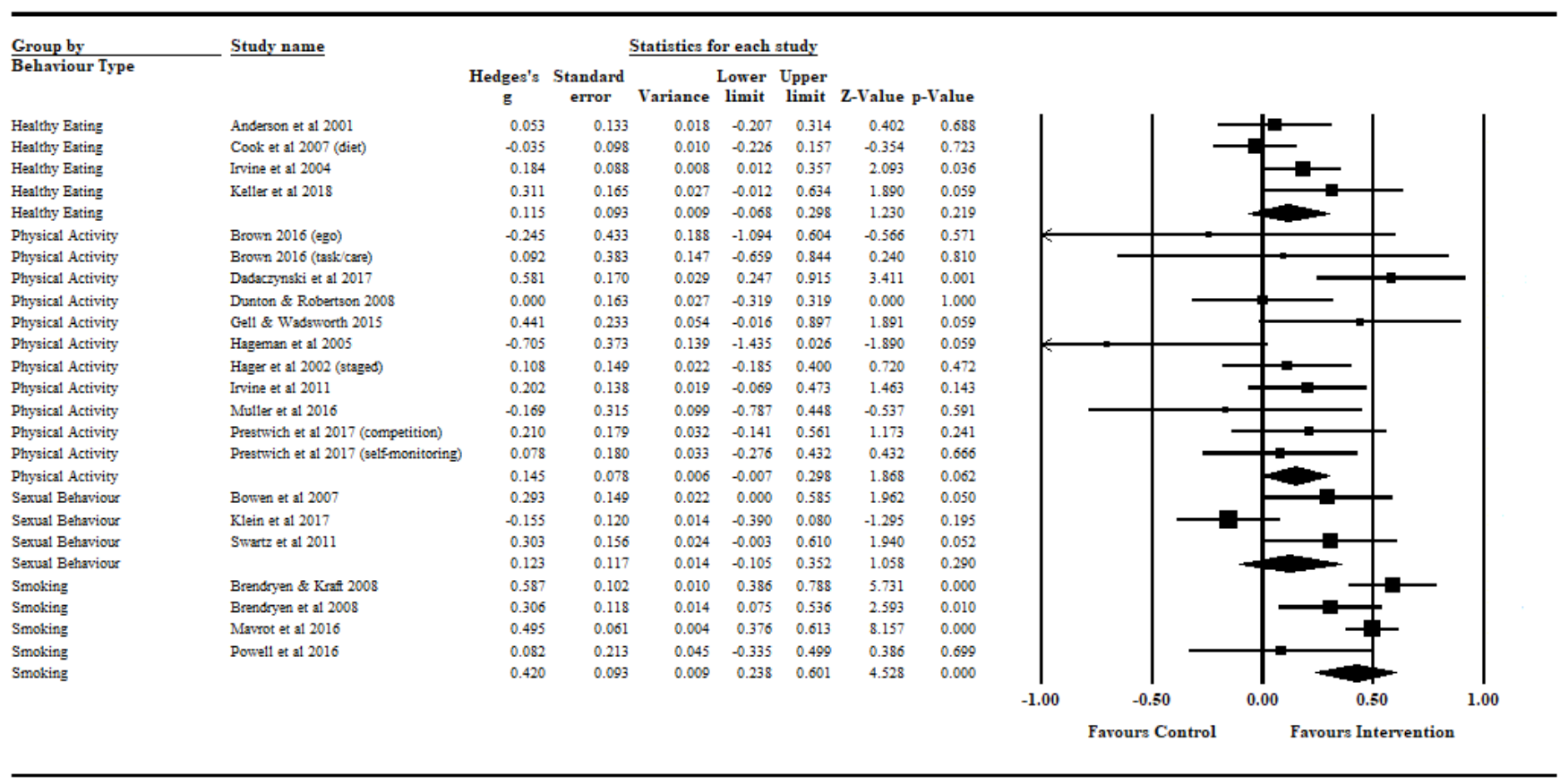


Do automated digital health behaviour change interventions have a positive effect on selfefficacy? A systematic review and meta-analysis

Supplemental material 9: Risk of bias plots of ratings by domain and by study

Risk of bias ratings by domain

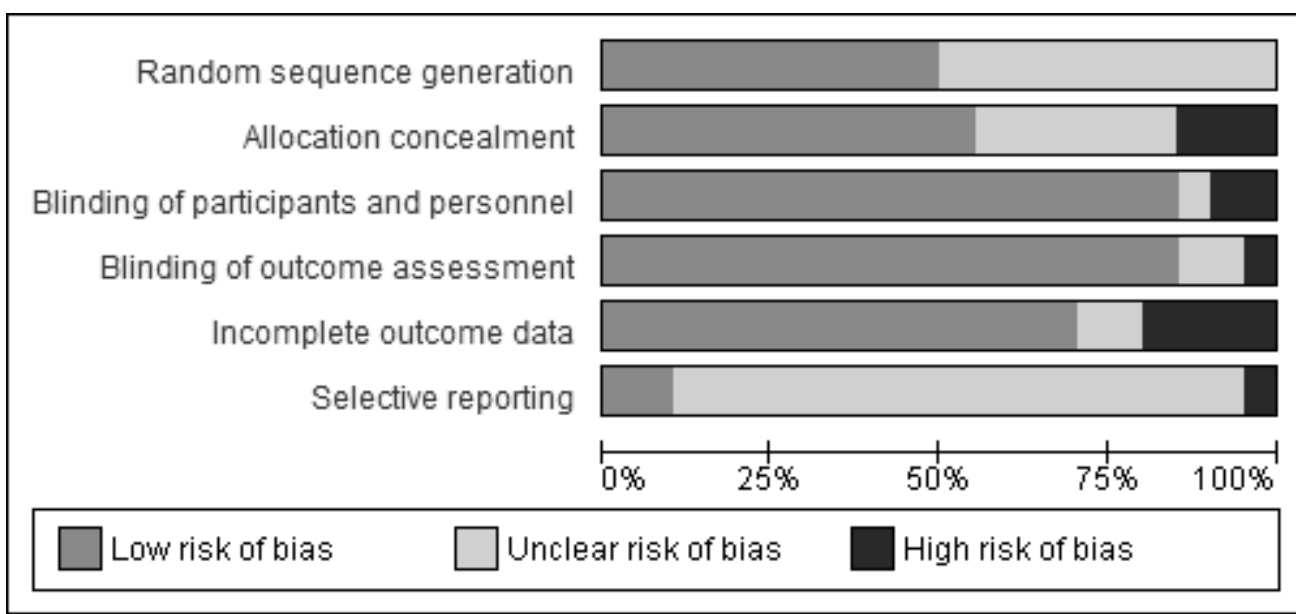


Do automated digital health behaviour change interventions have a positive effect on selfefficacy? A systematic review and meta-analysis

Risk of bias ratings by study

\begin{tabular}{|c|c|c|c|c|c|c|}
\hline & 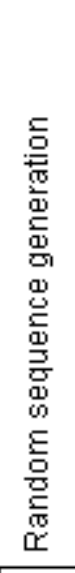 & 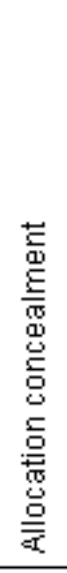 & 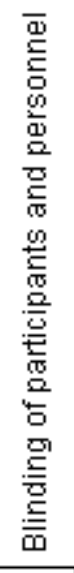 & 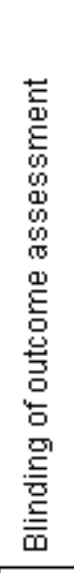 & 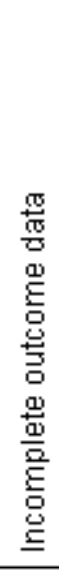 & 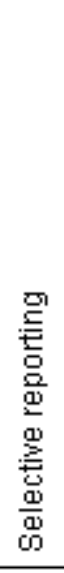 \\
\hline Anderson et al 2001 & $?$ & + & + & + & + & $?$ \\
\hline Bowen et al 2007 & + & + & + & + & + & $?$ \\
\hline Brendryen \& Kraft 2008 & + & + & 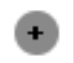 & $\oplus$ & - & $?$ \\
\hline Brendryen et al 2008 & + & + & + & + & - & $?$ \\
\hline Brown 2016 & $?$ & + & + & $?$ & + & $?$ \\
\hline Cook et al 2007 & $?$ & $?$ & + & + & + & - \\
\hline Dadaczynski et al 2017 & + & + & + & + & + & $?$ \\
\hline Dunton \& Robertson & + & $?$ & + & + & $?$ & $?$ \\
\hline Gell \& Wadsworth 2015 & $?$ & $?$ & + & + & + & $?$ \\
\hline Hager et al 2002 & $?$ & $?$ & + & + & $?$ & $?$ \\
\hline Hagerman et al 2005 & $?$ & $?$ & + & + & + & $?$ \\
\hline Irvine et al 2004 & $?$ & $?$ & + & + & - & $?$ \\
\hline Irvine et al 2011 & $?$ & + & + & + & + & $?$ \\
\hline Keller et al 2018 & + & + & + & + & + & + \\
\hline Klein et al 2017 & $?$ & - & 1 & 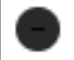 & + & $?$ \\
\hline Mavrot et al 2016 & + & F & ? & $?$ & - & $?$ \\
\hline Muller et al 2016 & + & - & + & + & + & + \\
\hline Powell et al 2016 & + & 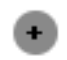 & + & + & + & ? \\
\hline Prestwich et al 2017 & + & + & + & + & + & $?$ \\
\hline Swart et al 2011 & $?$ & + & $?$ & + & + & $?$ \\
\hline
\end{tabular}


Do automated digital health behaviour change interventions have a positive effect on selfefficacy? A systematic review and meta-analysis

- High risk of bias

$\oplus$ Low risk of bias

$?$ Unclear risk of bias 
Supplemental material 10: PRISMA Checklist

\begin{tabular}{|c|c|c|c|}
\hline Section/topic & \# & Checklist item & $\begin{array}{l}\text { Reported on } \\
\text { page \# }\end{array}$ \\
\hline \multicolumn{4}{|l|}{ TITLE } \\
\hline Title & 1 & Identify the report as a systematic review, meta-analysis, or both. & 1 \\
\hline \multicolumn{4}{|l|}{ ABSTRACT } \\
\hline Structured summary & 2 & $\begin{array}{l}\text { Provide a structured summary including, as applicable: background; objectives; data sources; study } \\
\text { eligibility criteria, participants, and interventions; study appraisal and synthesis methods; results; } \\
\text { limitations; conclusions and implications of key findings; systematic review registration number. }\end{array}$ & 3 \\
\hline \multicolumn{4}{|l|}{ INTRODUCTION } \\
\hline Rationale & 3 & Describe the rationale for the review in the context of what is already known. & $4-7$ \\
\hline Objectives & 4 & $\begin{array}{l}\text { Provide an explicit statement of questions being addressed with reference to participants, interventions, } \\
\text { comparisons, outcomes, and study design (PICOS). }\end{array}$ & 7 \\
\hline METHODS & & & \\
\hline
\end{tabular}




\begin{tabular}{|c|c|c|c|}
\hline Protocol and registration & 5 & $\begin{array}{l}\text { Indicate if a review protocol exists, if and where it can be accessed (e.g., Web address), and, if available, } \\
\text { provide registration information including registration number. }\end{array}$ & 7 \\
\hline Eligibility criteria & 6 & $\begin{array}{l}\text { Specify study characteristics (e.g., PICOS, length of follow-up) and report characteristics (e.g., years } \\
\text { considered, language, publication status) used as criteria for eligibility, giving rationale. }\end{array}$ & $7-8$ \\
\hline Information sources & 7 & $\begin{array}{l}\text { Describe all information sources (e.g., databases with dates of coverage, contact with study authors to } \\
\text { identify additional studies) in the search and date last searched. }\end{array}$ & 8 \\
\hline Search & 8 & $\begin{array}{l}\text { Present full electronic search strategy for at least one database, including any limits used, such that it } \\
\text { could be repeated. }\end{array}$ & $\begin{array}{l}\text { Supplemental } \\
\text { material } 2\end{array}$ \\
\hline Study selection & 9 & $\begin{array}{l}\text { State the process for selecting studies (i.e., screening, eligibility, included in systematic review, and, if } \\
\text { applicable, included in the meta-analysis). }\end{array}$ & $9-10$ \\
\hline Data collection process & 10 & $\begin{array}{l}\text { Describe method of data extraction from reports (e.g., piloted forms, independently, in duplicate) and any } \\
\text { processes for obtaining and confirming data from investigators. }\end{array}$ & $10-13$ \\
\hline Data items & 11 & $\begin{array}{l}\text { List and define all variables for which data were sought (e.g., PICOS, funding sources) and any } \\
\text { assumptions and simplifications made. }\end{array}$ & $10-13$ \\
\hline
\end{tabular}


Do automated digital health behaviour change interventions have a positive effect on self-efficacy? A systematic review and meta-analysis

\begin{tabular}{|c|c|c|c|}
\hline $\begin{array}{l}\text { Risk of bias in individual } \\
\text { studies }\end{array}$ & 12 & $\begin{array}{l}\text { Describe methods used for assessing risk of bias of individual studies (including specification of whether } \\
\text { this was done at the study or outcome level), and how this information is to be used in any data synthesis. }\end{array}$ & 13 \\
\hline Summary measures & 13 & State the principal summary measures (e.g., risk ratio, difference in means). & $13-14$ \\
\hline Synthesis of results & 14 & $\begin{array}{l}\text { Describe the methods of handling data and combining results of studies, if done, including measures of } \\
\text { consistency (e.g., } \mathrm{I}^{2} \text { ) for each meta-analysis. }\end{array}$ & $13-14$ \\
\hline Risk of bias across studies & 15 & $\begin{array}{l}\text { Specify any assessment of risk of bias that may affect the cumulative evidence (e.g., publication bias, } \\
\text { selective reporting within studies). }\end{array}$ & 14 \\
\hline Additional analyses & 16 & $\begin{array}{l}\text { Describe methods of additional analyses (e.g., sensitivity or subgroup analyses, meta-regression), if } \\
\text { done, indicating which were pre-specified. }\end{array}$ & $14-15$ \\
\hline \multicolumn{4}{|l|}{ RESULTS } \\
\hline Study selection & 17 & $\begin{array}{l}\text { Give numbers of studies screened, assessed for eligibility, and included in the review, with reasons for } \\
\text { exclusions at each stage, ideally with a flow diagram. }\end{array}$ & $\begin{array}{l}10 \text { (figure } 1 \text { ), } \\
15-16\end{array}$ \\
\hline Study characteristics & 18 & $\begin{array}{l}\text { For each study, present characteristics for which data were extracted (e.g., study size, PICOS, follow-up } \\
\text { period) and provide the citations. }\end{array}$ & $\begin{array}{l}\text { 16-17, } \\
\text { Supplemental }\end{array}$ \\
\hline
\end{tabular}


Do automated digital health behaviour change interventions have a positive effect on self-efficacy? A systematic review and meta-analysis

\begin{tabular}{|c|c|c|c|}
\hline & & & material 4-7 \\
\hline Risk of bias within studies & 19 & Present data on risk of bias of each study and, if available, any outcome level assessment (see item 12). & $\begin{array}{c}18, \\
\text { supplemental } \\
\text { material } 9\end{array}$ \\
\hline $\begin{array}{l}\text { Results of individual } \\
\text { studies }\end{array}$ & 20 & $\begin{array}{l}\text { For all outcomes considered (benefits or harms), present, for each study: (a) simple summary data for } \\
\text { each intervention group (b) effect estimates and confidence intervals, ideally with a forest plot. }\end{array}$ & 17 (Figure 2) \\
\hline Synthesis of results & 21 & Present results of each meta-analysis done, including confidence intervals and measures of consistency. & 17 \\
\hline Risk of bias across studies & 22 & Present results of any assessment of risk of bias across studies (see Item 15). & $\begin{array}{c}18, \\
\text { supplemental } \\
\text { material } 9\end{array}$ \\
\hline Additional analysis & 23 & $\begin{array}{l}\text { Give results of additional analyses, if done (e.g., sensitivity or subgroup analyses, meta-regression [see } \\
\text { Item 16]). }\end{array}$ & $17-18$ \\
\hline \multicolumn{4}{|l|}{ DISCUSSION } \\
\hline Summary of evidence & 24 & $\begin{array}{l}\text { Summarize the main findings including the strength of evidence for each main outcome; consider their } \\
\text { relevance to key groups (e.g., healthcare providers, users, and policy makers). }\end{array}$ & $18-19$ \\
\hline
\end{tabular}


Do automated digital health behaviour change interventions have a positive effect on self-efficacy? A systematic review and meta-analysis

\begin{tabular}{|l|c|l|l|}
\hline Limitations & 25 & $\begin{array}{l}\text { Discuss limitations at study and outcome level (e.g., risk of bias), and at review-level (e.g., incomplete } \\
\text { retrieval of identified research, reporting bias). }\end{array}$ & 24-25 \\
\hline Conclusions & 26 & Provide a general interpretation of the results in the context of other evidence, and implications for future & $25-26$ \\
research. & & funders for the systematic review. & 2 \\
\hline \hline FUNDING & 27 & \begin{tabular}{l} 
Describe sources of funding for the systematic review and other support (e.g., supply of data); role of \\
\hline \hline
\end{tabular} \\
\hline \hline
\end{tabular}

From: Moher D, Liberati A, Tetzlaff J, Altman DG, The PRISMA Group (2009). Preferred Reporting Items for Systematic Reviews and Meta-

Analyses: The PRISMA Statement. PLoS Med 6(7): e1000097. doi:10.1371/journal.pmed1000097

For more information, visit: www.prisma-statement.org. 